\title{
Modeling and Analysis of the Effects of PCB Parasitics on Integrated DC-DC Converters
}

\author{
A Thesis \\ presented to \\ the Faculty of California Polytechnic State University, \\ San Luis Obispo
}

In Partial Fulfillment

of the Requirements for the Degree

Master of Science in Electrical Engineering

by

Darwin D. Fernandez

June 2011 
(C) 2011

Darwin D. Fernandez

ALL RIGHTS RESERVED 


\section{COMMITTEE MEMBERSHIP}

TITLE:

AUTHOR:

DATE SUBMITTED:

COMMITTEE CHAIR:

COMMITTEE MEMBER:

COMMITTEE MEMBER:
Modeling and Analysis of the Effects of PCB Parasitics on Integrated DC-DC Converters

Darwin D. Fernandez

June 2011
Dr. Tina Smilkstein, Assistant Professor

Dr. Vladimir Prodanov, Assistant Professor 


\title{
ABSTRACT \\ Modeling and Analysis of the Effects of PCB Parasitics on Integrated DC-DC Converters
}

\author{
Darwin D. Fernandez
}

Load transients are prevalent in every electronic device including semiconductor memory, card readers, microprocessors, disc drives, piezoelectric devices, and digitally based systems. They are capable of producing voltage stress, introducing noise, and degrading device functionality. In order to avoid damage to the device, a feedback control loop is implemented with system compensation to regulate the output voltage deviations by the converter. Because designing compensation networks can be rather complicated, DC-DC converters with integrated feedback control topologies help minimize design time and complexity of converter compensation at the expense of design flexibility. This thesis widens the limitations of an integrated DC-DC converter with a stability optimization technique that utilizes the feedback network to create a phase boost centered at the bandwidth of the converter to increase the phase margin and improve its transient response. Ideal modeling verifies stability optimization while non-ideal modeling that introduces PCB parasitics to the control loop suggest an additional phase boost in the feedback network. Experimental data confirms this non-deal model for parasitic capacitances higher than calculated. The modified non-ideal model shows more accuracy compared to the experimental data which indicates that there may be PCB parasitics that is unaccounted for. Modeling the modified non-ideal model to high orders may yield more accuracy. This thesis gives both DC-DC converter and PCB layout designers insight and considerations into PCB effects on the stability of DC-DC converters and the optimization of integrated compensation.

Keywords: PCB parasitics, compensation, feed forward capacitor, phase margin, bandwidth, integrated DC-DC converter, load transients 


\section{ACKNOWLEDGMENTS}

It brings me great pleasure to thank the many people who made this thesis possible.

Firstly, I thank my advisor Dr. Taufik for sharing his contagious enthusiasm and excitement for power electronics that captured my interest in the field on the first day of class. My academic career has benefitted tremendously through your guidance and encouragement. You have brought out my full potential and never accepted less than my best efforts.

I thank Michael Day and Chris Glaser from Texas Instruments Incorporated for proposing this thesis and helping me understand the control aspects of the TPS62120 with their technical expertise.

I thank my colleagues and lifelong friends in the Grad Lab. Thank you Timothy Rudd and Rithy Chhean for providing a stimulating environment to learn and grow. My sincerest thanks to Jameson Thornton, Ruth Leung, and Jeramie Bianchi for their motivation, sound advice, and interest during my thesis. You all have made my time at Cal Poly worthwhile.

I thank my parents Honesto and Aida Fernandez for their love and support of my academic goals. I am truly grateful to both of you for teaching me patience, responsibility, and confidence. I am thankful for your sacrifices; your hard work continues to inspire me. No matter what, I always know you are proud of me.

I thank my sisters Dashiell Aromin and Johna Fernandez for their continuous support and interest in my academic career. You both have influenced me greatly and have helped build my character.

I also would like to express my appreciation to my girlfriend Myla Moquia for your loving patience and encouragement during this thesis. I value the support you gave during my defense. Your care and insight have kept me motivated to pursue my ideas and interests. You have truly changed my life. 


\section{Table of Contents}

List of Tables..........................................................................vii

List of Figures............................................................................viii

Chapter 1 : Introduction ................................................................................................................. 1

Chapter 2 : Thesis Overview............................................................................................................ 7

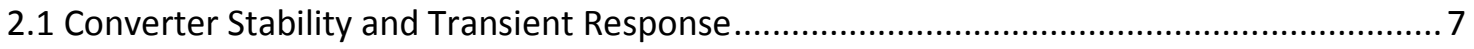

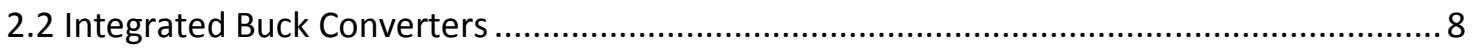

Chapter 3 : Background ..................................................................................................................... 13

3.1 PCB Layout Design Considerations .......................................................................... 13

3.2 Parasitic Components in DC-DC Converters ................................................................. 15

3.3 DC-DC Buck Converter Control Design Considerations .................................................... 19

Chapter 4 : Voltage-Mode Control Analysis ........................................................................ 24

4.1 Output Voltage Transient Response and Converter Frequency Response..........................24

4.2 Converter Frequency Response Voltage-Mode Derivation ............................................26

Chapter 5 : Device Introduction and Optimization.............................................................. 39

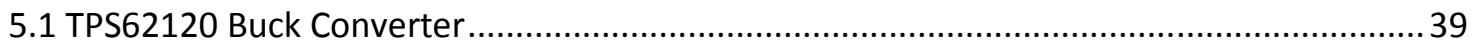

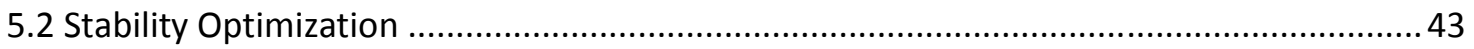

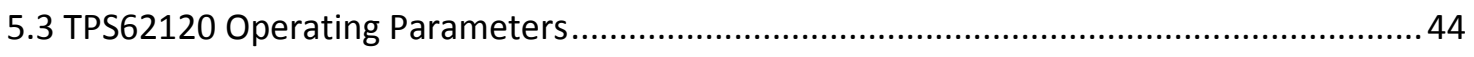

Chapter 6 : System Modeling......................................................................................................... 45

6.1 Ideal Modeling of the TPS62120 Stability Optimization ..................................................... 45

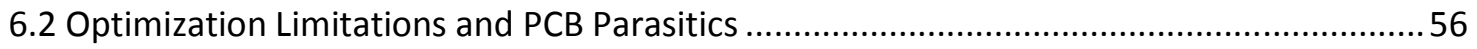

6.3 Non-Ideal Modeling of the TPS62120 Stability Optimization ...........................................57

Chapter 7 : PCB Design and Testing ......................................................................................... 69

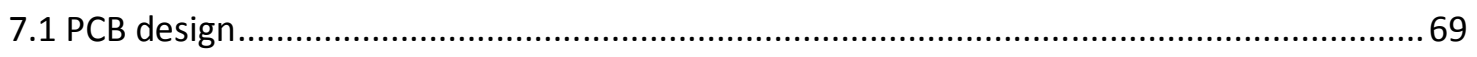

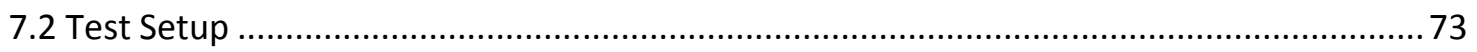

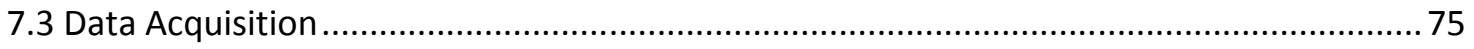

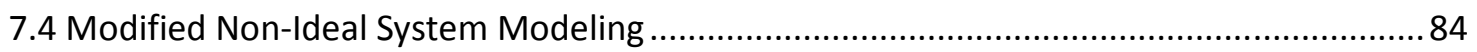

Chapter 8 : Conclusion................................................................................................................. 87

Bibliography ................................................................................................................. 90 


\section{List of Tables}

Table 1-1: Benefits and drawbacks to linear and switching regulators .......................... 4

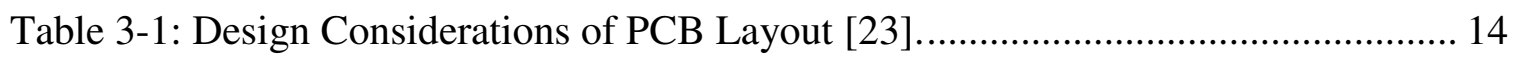

Table 3-2: Estimated parasitic inductances for various decoupling capacitances and

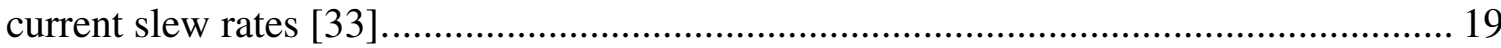

Table 5-1 Table from datasheet of recommended values. .......................................... 41

Table 6-1: Ideal model of (a) bandwidth, (b) phase margin, (c) calculated feed forward capacitor for stability optimization at different ranges of output filter.

Table 6-3: Non-ideal model of (a) bandwidth, (b) phase margin, (c) calculated feed forward capacitor for stability optimization at different ranges of output filter.

Table 7-1: Experimental data of (a) bandwidth, (b) phase margin, (c) calculated feed forward capacitor for stability optimization at different ranges of output filter. 


\section{List of Figures}

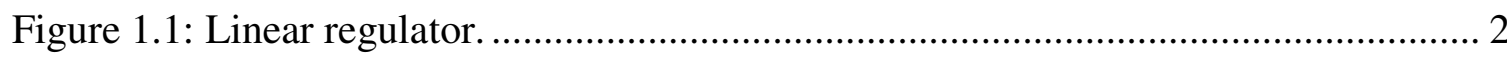

Figure 1.2: Push-pull isolated DC-DC converter......................................................... 3

Figure 1.3: Non-isolated Boost DC-DC converter. .................................................. 4

Figure 1.4: Buck Converter....................................................................................... 5

Figure 2.1: Buck converter output voltage response to a load step. ............................. 7

Figure 2.2: Circuit schematic for designing a discrete buck converter [17]................... 9

Figure 2.3: Circuit schematic for designing an integrated buck converter [17]. ............. 10

Figure 3.1: Dimensions of typical PCB components and their calculated parasitic

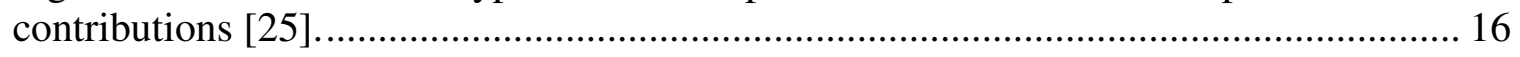

Figure 3.2: Voltage deviation during a load transient for a microprocessor [33]............ 18

Figure 3.3: Voltage-mode topology and corresponding waveforms[2] ........................ 20

Figure 3.4: Current-mode topology and corresponding waveforms [2] ....................... 21

Figure 3.5: Hysteretic control topology and corresponding waveforms [2]................... 23

Figure 4.1 Converter response to a load transient................................................... 24

Figure 4.2: Converter frequency response and its relation to the transient response [35]. The highest deviation to steady state corresponds to the lowest phase margin $\varphi$............ 25

Figure 4.3: Converter frequency response of the converter used in Figure 4.1............. 26

Figure 4.4: (a) A closed loop voltage-mode buck converter block diagram and (b) its

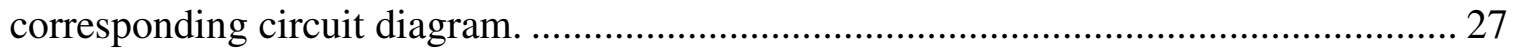

Figure 4.5: The voltage-mode modulator and its functional waveforms....................... 29

Figure 4.6 Output low-pass filter of the buck converter........................................ 31

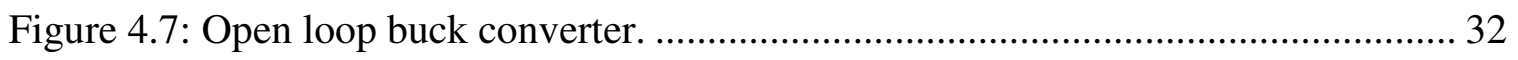

Figure 4.8: Open loop frequency response of a buck converter. ................................ 33 
Figure 4.9: General Compensation Network 34

Figure 4.10: Typical voltage-mode compensation networks [17] ............................... 35

Figure 4.11: Closed loop converter frequency response using Type 2 compensation...... 37

Figure 5.1: Typical circuit application of the TPS62120 [20]..................................... 39

Figure 5.2: Block diagram for regulating output voltage. ....................................... 40

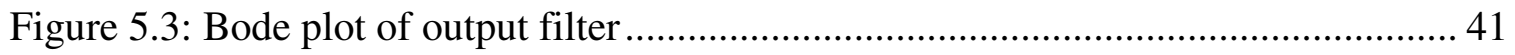

Figure 5.4: Bode plot of feedback network. ........................................................ 42

Figure 6.1 Ideal frequency response of the total system (red), output filter (blue), and

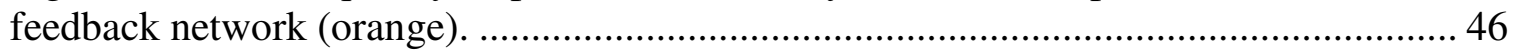

Figure 6.2: Frequency response of the total system (red), output filter (blue), and feedback network (orange) with no feed forward capacitor.

Figure 6.3: Frequency response of the total system (red), output filter (blue), and feedback network (orange) with optimized feed forward capacitor 48

Figure 6.4: Moving the output filter out of the datasheets recommended range with no feed forward capacitor. 50

Figure 6.5: Improved performance for an output filter outside the recommended range. 51

Figure 6.6: Frequency response at extremely low output filter. 54

Figure 6.7: Frequency response at extremely high output filter. 55

Figure 6.8: Feedback network with stray capacitance. ......................................... 56

Figure 6.9: Non-ideal circuit model of the (a) output filter and (b) feedback network.... 58

Figure 6.10: Bode plot comparing PCB parasitic output filter with an ideal and lossy output filter.

Figure 6.11: Bode plot comparing the feedback network with parasitics compared with an ideal feedback network both with no feed forward capacitor. 61

Figure 6.12: Bode plot of total closed loop (red), output filter (blue), and feedback network (orange) with PCB parasitics operating at low bandwidths 64 
Figure 6.13: Bode plot of total closed loop (red), output filter (blue), and feedback network (orange) with PCB parasitics operating at high bandwidths

Figure 6.14: Observing the effects of the feed forward capacitor in the parasitic model. 67

Figure 7.1: Typical application circuit schematic of the TPS62120 [39]. 69

Figure 7.2: PCB layout of the TPS62120 with its (a) top layer (b) bottom layer and (c) entire board. 71

Figure 7.3: (a) Final PCB assembly and (b) populated board..................................... 72

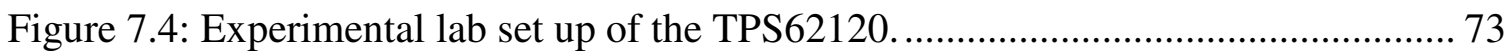

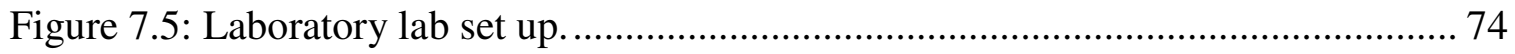

Figure 7.6: Frequency response analyzer technique for injecting AC signal ................ 75

Figure 7.7: Frequency response measurement at datasheet's recommended external component values

Figure 7.8: Experimental data compared to (a) ideal and (b) non-ideal model at datasheets recommended external component values.

Figure 7.9: Experimental data compared to (a) ideal and (b) non-ideal model at external component values out of the datasheets recommended range. 79

Figure 7.10: Effects of parasitic capacitance on the parasitic phase boost.................... 83

Figure 7.11: Modified non-ideal model on increasing parasitic capacitance compared to experimental data and nominal and low bandwidths. 85 


\section{Chapter 1 : Introduction}

There is an increasing demand for high performance power systems. They are found in applications ranging from high power, high efficiency aerospace and automotive systems to very low power efficient systems for consumer and medical applications [1]. These high performance power systems depend on several key factors such as efficiency, speed, and power management.

Power management is important because it controls, regulates, and distributes power throughout the system. At the heart of the field of power electronics and power management is the power supply. Strictly speaking, the power supply is a device used for the "conversion of available power of one set of characteristic to another set of characteristics to meet specified requirements" [2]. Power supplies enable an electronic device to function properly by supplying and controlling its power.

There are two types of power supplies: linear power supplies and switching power supply or switched-mode power supply (SMPS).

The linear regulator used in linear power supplies as shown in Figure 1.1 can only step down an input voltage to produce a lower output voltage by operating a BJT (or MOSFET) pass element in its linear mode of operation [3]. The output voltage is controlled through the resistor divider, reference, and error amplifier. 


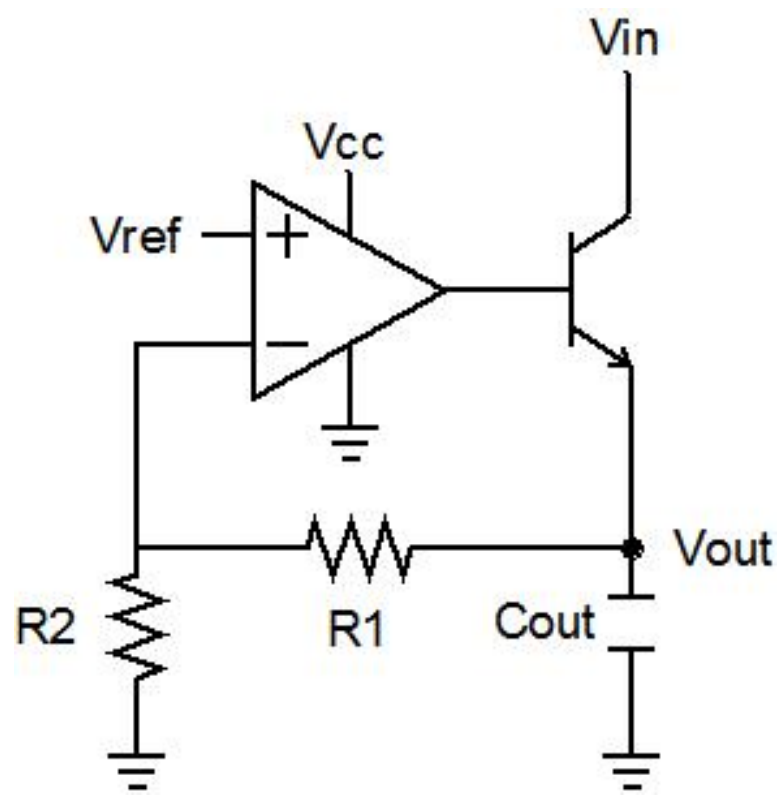

Figure 1.1: Linear regulator.

An ideal regulator can supply constant output voltage regardless of variations in input voltage, load current, or ambient temperature. The non-ideal linear regulator can achieve this result but at the expense of power dissipation on the pass element [4]. This reduces the power available at the output. This power loss is undesirable for such electronic devices that require high efficiencies.

An alternative to the linear power supply is the switching mode power supply (SMPS). These provide the desired performance through low loss components such as capacitors, inductors, transformers, and electronic switches.

SMPS employs the DC-DC converter that competes with the linear power supply in regulating the voltage of an electronic device. There are two common categories of DC-DC converters: isolated converters and non-isolated converters. 


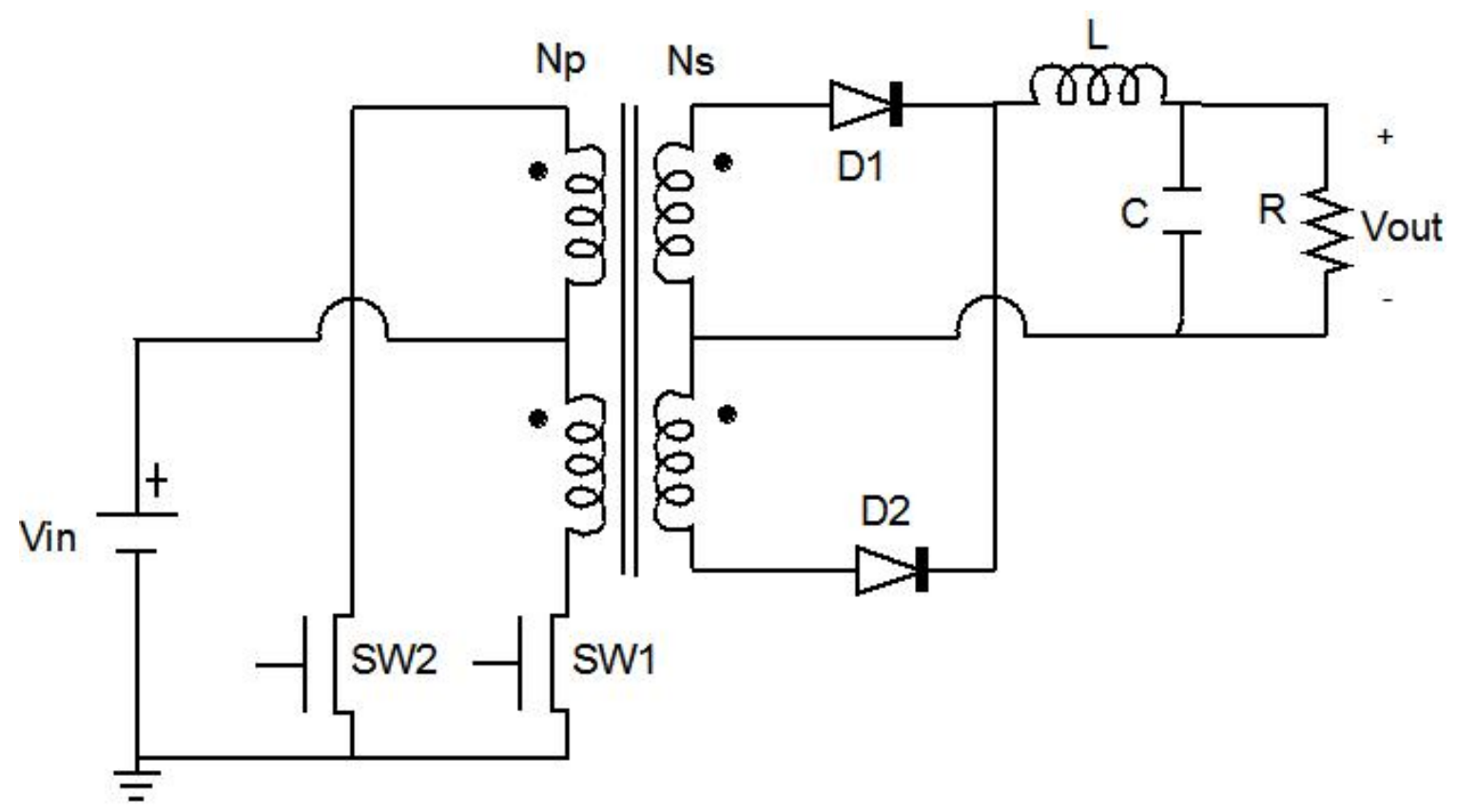

Figure 1.2: Push-pull isolated DC-DC converter.

Isolated DC-DC converters such as the push-pull converter shown in Figure 1.2 utilize a high frequency transformer whose secondary is rectified to produce a DC output voltage using a passive filter. This configuration has the advantage of producing multiple output voltages by adding secondary transformer windings. In addition, there may be isolation between system's input and output for safety considerations [5].

Non-isolated DC-DC converters such as the boost converter shown in Figure 1.3 do not use DC voltage isolation between the input and the output. The vast majority of applications do not require DC isolation between input and output voltages [5]. There are 3 commonly used non-isolated DC-DC converters:

1) Buck: Output voltage is less than the input voltage.

2) Boost: Output voltage is greater than the input voltage.

3) Buck-Boost: Output voltage can be greater or less than the input voltage depending on the duty cycle. 


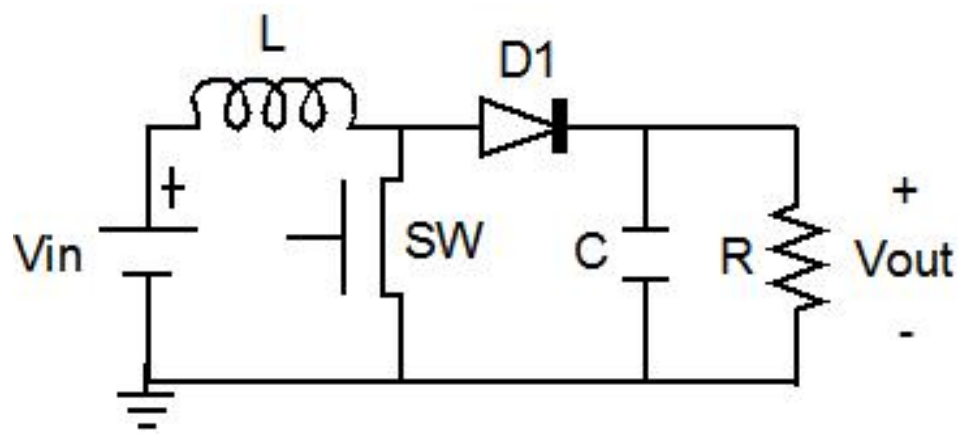

Figure 1.3: Non-isolated Boost DC-DC converter.

While linear regulators are desirable for its low noise, low cost, small size and ease of design, they can have low efficiencies, high thermal dissipation, and are limited to an output voltage less than its input. In comparison, DC-DC converters exhibit EMI (Electromagnetic Interference), have higher complexity, may have high cost due to added components, larger solution size with the benefits of high efficiencies, low heat dissipation, and the ability to step up, step down, or invert its output characteristics [5]. Table 1-1 details the comparison between the linear and switch-mode regulators.

Table 1-1: Benefits and drawbacks to linear and switching regulators

\begin{tabular}{|c|c|c|}
\hline & Linear Regulator & Switching Regulator \\
\hline Function & Only step down & Step down, Step up, Inverts \\
\hline Efficiency & $\begin{array}{l}\text { Low to Medium } \\
\text { High if Vin } \sim \text { Vout }\end{array}$ & High \\
\hline $\begin{array}{c}\text { Heat } \\
\text { Consumption }\end{array}$ & $\begin{array}{l}\text { High } \\
\text { Low if Vin Vout }\end{array}$ & Low for power $<10 \mathrm{~W}$ \\
\hline Complexity & $\begin{array}{l}\text { Low } \\
\text { Requires regulator } \\
\text { and capacitor }\end{array}$ & $\begin{array}{l}\text { Medium to High } \\
\text { Requires inductor, diode, capacitors, controller, } \\
\text { switches }\end{array}$ \\
\hline Size & $\begin{array}{l}\text { Small to Medium } \\
\text { High with heat sink }\end{array}$ & Small to High \\
\hline Cost & Low & Medium to High \\
\hline Ripple/Noise & $\begin{array}{l}\text { Low } \\
\text { Good noise rejection }\end{array}$ & $\begin{array}{l}\text { Medium to High } \\
\text { Due to switching }\end{array}$ \\
\hline
\end{tabular}




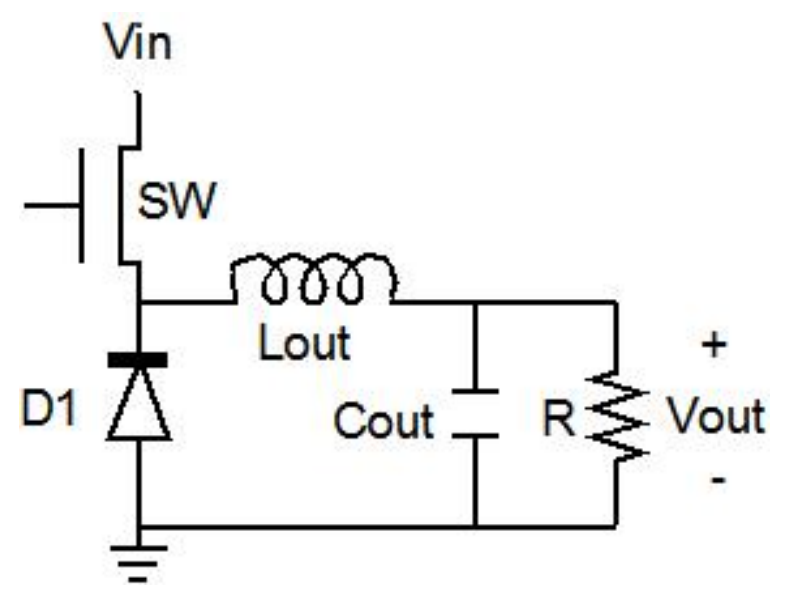

Figure 1.4: Buck Converter

The topology implemented in this thesis is the buck converter as shown in Figure 1.4. The buck converter is the most widely used DC-DC converter topology in power management because of its simple design and need for low output voltages in portable devices [6]. The power stage consists of a switch, diode, and passive filter. These combine to convert an applied input voltage to a lower output voltage. Using these nondissipative elements allows the transfer of energy with high efficiencies of around $90 \%$ for low power applications [7].

Buck converters have received great attention in low power, low voltage DC-DC converter applications in recent years for their ability in adapting to high functioning portable devices. The portable electronics industry has evolved in performance such as increased battery lifetime, smaller solution sizes, cheaper products, brighter, full-color displays, and increase in talk time in cellular phones. Highly efficient conversion techniques are important in achieving these consumer demands. [8]

Another application for the buck converter is in the energy sector. Energy plays an indispensable role in modern society. As the world becomes less reliant on fossil fuels, coal, and natural gas, and more conscious of renewable energy sources such as solar, 
wind, geothermal, biomass, and hydropower [9], it is the converter that plays some role in transforming these natural sources of energy into power for our homes, businesses, and transport [9]. Applications such as maximum power point tracking (MPPT) in photovoltaic systems [10] and piezoelectric energy harvesting systems [11] utilize the buck topology to implement their renewable designs.

Yet another application for the buck converter is in microprocessors. As the number of transistors in microprocessors increases per Moore's Law their power requirement increases accordingly. The output current requirements for microprocessors are rising while output voltage requirements are falling [12]. Next-generation high performance microprocessors may require 40 to 80 watts of power for the $\mathrm{CPU}$ alone [13] while the supply voltage decreases as microprocessors move to smaller process sizes [14]. Buck converters are ideally suited for microprocessor power applications by taking its high input voltage and low current and converting that power to a low output voltage and high current. Particularly, a multiphase interleaving buck converter shows promise in addressing this issue [12]. 


\section{Chapter 2 : Thesis Overview}

\subsection{Converter Stability and Transient Response}

Buck converter performance is not limited to parameters of efficiency, heat management, complexity, solution size, and cost. Central to the overall performance of the buck converter is the feedback control system. The control system continuously adjusts the power conversion to maintain a constant output voltage as the demand for power changes depending on the load requirements. The stability of a system relates to its ability to respond to inputs or disturbances. The output voltage deviation in response to a change in load is the converter's load transient [15].

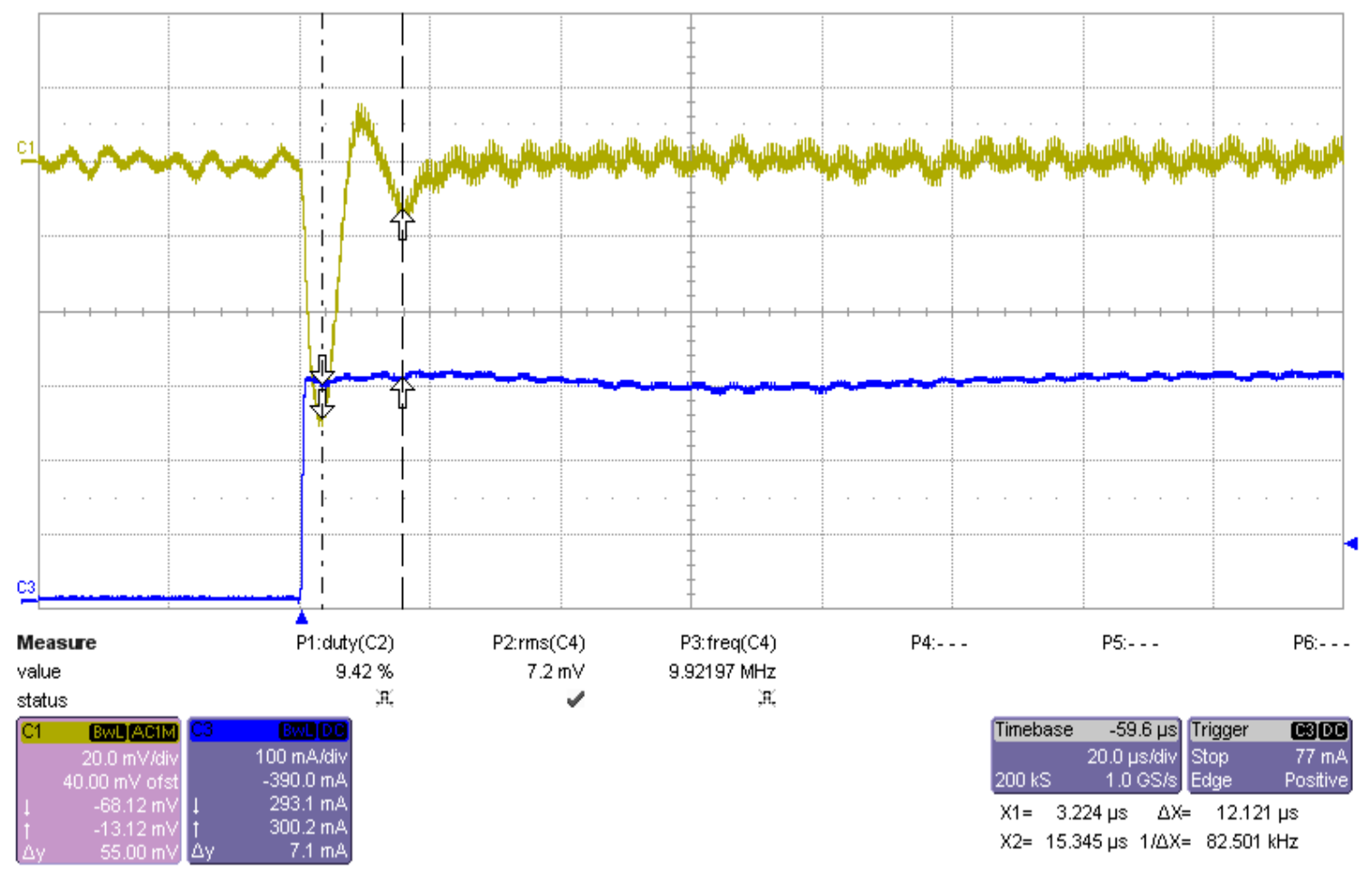

Figure 2.1: Buck converter output voltage response to a load step. 
A buck converter that regulates an output voltage (unless affected by an external action) and returns to a constant voltage when the external action is removed can be considered to be stable. Figure 2.1 shows the stability of a buck converter during a load step which represents a load transient. The output voltage eventually regulates back to nominal DC voltage.

Load transients are prevalent in every electronic device including semiconductor memory, card readers, microprocessors, disc drives, piezoelectric devices, and digitally based systems [16] because of their dynamic load changes due to device responses such as sensors and user interface. Ideally, a converter is invariant to load transients; however, in practice, they are susceptible to variations and must rely on a fast response of the converter in order to stabilize the output.

Fast response of DC-DC converters are critical in device protection. Load transients are capable of producing voltage stress from overshoots, disrupting sensitive equipment, introducing noise to the system, compromising the protection of the power system, and degrading device functionality [15]. This can be a serious issue for medical, military, telecom, and computing applications.

\subsection{Integrated Buck Converters}

Consumer demand for new technologies causes industry to push power supply designers for fast-paced design schedules. This becomes more and more difficult to accomplish as the complexity of power supplies grow. IC manufacturers help overcome these issues by making power supply design quicker and easier for the designer by 
providing power supply parts with integrated FETs, controller, and internal compensation.

A typical design procedure for a discrete buck converter shown in Figure 2.2 involves choosing a DC-DC IC controller, choosing a switching frequency, calculating and selecting the output inductor, the output capacitor, and a switch(s) that meet specifications. Afterwards, the power supply's controller compensation must be designed by calculating the power stage frequency response, choosing a desired bandwidth and margins, calculating the required error amplifier gain, and calculating the correct poles and zeros for the compensation network. Taking into account power supply protection and design optimization/iteration, the design process can quickly become prolonged and complicated.

Alternatively, the design procedure for an integrated buck converter shown in Figure 2.3 involves choosing an IC that meets input voltage, output voltage, and output current requirements, and selecting the external output inductor and capacitor from a list of recommended components in the datasheet.

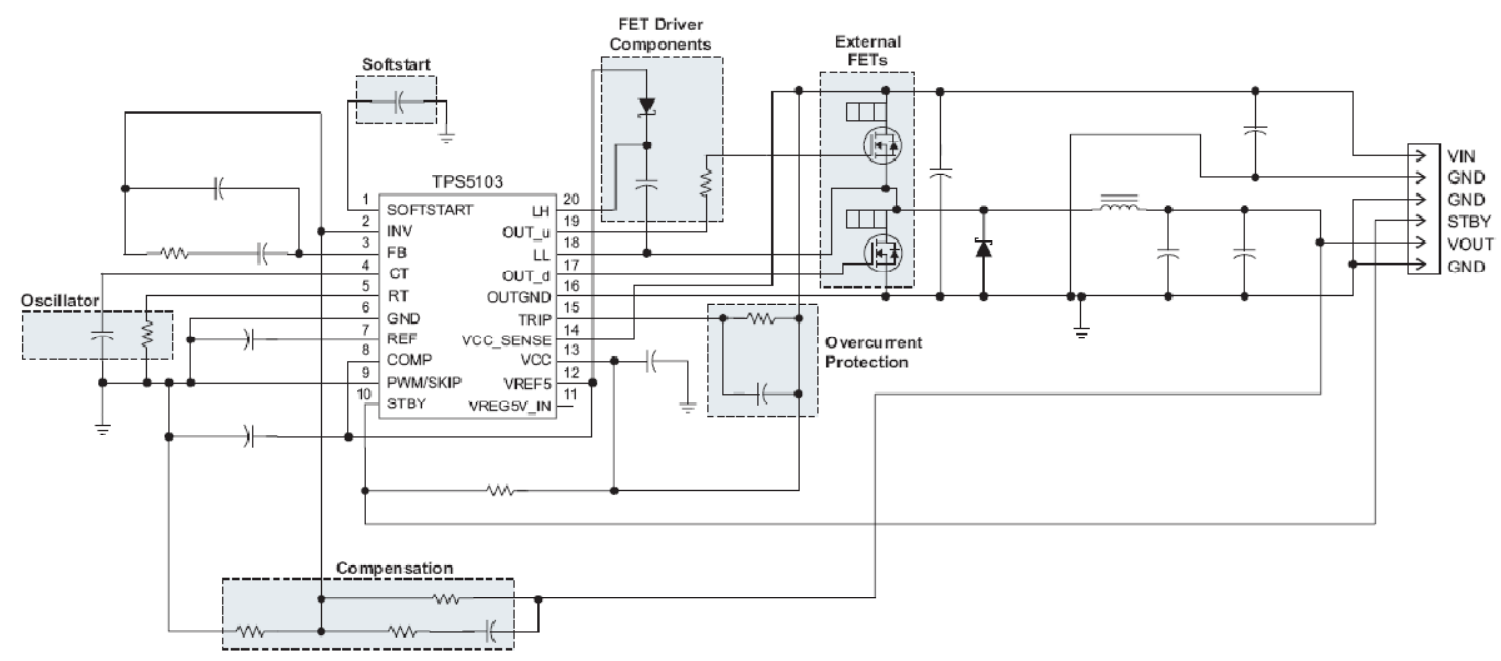

Figure 2.2: Circuit schematic for designing a discrete buck converter [17]. 


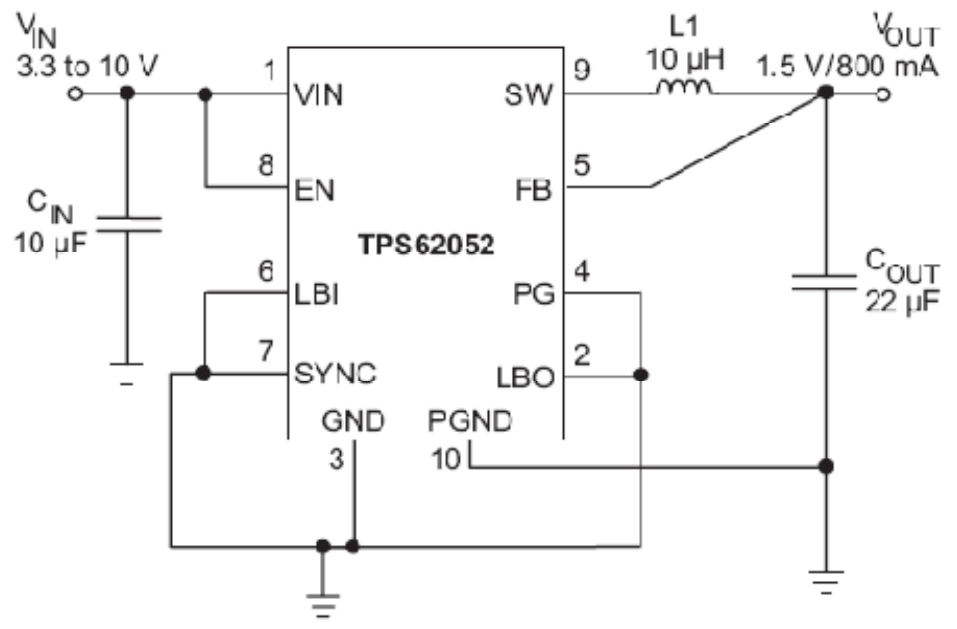

Figure 2.3: Circuit schematic for designing an integrated buck converter [17].

In addition to a reduction in design time and circuit complexity, integrated power supplies offer benefits in cost and solution size. An integrated design requires fewer external components which decrease the cost of purchasing parts, manufacturing, testing, and man-hours. Also, an integrated design requires fewer interconnections and allows for a smaller footprint in an overall system.

Despite its benefits over discrete design, the integrated design approach suffers from several drawbacks. For example, the use of discrete components gives the designer full control over all aspects of the power supply and the freedom to optimize the system for size, efficiency, and transient response. This design flexibility is not realized in integrated converters due to its set frequency, recommended external components, and fixed internal compensation. As a result, choosing components outside the recommended data sheet range can lead to an unstable design. In most cases, choosing the recommended component values for an internally compensated power supply provides an acceptable solution. However, there are times when the designer may need to optimize the design. With an integrated buck converter, the compensation and switches are 
inherent to the IC strictly leaving the output filter and resistor divider networks as external components. Even with this restriction, the savvy power supply designer can stray from the recommended component values in an attempt to optimize critical system parameters such as transient response, size, and efficiency [17]. The key to accomplishing this safely is to understand the limitations and implications of the choices which will be discussed in later chapters.

Another important aspect of converter design is the printed circuit board (PCB) layout considerations. Designers are familiar with how to use ICs and passive components in implementing a design. However, the printed circuit board for which the circuit will be placed on is an additional circuit component that must be considered for a successful design. Printed circuit board effects are common in high-speed analog circuits and audio design [18].

For the case of high frequency DC-DC converters, lay out is crucial for its proper operation. PCB parasitic components create havoc with converter design and cause degradation in efficiency, high ripple, current spikes, electromagnetic interference, and instability [slup224]. Techniques to minimize the impact of parasitic inductances, capacitances, and trace resistance must be implemented.

A great deal of research has been conducted on calculating, measuring, and observing the effects of PCB parasitics on efficiency, signal integrity, and EMI of switch mode power supplies. However, there is an insufficient amount of information relating power supply stability and PCB parasitics (other than highly generalized board layout considerations for minimizing these parasitics). In addition, there are many circuit simulation packages that determine the general performance of a switching power supply. 
However, a common mistake is for engineers to oversee "real" circuit performance and assume that the supply will perform comparably to the simulation model where parasitic effects usually go unaccounted for.

In most cases, adhering to the data sheet's board layout considerations and recommended components for integrated DC-DC converters will lead to a functional and stable power supply. However, optimizing the tradeoffs between efficiency, solution size, and cost may lead to component values not suggested in the datasheet. In this case, stability of the converter may be compromised.

This thesis will examine PCB parasitics as the limiting factor for integrated DCDC converter optimization by modeling the control system of an integrated buck converter, the TPS62120, along with calculated PCB parasitic components and assessing its effect on the converter's stability. In addition, this thesis will implement a hardware method to improve the stability of an integrated buck converter outside of its recommended ratings using only the external components. The frequency response of the converter together with the PCB parasitics will then be measured to evaluate the converter's stability. The data taken will be compared to the model to evaluate its accuracy. This will be useful for both PCB layout and DC-DC converter designers in implementing their designs and considering the limitations that may affect both converter stability and performance. 


\section{Chapter 3 : Background}

This chapter discusses what is currently present in literature and research relating to PCB layout parasitics and DC-DC converter performance. The research investigated in this thesis relates to the PCB parasitic effects on DC-DC converter stability. Exploration into this topic has yielded practical design considerations and circuit simulations have generated accurate waveforms. However, modeling of the converter's control system will produce a more calculated and accurate understanding of how the PCB parasitics effects the converter's stability.

\subsection{PCB Layout Design Considerations}

Any effect caused by the PCB itself should be minimized such that the operation of the converter will be the same as the performance of the design or simulation. For this reason, datasheets contain general design rules for converter layout and component placement [20]. More detailed literature on PCB design considerations that may affect converter operation such as PCB material, number of layers, trace angles, humidity, dust, and flux residue can also be useful to the designer [14], [21], [22], [23]. Furthermore, there is literature specific to mitigating performance issues of PCB layout such as grounding, trace antennas, current and voltage spikes, radiated and conducted noise, mutual inductance, and dielectric absorption on general analog circuit designs [5008249, slyt166, high frequency implications for DC-DC converters]. Lastly, stability and transient response considerations are discussed briefly in literature. Datasheets describe designing the converter with additional phase to the desired phase margin to account for possible decreases in stability due to board parasitics [datasheet62120]. In addition, 
general PCB design literature suggest component placement, specifically, the output

capacitor, to be placed as close as possible to the load in order for the capacitor to supply

all the transient current.

These highly general design guidelines, illustrated in Table 3-1, are the bare

minimum considerations when building a converter and serve as "rules of thumb" on a

PCB to yield a decent design. Therefore, in order to fully optimize design, one must

obtain a more accurate understanding of parasitics.

Table 3-1: Design Considerations of PCB Layout [23].

\begin{tabular}{|c|c|c|}
\hline & Culprit & Approach \\
\hline Functionality & $\begin{array}{l}\text { Parasitic L } \\
\text { Parasitic R }\end{array}$ & $\begin{array}{l}\text { - Reduce parasitic inductances in fast-switching current paths to suppress } \\
\text { unwanted } \mathrm{Ld}_{\mathrm{i}} / \mathrm{dt} \text { voltage drops. } \\
\text { - Reduce parasitic resistances in high-current paths to eliminate unwanted RI } \\
\text { voltage drops. } \\
\text { - Priority is with fast-switching connections since } \mathrm{Ld}_{\mathrm{i}} / \mathrm{dt} \text { dominates if switching } \\
\text { frequency is high. } \\
\text { - Place power components as close as possible to each other. } \\
\text { - Reduce the parasitic inductances and resistances by routing them as short and } \\
\text { wide as possible. }\end{array}$ \\
\hline Efficiency & Parasitic R & $\begin{array}{l}\text { - Reduce parasitic resistances in high-current paths. } \\
\text { - Place power components as close as possible to each other to reduce the length } \\
\text { of connections. Route their connections as wide as possible. }\end{array}$ \\
\hline DC Accuracy & Parasitic R & $\begin{array}{l}\text { - Connect the controller IC output voltage sense and analog ground pins as close } \\
\text { as possible to the load. } \\
\text { - Place the output capacitor as close as possible to the load to suppress the } \\
\text { parasitic resistances between load and output capacitor. As a result, the AC } \\
\text { ripple is reduces. }\end{array}$ \\
\hline $\begin{array}{l}\text { Transient } \\
\text { Accuracy }\end{array}$ & $\begin{array}{l}\text { Parasitic L } \\
\text { Parasitic R }\end{array}$ & $\begin{array}{l}\text { - Reduce the parasitic resistance and inductance between output capacitor and the } \\
\text { load to reduce voltage drops across parasitic inductors and resistors at load } \\
\text { transients. }\end{array}$ \\
\hline $\begin{array}{l}\text { Switching } \\
\text { Noise } \\
\text { Injection }\end{array}$ & & $\begin{array}{l}\text { - Route sensitive connections connected to high impedance nodes as short as } \\
\text { possible. } \\
\text { - Route them as far as possible from noisy signals to reduce capacitor coupling to } \\
\text { noisy signals. } \\
\text { - The trace that connects the sensed output voltage from feedback resistors to the } \\
\text { input of the controller effort amplifier is the sensitive connection in switching } \\
\text { regulators. }\end{array}$ \\
\hline EMI & & $\begin{array}{l}\text { - Route fast-switching connections as short as possible. } \\
\text { - Route return paths of fast switching connections close to their forward paths. } \\
\text { - Priority is with routing connections that their currents change suddenly (fast- } \\
\text { switching currents). } \\
\text { - Fill empty spaces with ground plane. }\end{array}$ \\
\hline $\begin{array}{c}\text { Test and } \\
\text { Measurement }\end{array}$ & & $\begin{array}{l}\text { - Beware of ground place changes because of connecting test and measurement } \\
\text { instruments to the converter circuitry. Avoid ground loops by: } \\
\text { - Floating supplies and loads } \\
\text { - An isolated oscilloscope }\end{array}$ \\
\hline
\end{tabular}




\subsection{Parasitic Components in DC-DC Converters}

The design considerations discussed in the previous section serve only to minimize PCB parasitics meaning that they are nevertheless present in a system. PCB resonance effects may lead to additional signal delay, signal reflections, parasitic electromagnetic propagation, signal distortions, crosstalk, and EMI problems [24]. Because of this, a great deal of research has been conducted in calculating or simulating an accurate model of stray capacitances, inductances, and resistances from PCB layout design such as package leads, excess trace lengths, pad-to-ground, pad-to-power-place, pad-to-trace capacitances, and interactions with via connections.

One approach in calculating an accurate model for inductance, capacitance, and resistance is by directly measuring PCB trace or via lengths and pairing them with board component electrical properties as discussed in [25], [26], and [27] shown in Figure 3.1. This method only assumes rectangular trace geometries; otherwise, conformal mapping calculations using the Schwarz-Cristoffel transformation must be implemented to convert polygonal traces to effective rectangular traces [28]. 


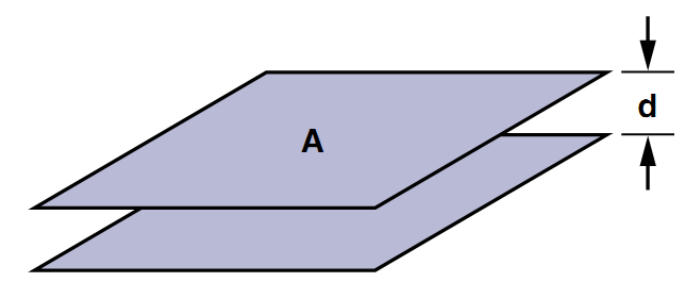

$C[p F]=\frac{k A\left[\mathrm{~cm}^{2}\right]}{11.3 d[\mathrm{~cm}]}$

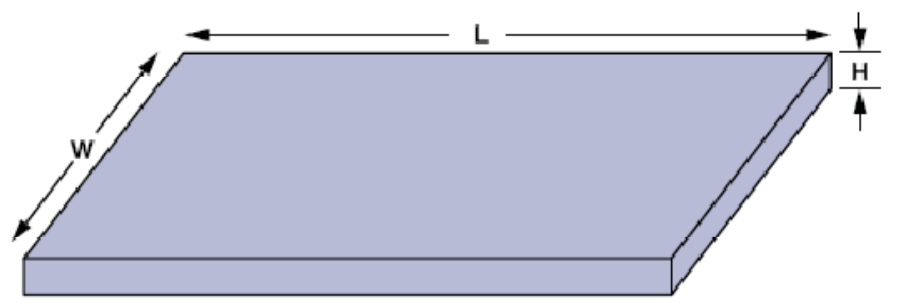

$$
\begin{gathered}
L[u H]=0.0002 L[\mathrm{~cm}]\left[\ln \frac{2 L[\mathrm{~cm}]}{W[\mathrm{~cm}]+H[\mathrm{~cm}]}+0.2235 \frac{W[\mathrm{~cm}]+H[\mathrm{~cm}]}{L[\mathrm{~cm}]}+0.5\right] \\
R[\Omega]=\frac{\rho[\Omega \mathrm{cm}] \mathrm{L}[\mathrm{cm}]}{A\left[\mathrm{~cm}^{2}\right]}
\end{gathered}
$$

Figure 3.1: Dimensions of typical PCB components and their calculated parasitic contributions [25].

A second approach is to utilize electromagnetic simulation software such as IE3D, Maxwell Q3D, and SABER capable of determining EM interactions on systems. Traces can be created and simulated values can be used as an accurate lumped parasitic model [28], [29], [30].

As for diagnosing a fabricated PCB for parasitic components, in some cases it involves direct measurements using an LCR meter or network analyzer. However, this can prove to be expensive and not typical equipment in a power electronics laboratory. An easy method for measuring parasitic components in a PCB design can be implemented by using simple electronics equipment such as a standard oscilloscope and a 
low frequency waveform generator. This technique involves injecting a triangular waveform at high frequencies through a trace, extracting its inductive and capacitive properties through the oscilloscope, and calculating the parasitic component values [31].

One major reason for measuring board parasitic is Electromagnetic Interference (EMI). Electromagnetic interference regulation is exceedingly strict for device operation because it degrades the performance of the device and any nearby electronic systems around it. EMI is strongly associated with parasitic components in power electronics PCBs. One of the major challenges is accurately predicting the levels of the electromagnetic interference. To achieve this, precise models of all components of the converter must be used which depends on geometrical structures of the system [30]. The literatures show very accurate forecasting of EMI [29], [28]. As a result, methods for improving EMI performance of converters through parasitic reduction have been developed and are effective in optimizing device performance [32].

Besides EMI, parasitic on DC-DC converters may have severe effects on stability. A good example may be observed from DC-DC converters for microprocessors. New generation microprocessors require a tight regulation of the output voltage at typically $+5 \%$ or better [33]. Voltage deviations as shown in Figure 3.2 represent a major problem for large load changes that are usually encountered in DC-DC converters. Parasitic impedance of the power supply connection to the load has a major effect on the power supply voltage. If the impedance is high enough, the supply voltage may fall out of the required range during the transients. 

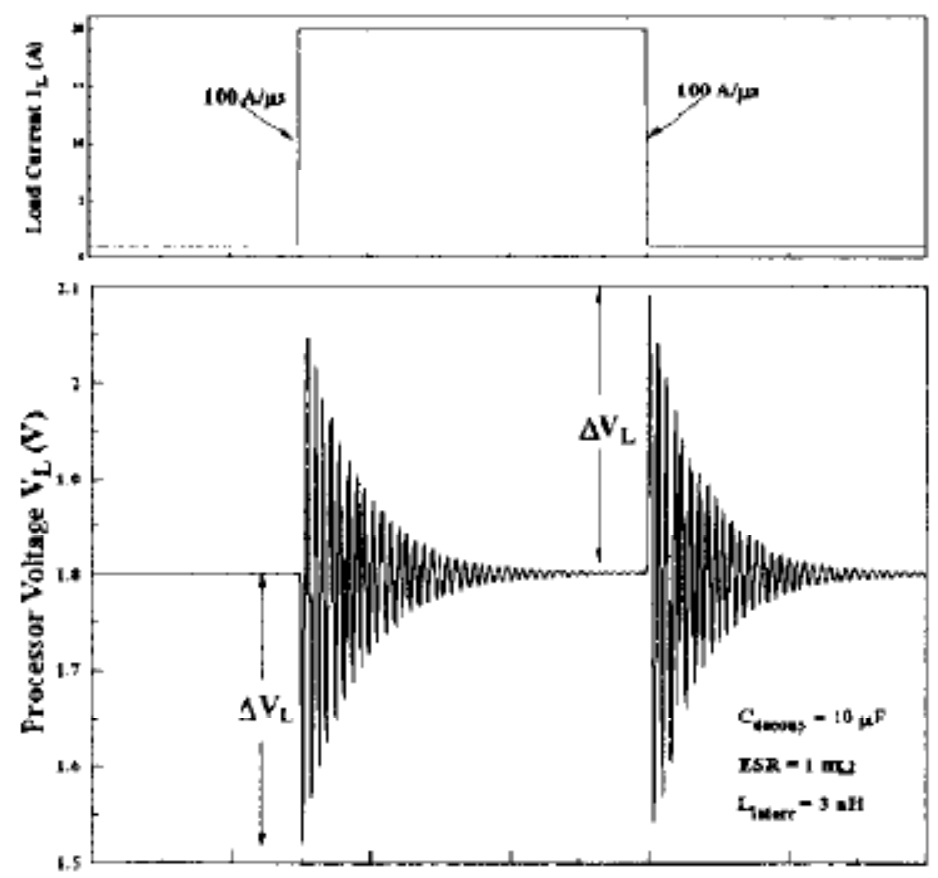

Figure 3.2: Voltage deviation during a load transient for a microprocessor [33].

To alleviate this problem, decoupling capacitors are connected across the microprocessor. However, no matter how close the power supply is placed to the load a certain amount of interconnect parasitics is always present and the amount of the decoupling capacitance is limited by the available space. Research has been done observing the voltage deviation and determining how much parasitic inductance can be tolerated for a given amount of decoupling capacitance and a 5\% regulation during various slew rated load transients [33]. Verification of this system was carried through SPICE simulation and the results of this study are shown in Table 3-2. For example, a microprocessor rated for $1.2 \mathrm{~V}$ must have a decoupling capacitor of at least $1 \mathrm{uF}$ in order to regulate the voltage within $5 \%$. 
Table 3-2: Estimated parasitic inductances for various decoupling capacitances and current slew rates [33].

\begin{tabular}{|c|c|c|c|c|c|c|c|c|c|c|}
\hline \multirow[b]{4}{*}{$\mathrm{C}_{\text {decoup }}[\mu \mathrm{H}]$} & \multicolumn{10}{|c|}{$\mathbf{L}_{\text {minterc }} \max [n \mathrm{H}]$} \\
\hline & \multicolumn{5}{|c|}{ Slew Rate $=10 \mathrm{~A} / \mu \mathrm{s}$} & \multicolumn{5}{|c|}{ Slew Rate $=100 \mathrm{~A} / \mu \mathrm{s}$} \\
\hline & \multicolumn{5}{|c|}{$\mathrm{V}_{\mathrm{L}}(\mathrm{V})$} & \multicolumn{5}{|c|}{$V_{L}(V)$} \\
\hline & 3.3 & 2.9 & 2.5 & 1.8 & 1.2 & 3.3 & 2.9 & 2.5 & 1.8 & 1.2 \\
\hline 1 & 8.0 & 7.0 & 6.0 & 4.5 & 3.5 & 1.0 & 0.9 & 0.8 & 0.5 & 0.4 \\
\hline 10 & 9.0 & 8.0 & 7.0 & 5.0 & 4.0 & 2.0 & 1.5 & 1.3 & 0.8 & 0.5 \\
\hline 100 & 13 & 11 & 10 & 7.0 & 5.0 & 2.0 & 1.5 & 1.3 & 0.8 & 0.5 \\
\hline 1,000 & 25 & 16 & 11 & 8.0 & 5.0 & 2.0 & 1.5 & 1.3 & 0.8 & 0.5 \\
\hline 2,000 & 25 & 16 & 11 & 8.0 & 5.0 & 2.0 & 1.5 & 1.3 & 0.8 & 0.5 \\
\hline
\end{tabular}

In order to properly model these parasitics on converters stability accurately, there needs to be an understanding on how the converter reaches stability based on the control design.

\subsection{DC-DC Buck Converter Control Design Considerations}

Various control techniques can be implemented in a DC-DC converter design to regulate the output voltage. It is important to note that there is no single control method which is optimum for all applications. There are typically three control techniques each with their advantages and disadvantages:

- Voltage-Mode Control

- Current-Mode Control

- Hysteretic Control

Typical voltage-mode design as shown in Figure 3.3 is that there is a single voltage feedback path. Pulse width modulation is performed by comparing the voltage error signal with a constant ramp waveform. 


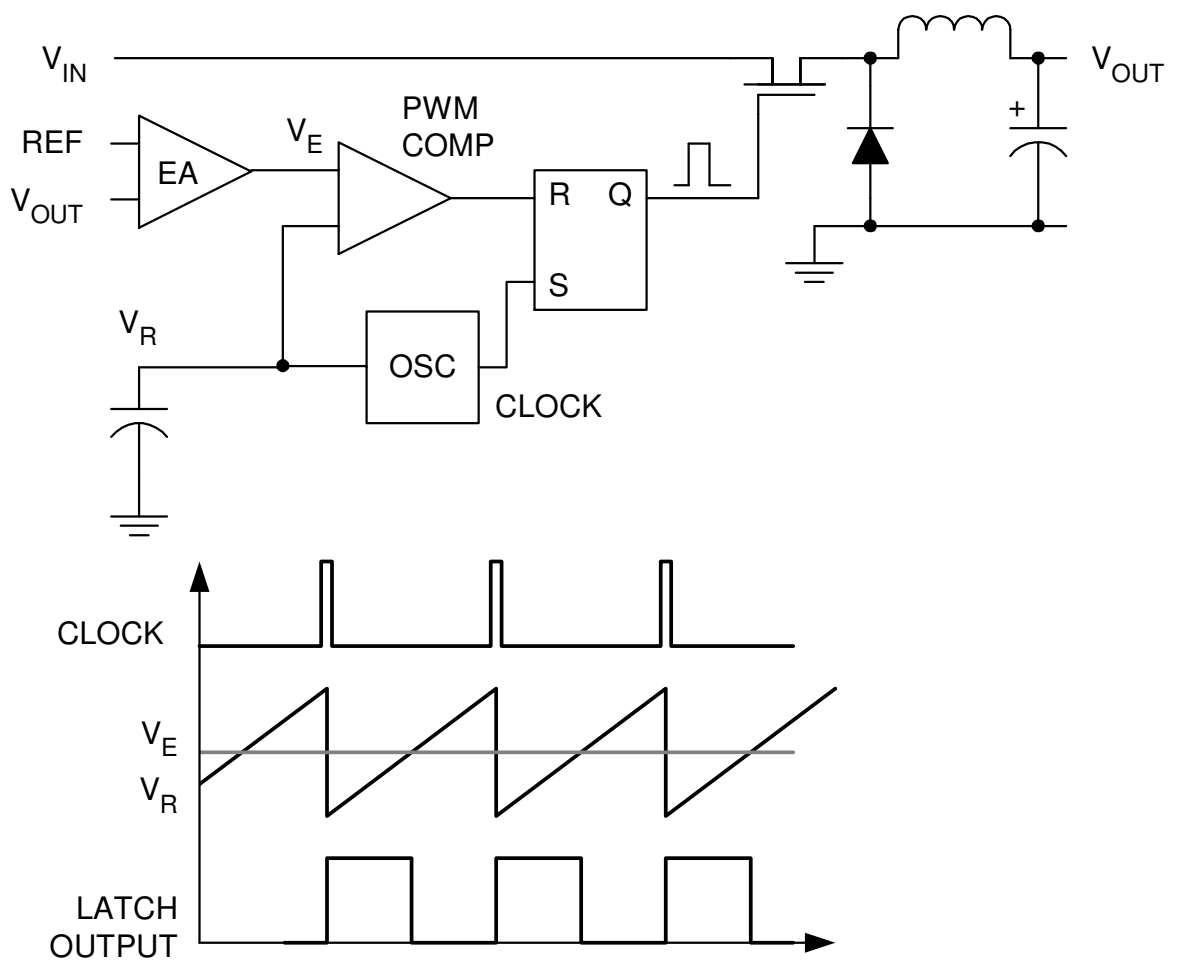

Figure 3.3: Voltage-mode topology and corresponding waveforms [2]

The advantages of voltage-mode control are the following [34]:

- A single feedback loop is easier to design and analyze.

- A large-amplitude ramp waveform provides good noise margin for a stable modulation process.

- A low-impedance power output provides better cross-regulation for multiple output supplies.

Voltage-mode's disadvantages are the following [34]:

- Slow response. Any change in the line or load must first be sensed as an output change and then corrected by the feedback loop.

- Added compensation circuitry. 
Typical current-mode control as shown in Figure 3.4 uses the oscillator only as a fixed-frequency clock and the ramp waveform is replaced with a signal derived from the inductor current.
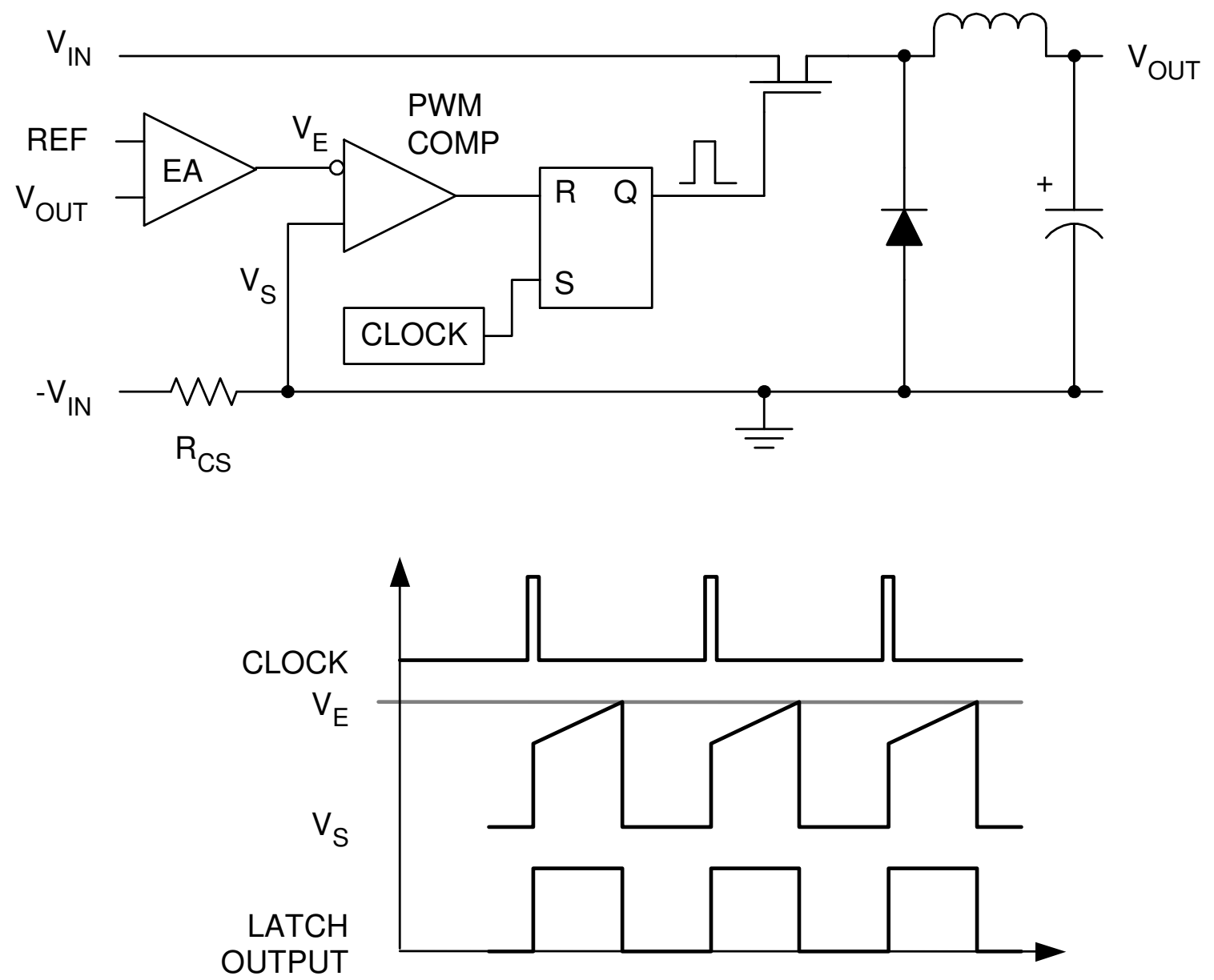

Figure 3.4: Current-mode topology and corresponding waveforms [2].

The advantages of current-mode control are the following [34]:

- Fast line voltage response due to inductor current rise related to Vin-Vo. This eliminates both the delayed response and gain variation with changes in input voltage.

- Inherent current limiting pulse-by-pulse by clamping the command from the error amplifier. 
The disadvantages of current-mode control are the following [34]:

- Two feedback loops make circuit analysis more difficult.

- The control loop becomes unstable at duty cycles above 50\% unless slope compensation is added.

- Noise from the power stage can flow into the control loop.

- Load regulation is worse due to the control loop forcing a current drive.

Hysteretic control, also called bang-bang control or ripple regulator control, shown in Figure 3.5 maintains the output voltage within the hysteresis band centered about the internal reference voltage. If the output voltage is at or below the level of the reference minus one-half of the hysteresis band, the switch turns on causing the output voltage to increase. When the output voltage reaches or exceeds the reference plus one-half of the hysteresis band, the switch turns on causing the output voltage to decrease. This hysteretic method of control keeps the output voltage within the hysteresis band around the reference voltage.

The advantages of hysteretic control are the following [13]:

- Fastest response to load changes.

- Simple control design.

- No complicated loop compensation.

The disadvantages of hysteretic control are the following [13]:

- Variable switching frequency

- Requires some output ripple

- Sensitive to output noise

- Circuit delays limit maximum frequency

- Need protection against magnetic saturation 

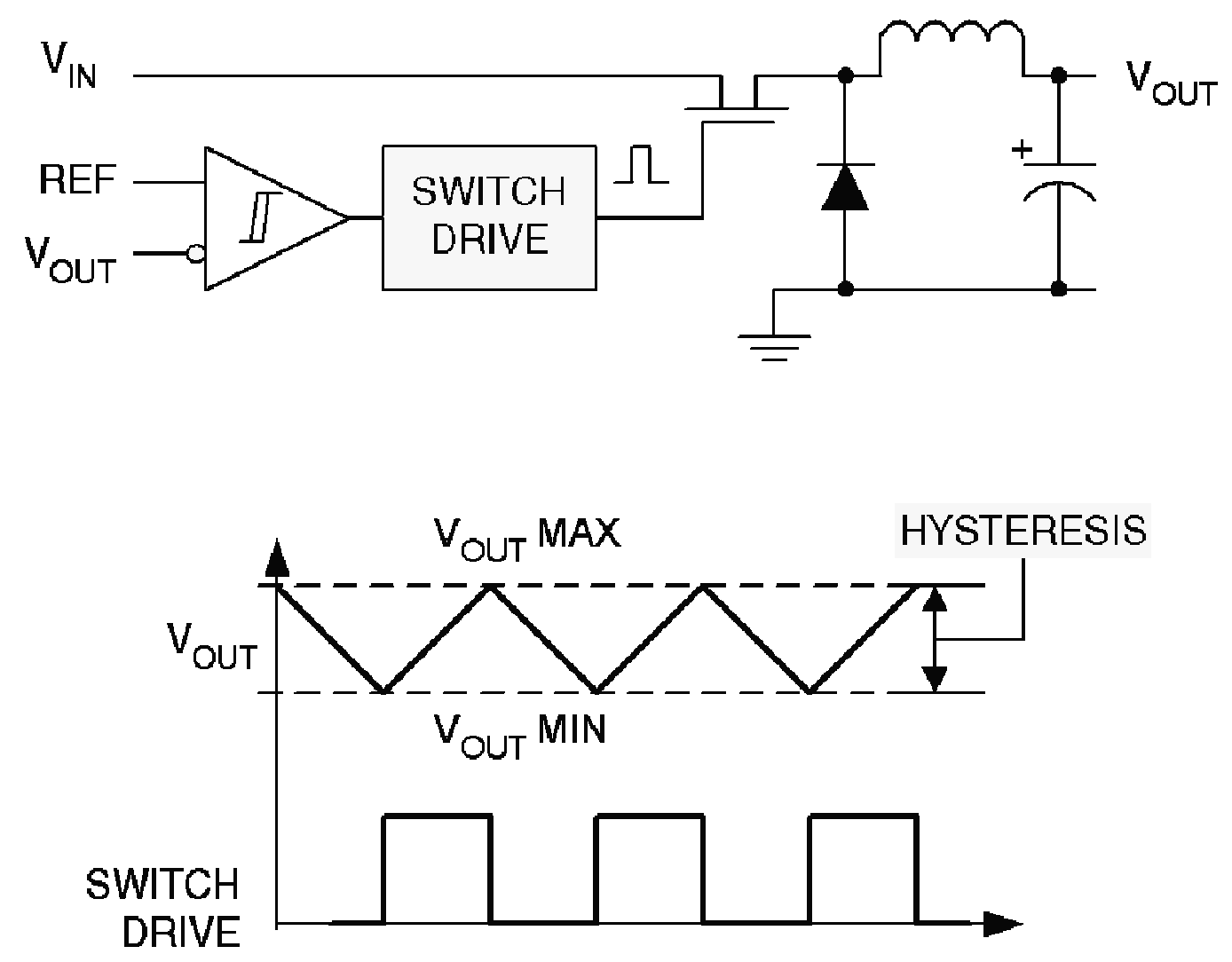

Figure 3.5: Hysteretic control topology and corresponding waveforms [2].

Evidently, the choice of control topology is ultimately up to the designer and it changes from application to application. However, considerations for an optimum control scheme include output voltage ripple, dynamic response, input voltage variations, load sharing, cost, and noise [34]. For design analysis and conceptual understanding, we will discuss voltage-mode compensation control in the next chapter. 


\section{Chapter 4 : Voltage-Mode Control Analysis}

\subsection{Output Voltage Transient Response and Converter Frequency Response}

For DC-DC converters, a sufficient measurement of stability may be obtained by observing the output voltage from a step response. Figure 4.1 shows an example of a step response introduce on the output current while stability is being observed on the output voltage.

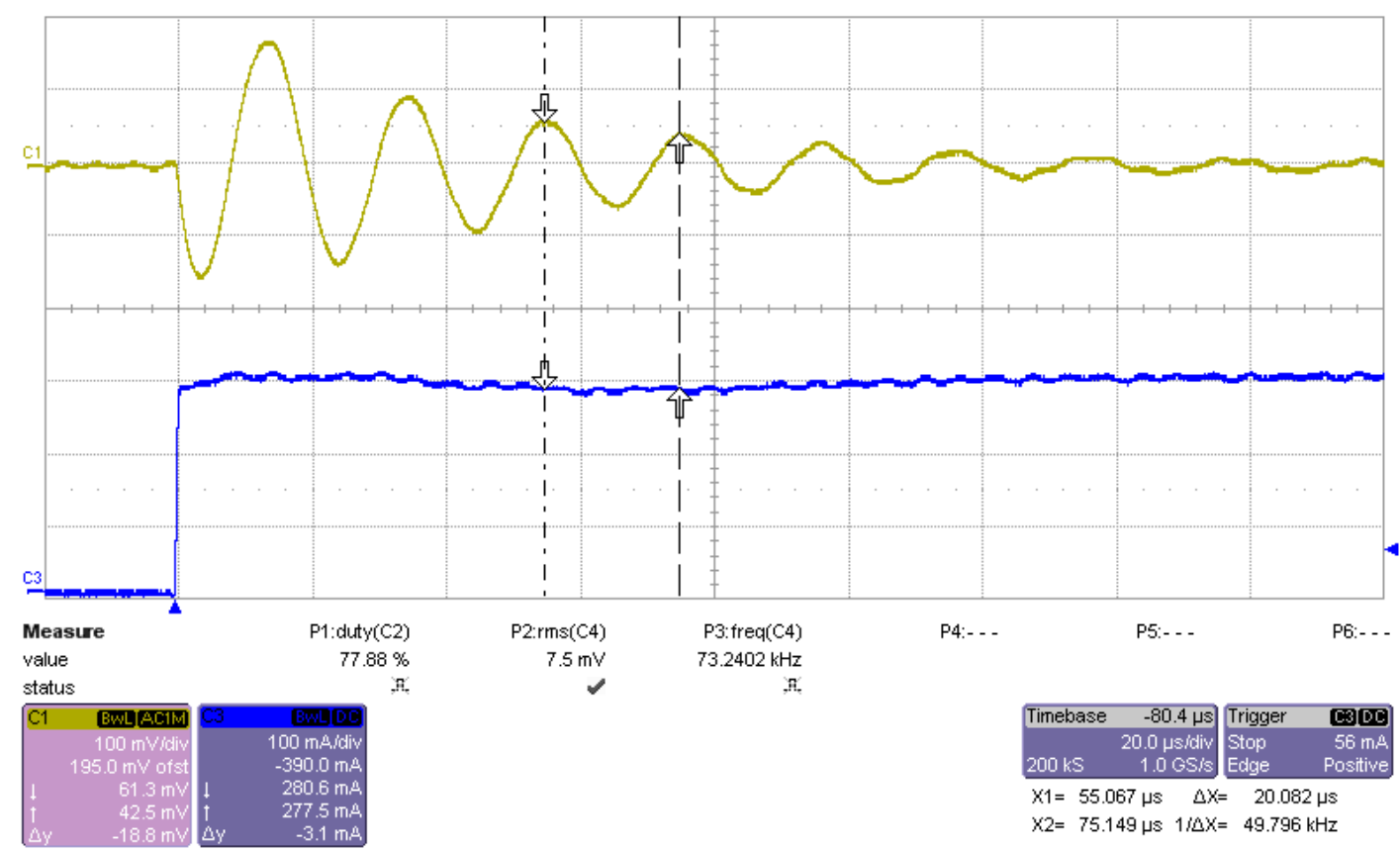

Figure 4.1 Converter response to a load transient.

Measurements such as percent overshoot, percent undershoot, and settling time in seconds help quantify this stability. An alternative measurement of stability relating to the transient response is the loop frequency response of the converter as shown in Figure 4.2. Measurements such as phase margin and crossover frequency help quantify attributes in the transient response such as overshoot and settling time. 


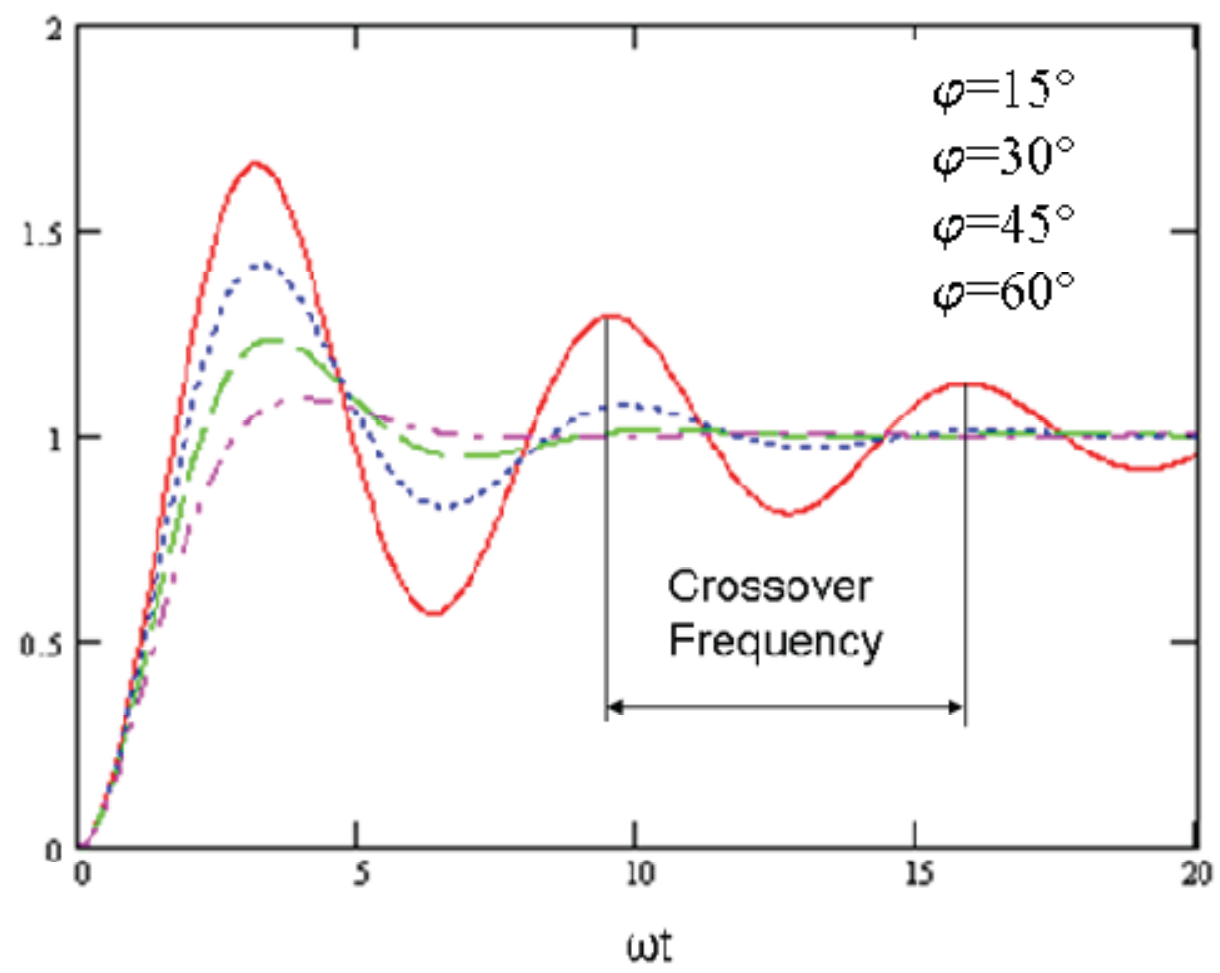

Figure 4.2: Converter frequency response and its relation to the transient response [35]. The highest deviation to steady state corresponds to the lowest phase margin $\varphi$.

Figure 4.3 demonstrates the frequency response of the converter whose transient response is shown in Figure 4.2. The crossover frequency is measured to be $52 \mathrm{kHz}$ at 20 degrees of phase margin while the transient response displays an oscillating frequency of $50 \mathrm{kHz}$ with a fairly prominent overshoot.

Measurements such as percent overshoot, percent undershoot, and settling time in seconds help quantify this stability. An alternative measurement of stability relating to the transient response is the loop frequency response of the converter as shown in Figure 
4.2. Measurements such as phase margin and crossover frequency help quantify attributes in the transient response such as overshoot and settling time.

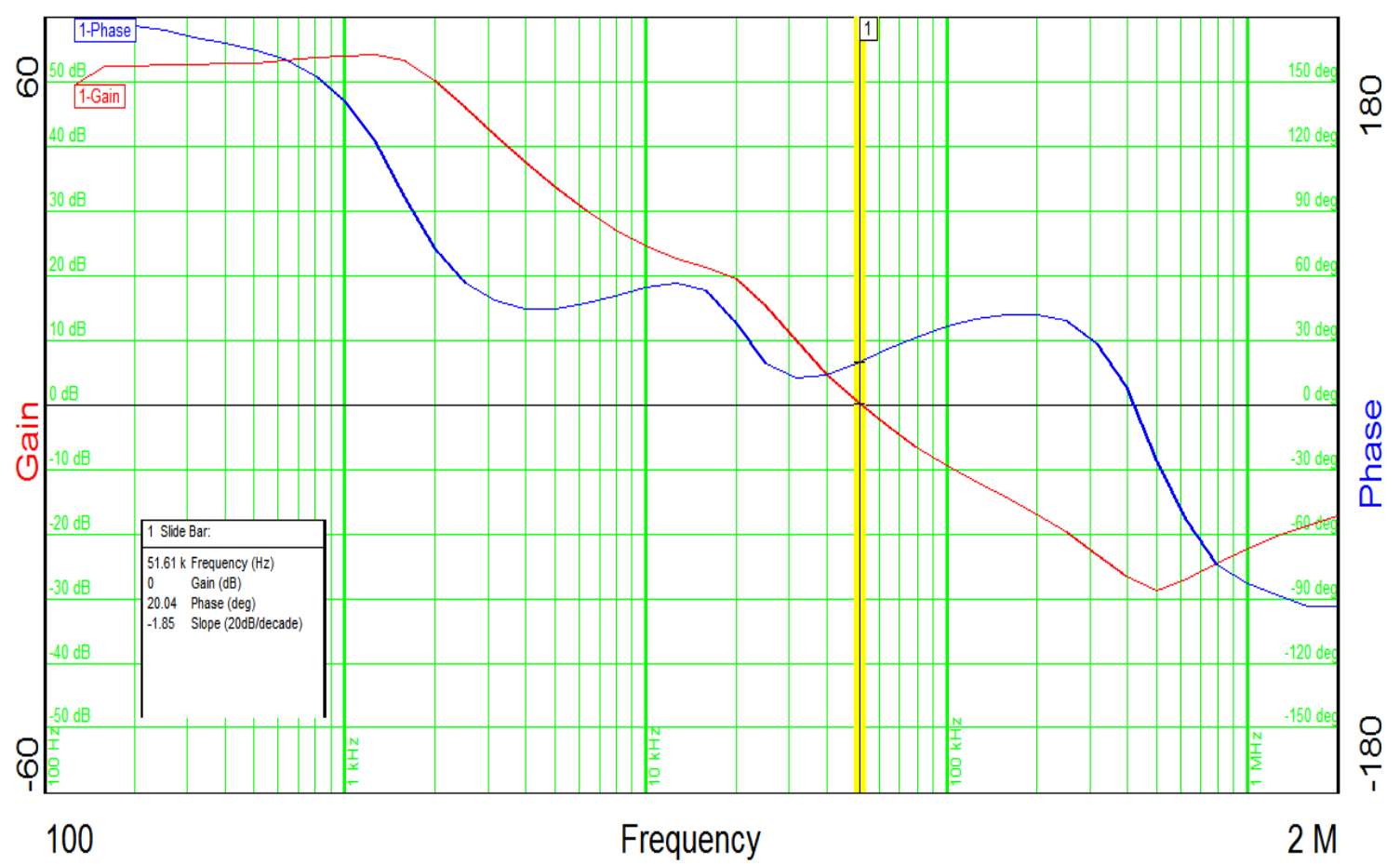

Figure 4.3: Converter frequency response of the converter used in Figure 4.1.

\subsection{Converter Frequency Response Voltage-Mode Derivation}

Synchronous and non-synchronous buck converters have three basic blocks that contribute to the closed loop system as shown in Figure 4.4 along with its corresponding circuit diagram for voltage mode control. The block is the modulator block which consists of the PWM circuitry to drive the switches at a certain duty cycle to control power transfer. The next block is the output filter that stores the energy to be transferred to the output. Finally, the compensation network contains the error amplifier for producing the nominal output voltage. 


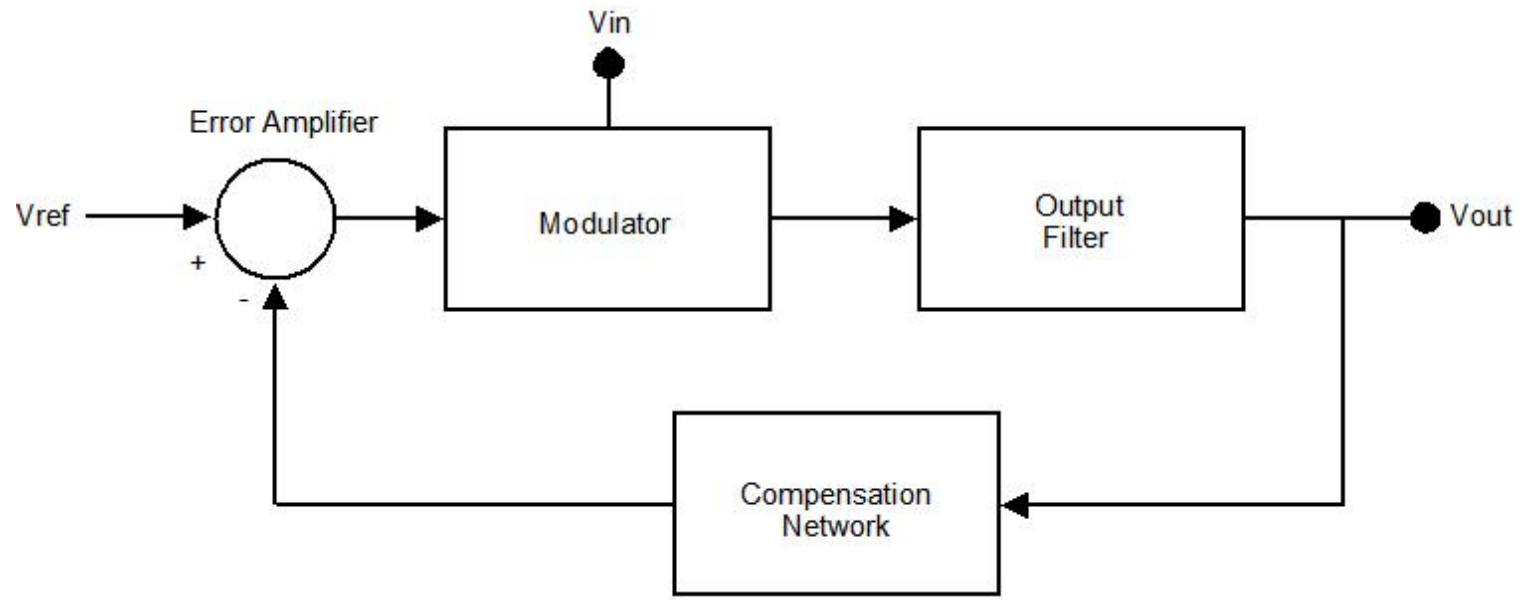

(a)

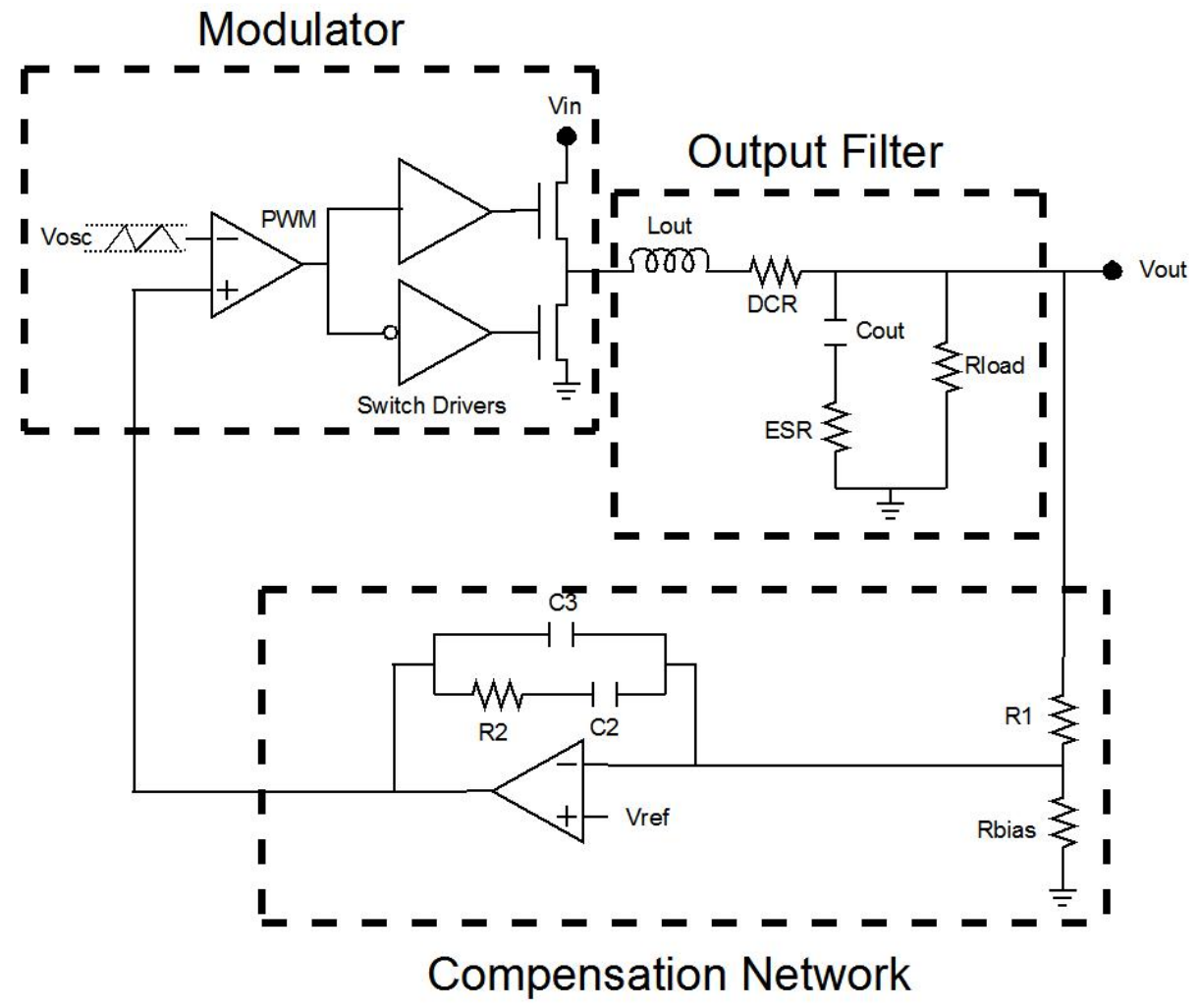

(b)

Figure 4.4: (a) A closed loop voltage-mode buck converter block diagram and (b) its corresponding circuit diagram. 
The closed loop transfer function of the system shown as the block diagram in Figure 4.4(a) is

$$
\begin{aligned}
& H_{\text {system }}(s)=\frac{V_{\text {out }}}{V_{\text {ref }}}=\frac{H_{\text {mod }}(s) H_{\text {filter }}(s)}{1+H_{\text {mod }}(s) H_{\text {filter }}(s) H_{\text {compensator }}(s)} \\
& H_{\text {system }}(s)=\frac{H_{\text {mod }}(s) H_{\text {filter }}(s)}{1+H_{\text {loop }}(s)}
\end{aligned}
$$

The denominator of the system transfer function, $1+\mathrm{H}_{\text {loop }}(\mathrm{s})$, is the characteristic equation of the system, and $\mathrm{H}_{\text {loop }}(\mathrm{s})$ is the loop gain (the gain of the loop consisting of the modulator, filter, and compensator). By inspection, it is clear that if $\mathrm{H}_{\text {loop }}(\mathrm{s})=1$, the transfer function of the system, $\mathrm{H}_{\text {loop }}(\mathrm{s})$ will become infinite and would be an unstable system. Because of the relative complexity of a typical buck converter, the most convenient way to analyze stability is by the use of graphical methods such as bode plots. 

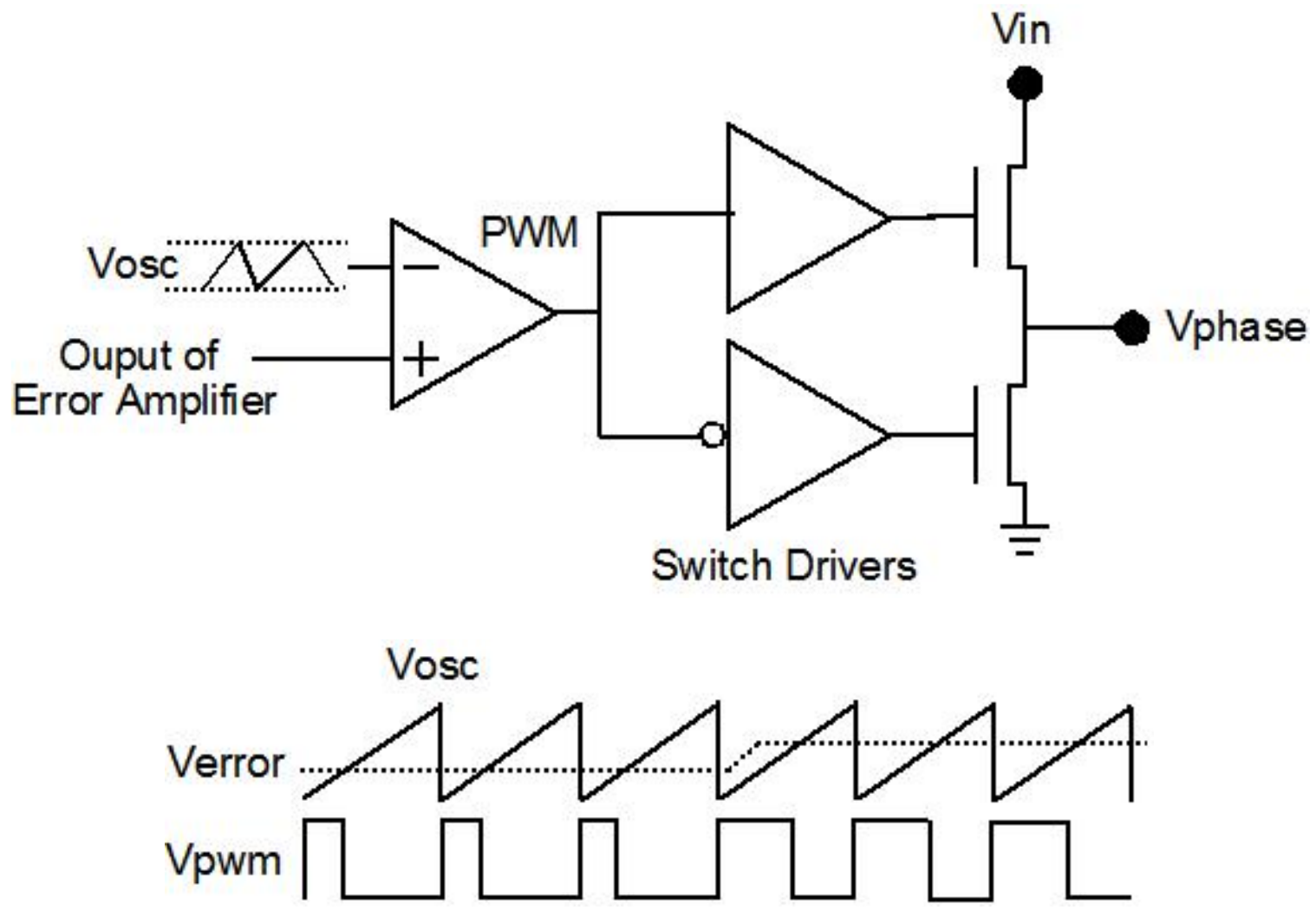

Figure 4.5: The voltage-mode modulator and its functional waveforms.

As previously mentioned, the modulator block consists of a voltage comparator and a sawtooth generator. These blocks are combined to produce the desired result as shown in Figure 4.5. As the control voltage increases, the duty cycle of the output increases as well. When the control voltage equals (or is greater than) the peak voltage of the ramp signal, the output is continuously high. Conversely, if the control voltage is below the minimum of the ramp voltage, the output of the comparator is continuously low. The modulator's output is a rectangle wave. This rectangle is averaged by the output 
filter and applied to the load as a dc voltage. The dc voltage is therefore the average of the rectangular pulse waveform, or

$$
\begin{aligned}
& V_{\text {out }}=\frac{1}{T} \int_{0}^{T} v_{\text {mod }}(t) d t=\frac{1}{t} \int_{0}^{t_{\text {on }}} V_{\text {in }} d t \\
& V_{\text {out }}=\frac{V_{\text {in }} t_{\text {on }}}{t_{\text {on }}+t_{\text {off }}}=V_{\text {in }} D
\end{aligned}
$$

In terms of the transfer function of the modulator, this is defined as the averaged value of the pulse train output divided by the control voltage input, or

$$
H_{\text {mod }}=\frac{\Delta V_{\text {out }}}{\Delta V_{\text {error }}}
$$

This refers to the change in output voltage as a result of a change in the control voltage. Remembering that the control voltage is bounded by the ramp voltage (which is considered a part of the modulator), and including the fact that the range of $\mathrm{V}_{\text {out }}$ is $0 \mathrm{~V}$ to Vin, the previous equation becomes:

$$
H_{\text {mod }}=\frac{d V_{\text {out }}}{d V_{\text {error }}}=\frac{d}{d V_{\text {error }}}\left(V_{\text {in }} \frac{V_{\text {error }}}{V_{\text {osc }}}\right)=\frac{V_{\text {in }}}{V_{\text {osc }}}
$$

This is the gain of the modulator. On a bode plot, $\mathrm{H}_{\text {mod }}$ is a constant gain and it causes no phase shift.

The modulator provides a pulse train, bounded by the input voltage, whose duty cycle is determined by an applied control voltage. The non-ideal output filter shown in Figure 4.6 performs the averaging function that converts this pulse train into the output 
voltage of the converter. This filter operates as a low-pass filter in the frequency domain, suppressing the ac components of the modulator's pulse train. It is a simple second-order L-C section, terminated by the load resistance. Therefore, the load resistance is a critical component of the filter. It must be known in order to predict the filter's performance, the loop response, and the stability of the converter.

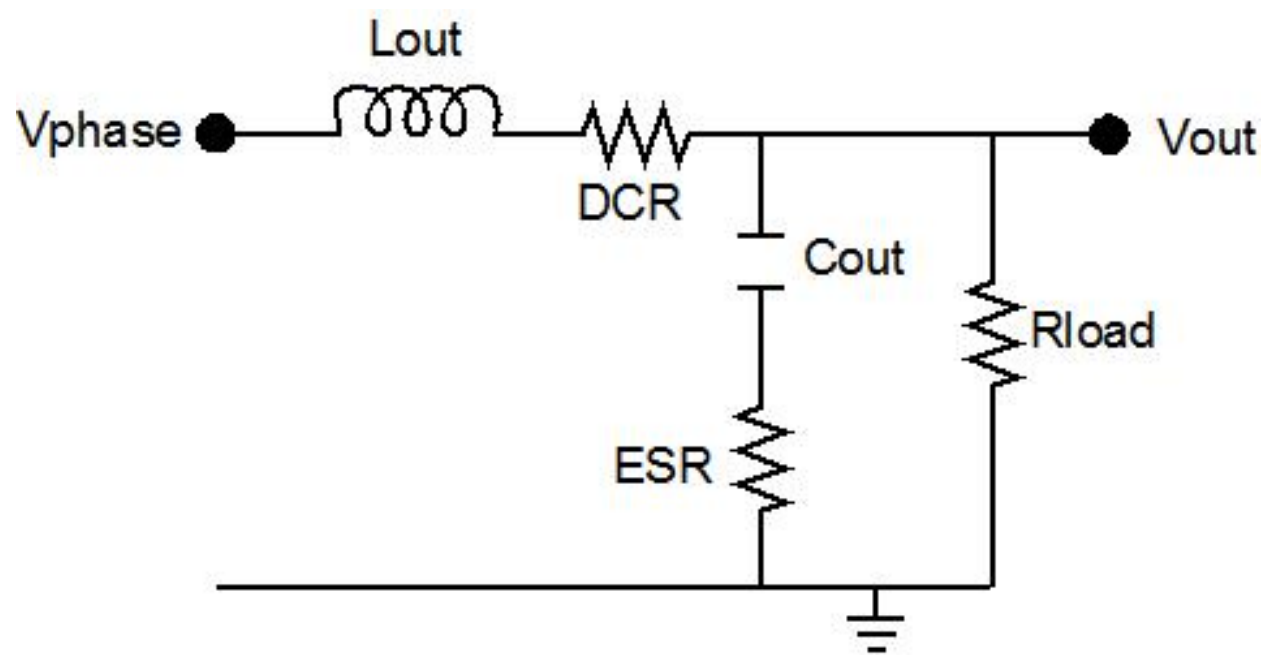

Figure 4.6 Output low-pass filter of the buck converter.

It is important to include the DC resistance (DCR) of the output inductor and the total equivalent series resistance (ESR) of the output capacitor. The transfer function can be easily derived and is therefore expressed as

$$
\begin{aligned}
& H_{\text {filter }}(s) \\
& =\frac{1+C_{\text {out }} R_{E S R} S}{1+\frac{R_{D C R}}{R_{\text {load }}}+\left(\frac{L_{\text {out }}}{R_{\text {load }}}+R_{E S R} C_{\text {out }}+R_{D C R} C_{\text {out }}+\frac{R_{D C R} R_{E S R} C_{\text {out }}}{R_{\text {load }}}\right) s+\left(\frac{R_{\text {load }}+R_{E S R}}{R_{\text {load }}}\right) L_{\text {out }} C_{\text {out }} s^{2}}
\end{aligned}
$$


For the same closed loop system shown in Figure 4.4, we could obtain the open loop frequency response by breaking the feedback path from $\mathrm{V}_{\text {out }}$ to compensator. The open loop frequency response consists of the modulator and the output filter as shown in Figure 4.7. The open loop transfer function is the combination of the modulator and output filter transfer functions expressed as

$$
\begin{aligned}
& H_{\text {open }}(s)=H_{\text {mod }}(s) H_{\text {filter }}(s) \\
& H_{\text {open }}(s)=\frac{V_{\text {in }}}{V_{\text {osc }}} \frac{1+s R_{E S R} C_{\text {out }}}{1+s\left(R_{E S R}+R_{D C R}\right) C_{\text {out }}+s^{2} L_{\text {out }} C_{\text {out }}}
\end{aligned}
$$

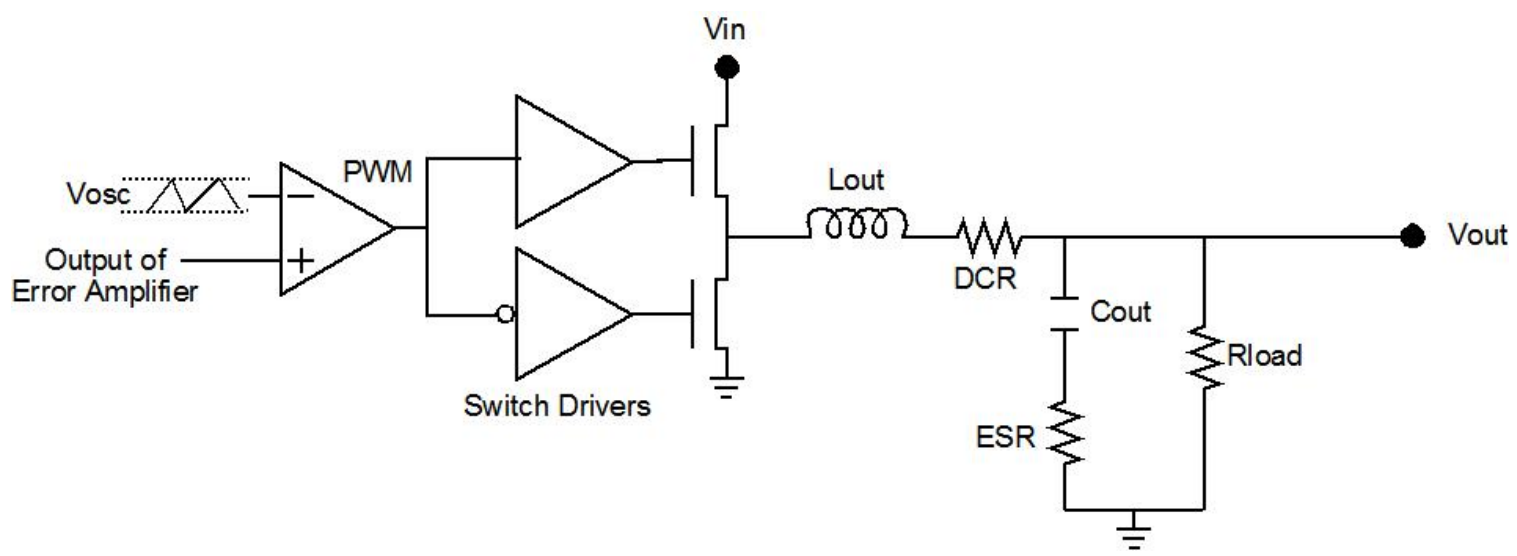

Figure 4.7: Open loop buck converter.

The open loop transfer function can be graphed as the bode plot shown in Figure 4.8. Before the roll-off, the open loop gain is that of the modulator until the frequency at which the LC filter resonates. This pole frequency is

$$
f_{L C}=\frac{1}{2 \pi L_{\text {out }} C_{\text {out }}}
$$


After which, the gain rolls-off at $40 \mathrm{~dB} / \mathrm{dec}$ because it is a second order filter. A zero occurs at

$$
f_{E S R}=\frac{1}{2 \pi R_{E S R} C_{\text {out }}}
$$

This increases the roll-off by $20 \mathrm{~dB} / \mathrm{dec}$ because the $\mathrm{C}_{\text {out }}-\mathrm{R}_{\mathrm{ESR}}$ pair is first order.

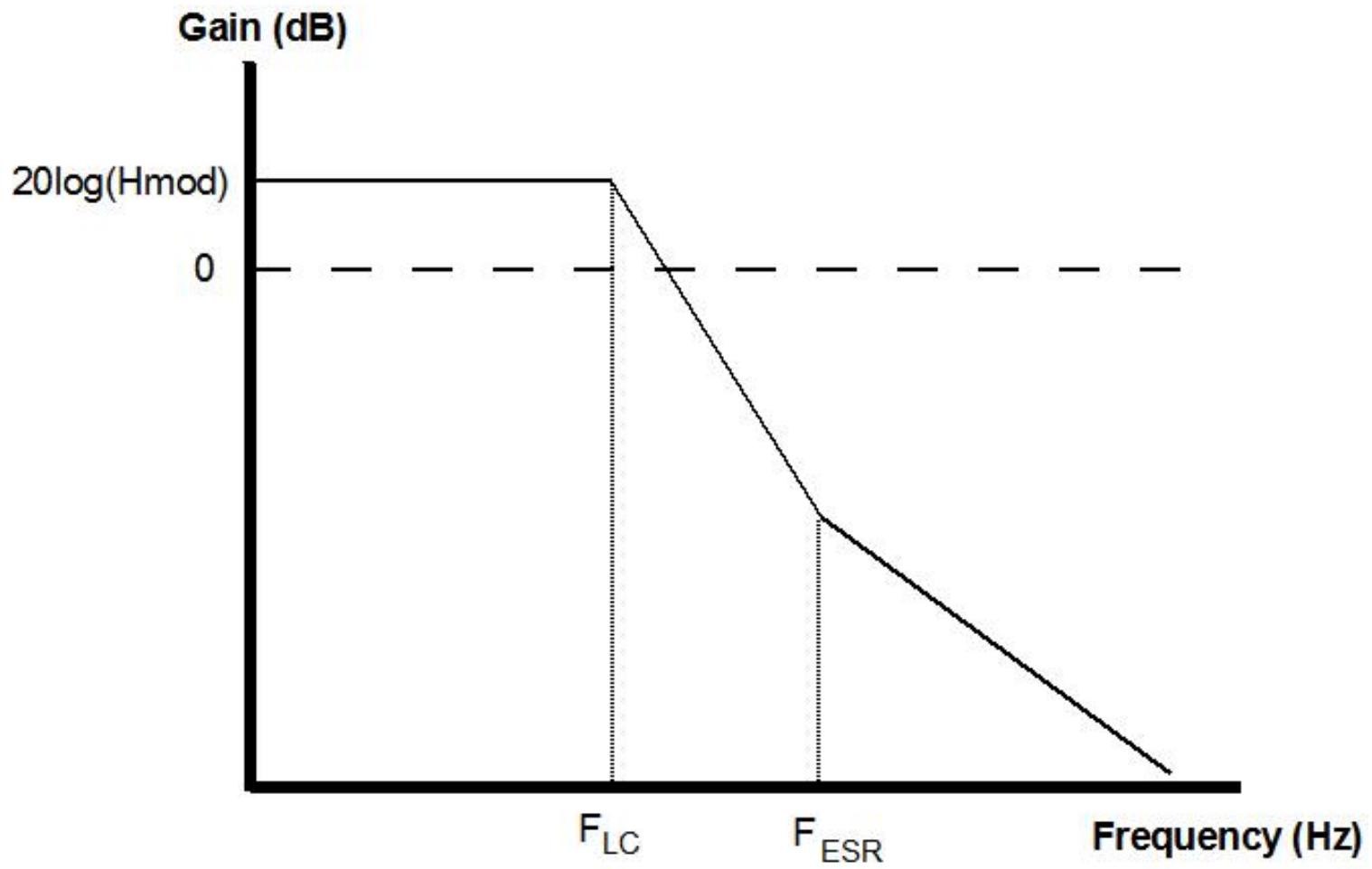

Figure 4.8: Open loop frequency response of a buck converter.

Looking at the open loop response, we can see that the output filter causes a dominant pole to the system. This means low phase such that it will cause stability issues in the converter. Closing the control loop allows the converter to adjust to load perturbations or changes in the input voltage which may adversely affect the output by 
comparing the output voltage to a voltage reference. The error is amplified and that error is applied to the modulator as its control voltage input. As the output voltage approaches the reference voltage, the error produced becomes small, and the system reaches equilibrium. How the system reaches the equilibrium state depends on the compensation scheme of the feedback loop.

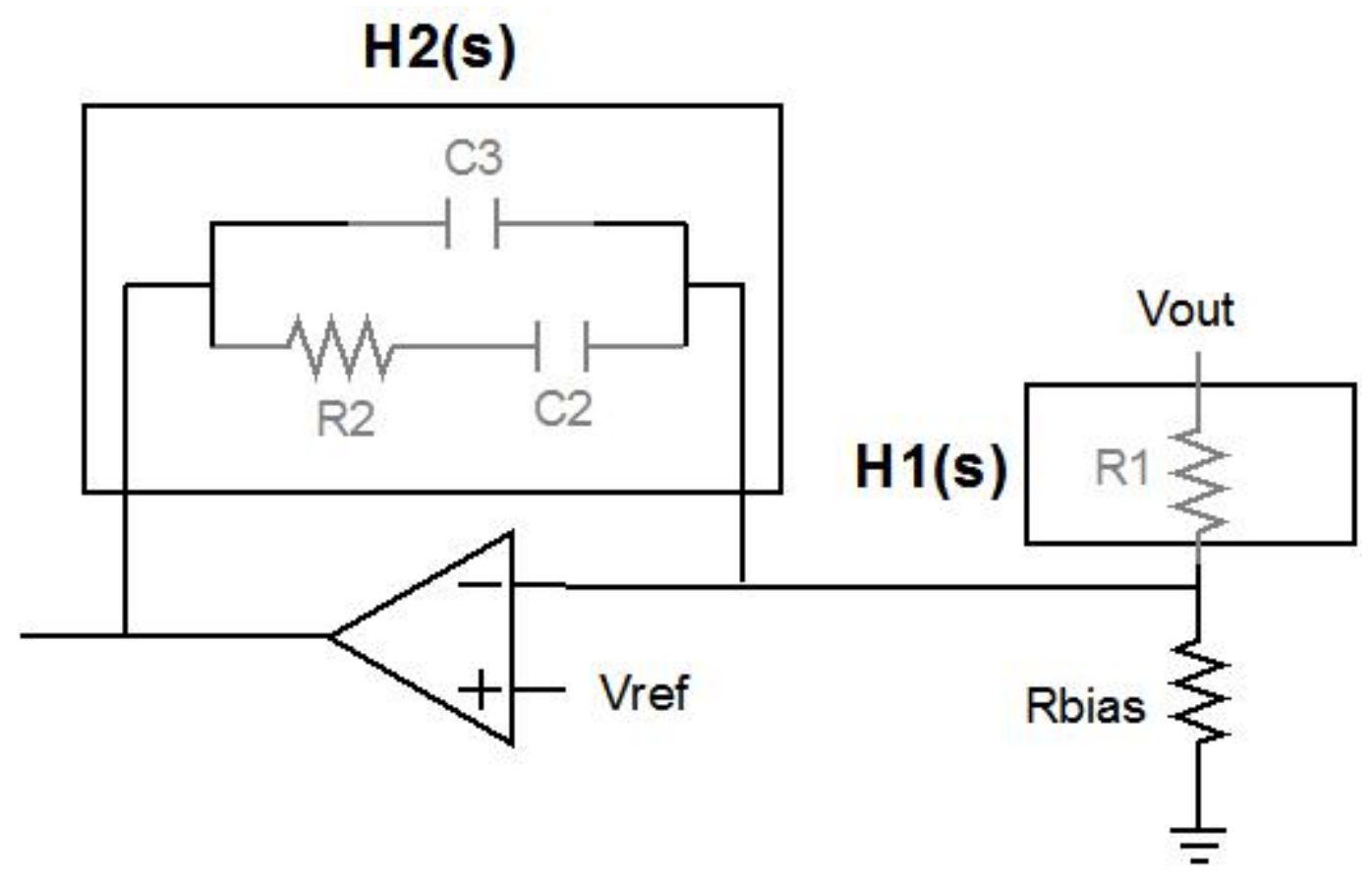

Figure 4.9: General Compensation Network

Generally, the compensation circuit is an output voltage feedback sense divider and a negative feedback amplifier as shown in Figure 4.9. Three different types of erroramplifier responses, shown in Fig. 4.10, are commonly used to compensate power supplies: Type 1, Type 2, and Type 3 [17]. As one can imagine, the compensation serves to manipulate the open loop response to higher gains and phases. Stability usually increases are a designer goes to a higher type of compensation. 


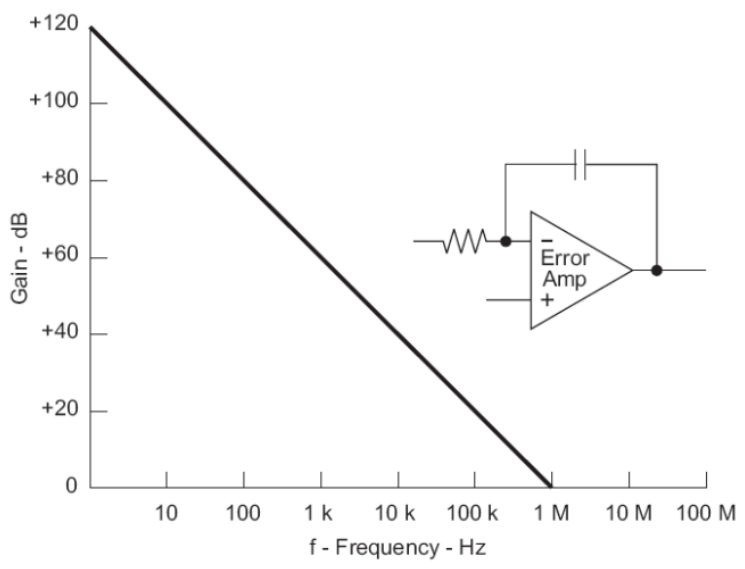

a. Type 1 compensation.

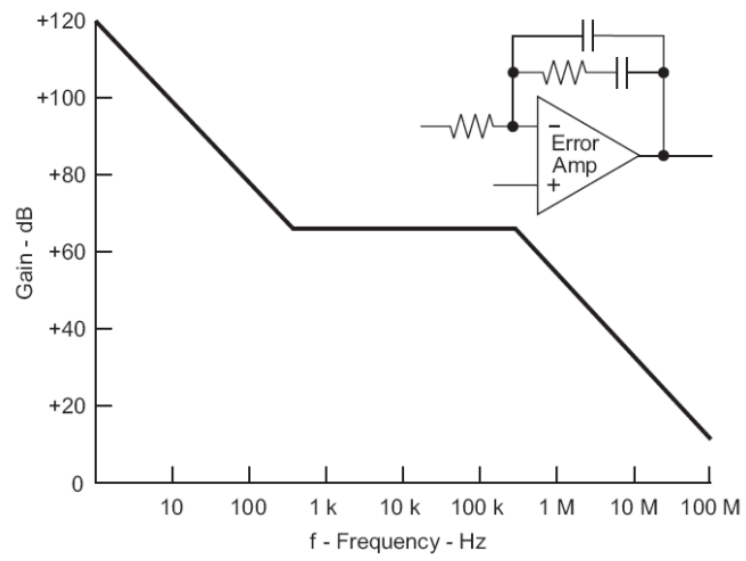

b. Type 2 compensation.

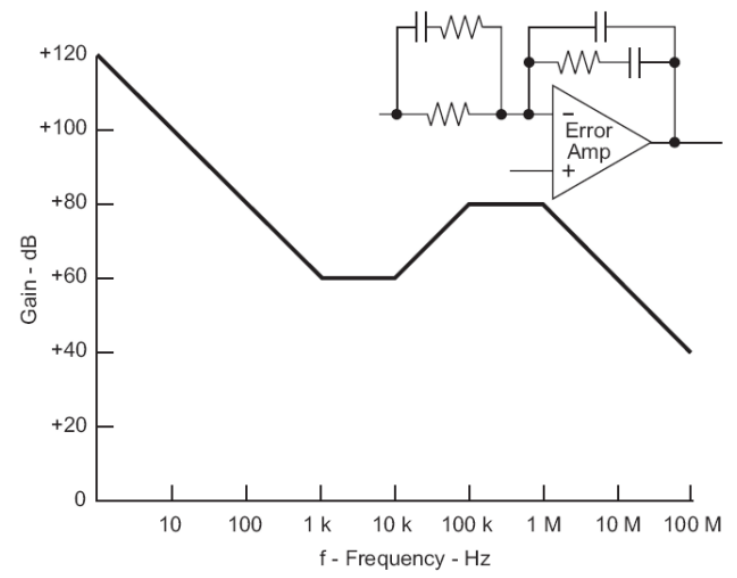

c. Type 3 compensation.

Figure 4.10: Typical voltage-mode compensation networks [17]. 
For integrated DC-DC converters and for application to this thesis, Type 2 compensation will be analyzed. This is because it is easier to observe the benefits of the proposed stability optimization technique that is proposed in the following chapter.

The transfer function for Type 2 compensation in Figure 4.9 can be expressed as

$$
H_{\text {type } 2}=\frac{1}{R_{1} C_{3}} \frac{s+\frac{1}{R_{2} C_{2}}}{s\left(s+\frac{C_{3}+C_{2}}{R_{2} C_{3} C_{2}}\right)}
$$

As discussed in Equation 4-2, the converter becomes unstable when the denominator $1+\mathrm{H}_{\text {loop }}(\mathrm{s})$ is zero. Therefore, we must analyze the frequency response in the following condition:

$$
\begin{aligned}
& -H_{\text {loop }}(s)=1 \\
& 20 \log \left(-H_{\text {loop }}(s)\right)=0 d B \\
& 20 \log \left(-H_{\text {mod }} H_{\text {filter }} H_{\text {type } 2}\right)=0 d B
\end{aligned}
$$

Figure 4.11 shows the closed loop frequency response of the buck converter using Type II compensation. The crossover or bandwidth is the frequency at which the gain is 0 $\mathrm{dB}$ and relates to the oscillation frequency during a transient response and the phase margin is the phase in degrees where the gain is $0 \mathrm{~dB}$. 


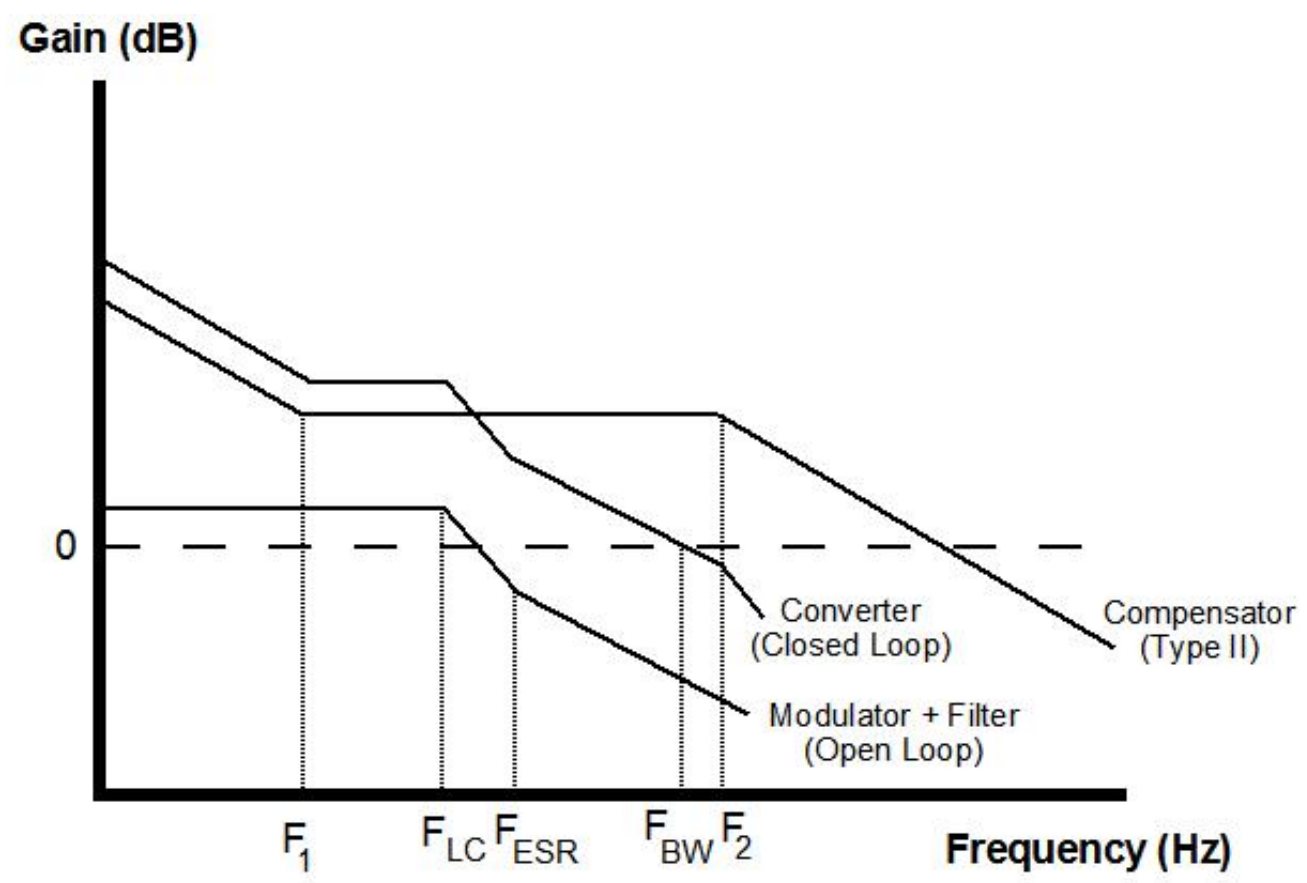

Figure 4.11: Closed loop converter frequency response using Type 2 compensation.

Poles and zeros of the system must be adjusted to allow for the designers desired bandwidth and phase margin. The following criteria show the characteristics for controlling the converter [6]:

- Nyquist sampling theorem limits.

- The loop bandwidth must be $\leq 0.5 \mathrm{x}$ the switching frequency $\left(\mathrm{F}_{\mathrm{s}}\right)$.

- Small signal stability.

Crossover frequency: The control loop bandwidth should be $\leq 0.3 \times \mathrm{F}_{\mathrm{s}}[36]$.

Phase margin: $45^{\circ}-60^{\circ}$ is recommended.

- Less than $45^{\circ}$ can give a "ringing" response to disturbances, but it is actually faster transient response.

- More than $45^{\circ}$ slows settling time, but provides more damping. 
These design considerations and knowledge of pole/zero placement is important to understanding the limitations of integrated DC-DC converters, stability optimization, and pole/zero effects of PCB parasitics. The next chapter will describe stability optimization and the chapter after this will introduce possible effects of PCB parasitic. 


\section{Chapter 5 : Device Introduction and Optimization}

\subsection{TPS62120 Buck Converter}

The TPS62120 is a synchronous step-down buck converter capable of supporting low power applications such as low power RF, ultra low power microprocessors, energy harvesting, and industrial measuring because of its wide operating input range [20]. In addition, the TPS62120 has an integrated modulator and control/compensation design to ensure fewer external components. Figure 5.1 shows a typical design application using the TPS62120.

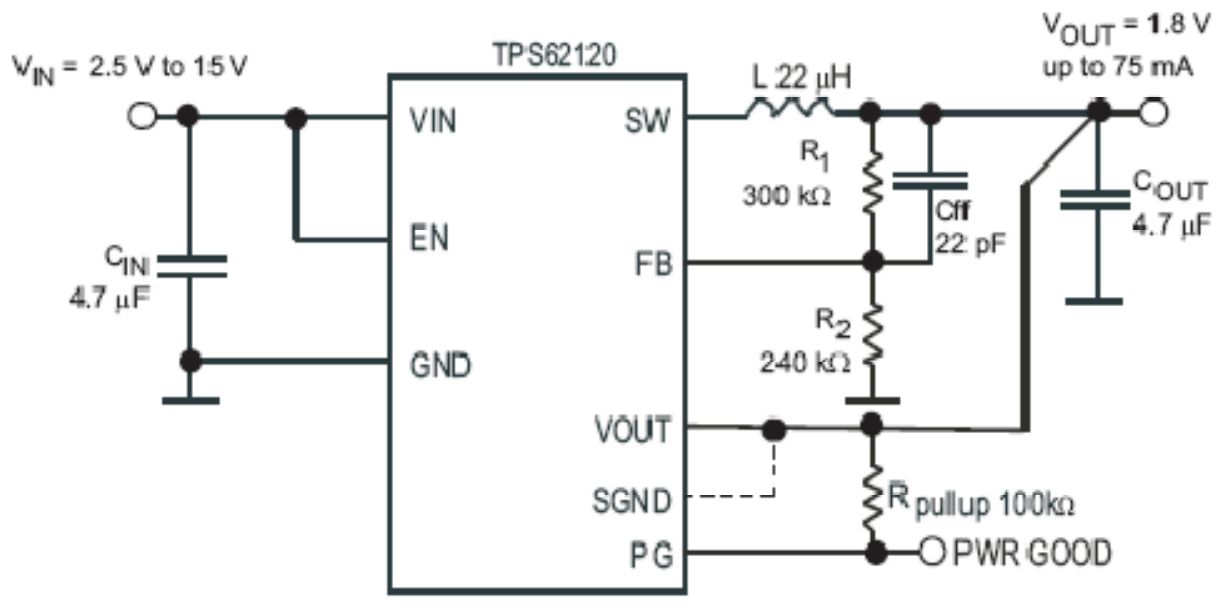

Figure 5.1: Typical circuit application of the TPS62120 [20].

A new control topology that is used to regulate the TPS62120 is called Direct Control with Seamless Transition to Power Save Mode (DCS-Control). This topology combines the advantages of hysteretic, voltage mode, and current mode control. 


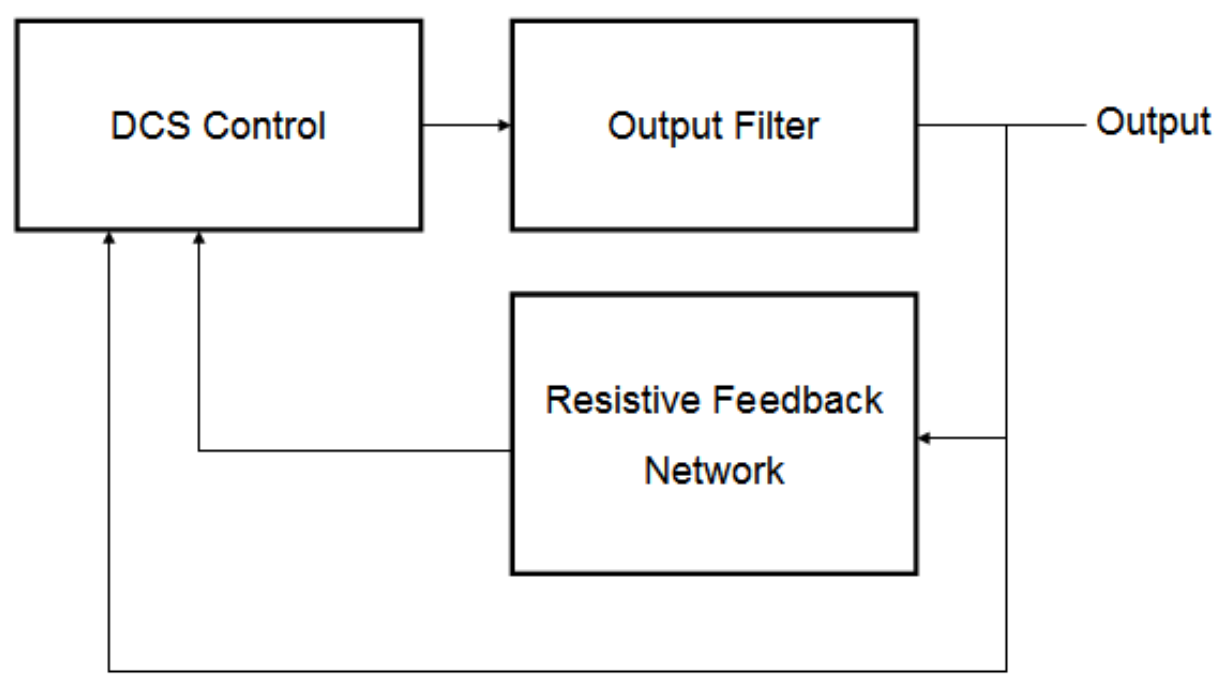

Figure 5.2: Block diagram for regulating output voltage.

Because the device is internally compensated, the converter design is limited to an effective range of output filter and feedback feedback network components to ensure converter stability. As described in the TPS62120 datasheet, the device is optimized to operate for an output filter of $\mathrm{L}=22 \mathrm{uH}$ and $\mathrm{C}=4.7 \mathrm{uF}$. However, if design permits, the device may operate with an output filter range of $10 \mathrm{uH}-33 \mathrm{uH}$ and $1 \mathrm{uF}-33 \mathrm{uF}$. Depending on the application the inductor and capacitor may increase or decrease to account for converter layout size, efficiency, or ripple. Increasing the corner frequency of the output filter will increase the bandwidth of the converter for a faster transient response and decreasing the corner frequency of the output filter will decrease the bandwidth of converter for a slower transient response. Either way, a corner frequency outside the recommended range may yield a phase margin lower than $45 \mathrm{deg}$. 


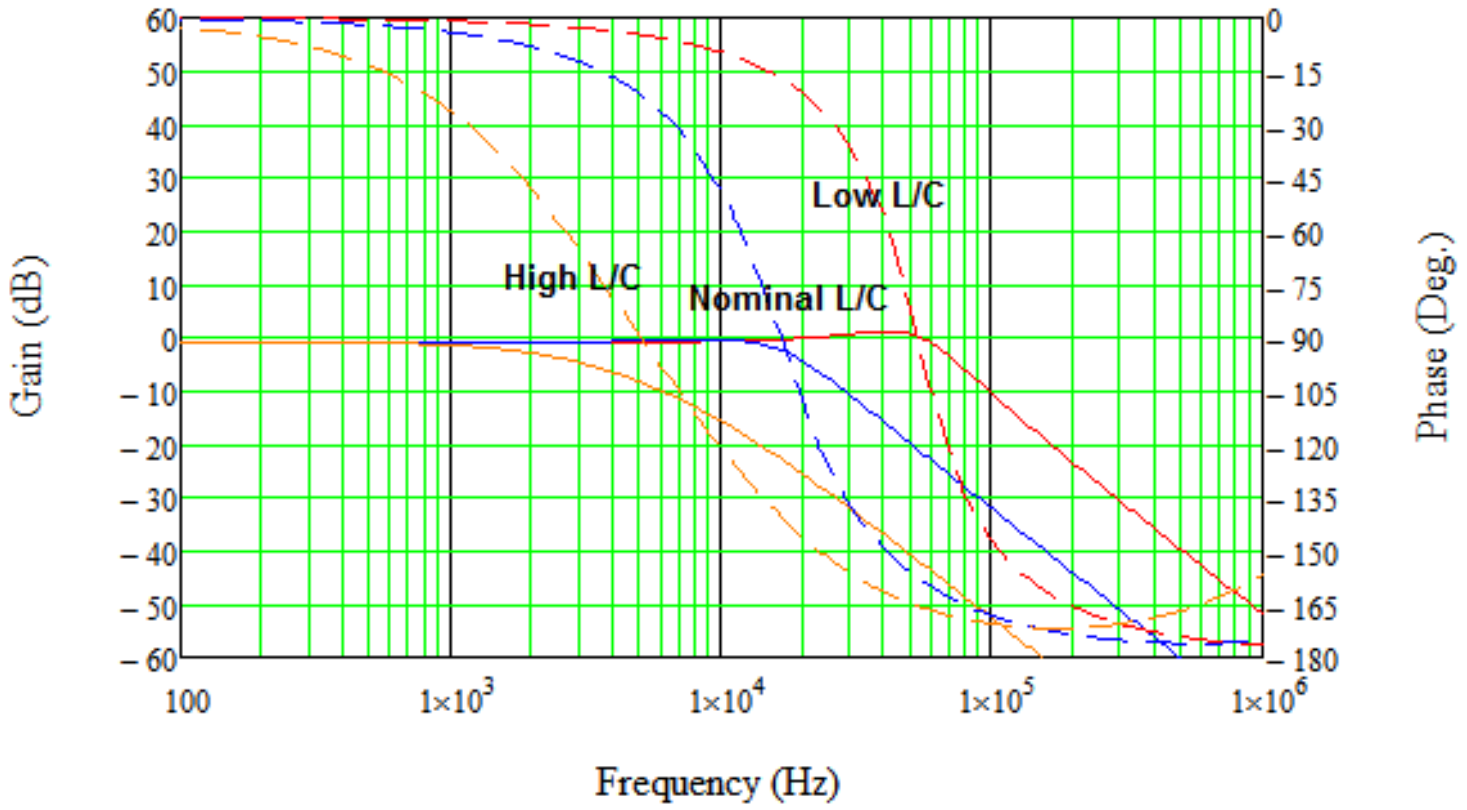

Figure 5.3: Bode plot of output filter

The Figure 5.3 shows that the internal DCS-Control is centered around a bandwidth of approximately $25 \mathrm{kHz}$. The feedback network sets the output voltage with $\mathrm{R}_{1}$ and $\mathrm{R}_{2}$, and adds additional gain and phase to the feedback loop of the system at 25 $\mathrm{kHz}$ by use of the feed forward capacitor $\mathrm{C}_{\mathrm{ff}}$ in parallel with $\mathrm{R}_{1}$ as shown in Figure 5.4. The datasheet therefore suggests feedback network values for different output voltages as shown in Table 5-1.

Table 5-1 Table from datasheet of recommended values.

\begin{tabular}{|c|c|c|c|c|c|c|}
\hline Voltage Setting [V] & $\mathbf{3 . 0 6}$ & $\mathbf{3 . 2 9}$ & $\mathbf{2 . 0 0}$ & $\mathbf{1 . 8 0}$ & $\mathbf{1 . 2 0}$ & $\mathbf{5 . 0 0}$ \\
\hline $\mathbf{R}_{\mathbf{1}}[\mathbf{k} \boldsymbol{\Omega}]$ & 510 & 560 & 360 & 300 & 180 & 430 \\
\hline $\mathbf{R}_{\mathbf{2}}[\mathbf{k} \boldsymbol{\Omega}]$ & 180 & 180 & 240 & 240 & 360 & 82 \\
\hline $\mathbf{C}_{\text {ff }}[\mathbf{p F}]$ & 15 & 22 & 22 & 22 & 27 & 15 \\
\hline
\end{tabular}




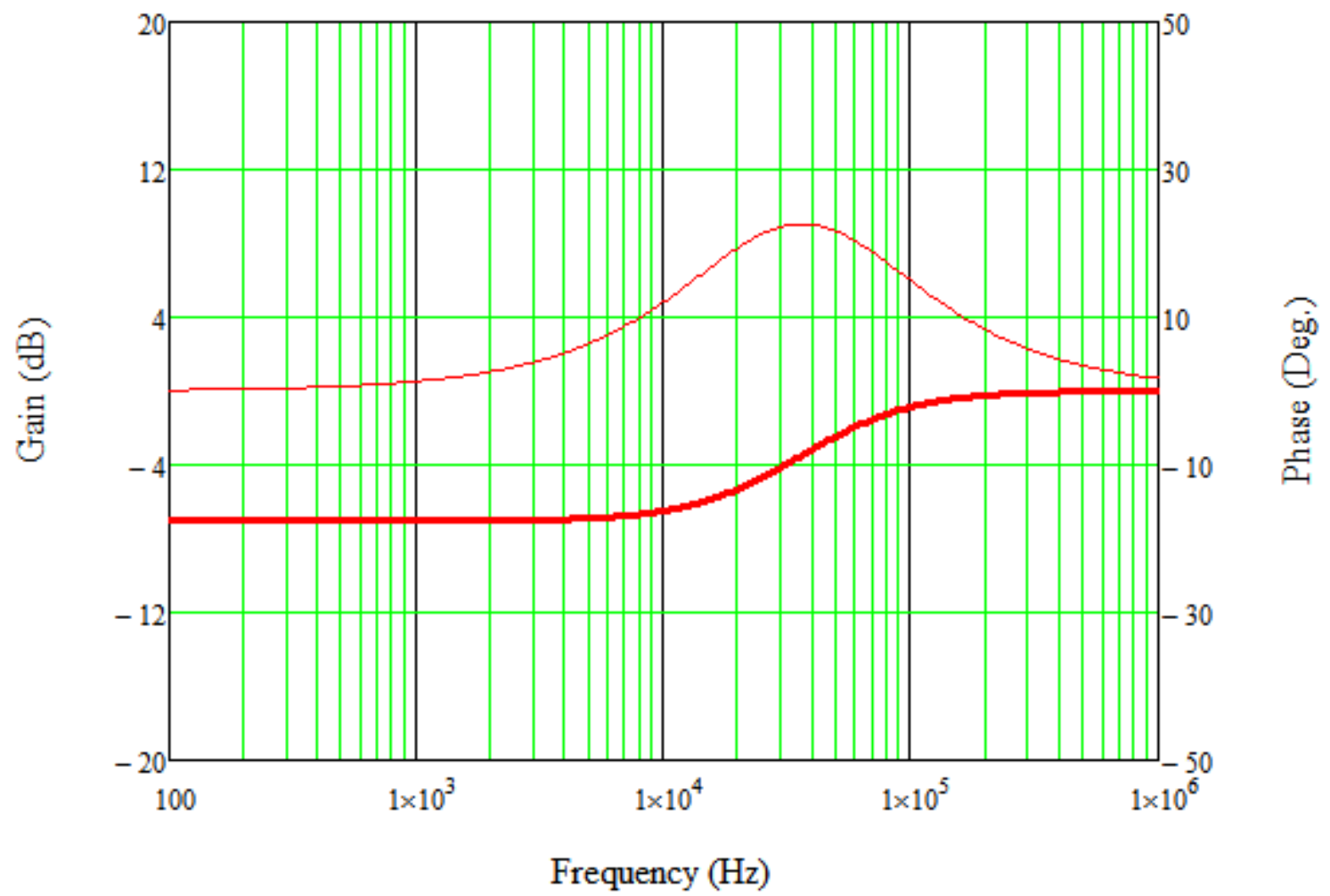

Figure 5.4: Bode plot of feedback network.

The strict range of values in the external components for the TPS62120 suggests that the DCS-Control yields the most phase at $25 \mathrm{kHz}$ to obtain an operating and stable buck converter; values outside of the recommended range may compromise its performance. This thesis suggests a procedure for operating the TPS62120 out of the datasheet's recommended component values and optimizing the stability using only the external components. Even though this may not obtain the most stable converter, it will be optimized to meet the minimum stability requirements suitable for a converter. 


\subsection{Stability Optimization}

Stability optimization involves designing extra phase in the feedback network situated at the bandwidth of the converter set by the output filter. This is done by utilizing a feed forward capacitor as in Figure 6.1 but will be used differently than in typical design in that the poles and zeros will be placed near the bandwidth of the converter instead of the recommended corner frequency of the output filter [37].

The transfer function of the feedback network in Figure 5.1. is

$$
H_{\text {feedback }}(s)=\frac{V_{f b}}{V_{\text {out }}}=\frac{1+s C_{f f} R_{1}}{1+\frac{R_{1}}{R_{2}}+s C_{f f} R_{1}}
$$

where the poles and zeros are

$$
\begin{aligned}
& f_{z}=\frac{1}{2 \pi R_{1} C_{f f}} \\
& f_{p}=\frac{1}{2 \pi C_{f f} \frac{R_{1} R_{2}}{R_{1}+R_{2}}}
\end{aligned}
$$

From the bode plot shown in Figure 5.4 peak of the phase boost occurs at the geometric mean of the zero and pole. Therefore,

$$
f_{\text {geometric }}=\sqrt{f_{z} f_{p}}
$$

The peak of the phase boost must be placed at the bandwidth of the converter that does not yet incorporate the feed forward capacitor. Therefore,

$$
f_{\text {no } c f f}=\sqrt{f_{z} f_{p}}
$$




$$
f_{\text {no } c f f}=\sqrt{\left(\frac{1}{2 \pi R_{1} C_{f f}}\right)\left[\frac{1}{2 \pi C_{f f}}\left(\frac{1}{R_{2}}+\frac{1}{R_{1}}\right)\right]}
$$

Solving for $\mathrm{C}_{\mathrm{ff}}$,

$$
C_{f f_{\text {optimized }}}=\frac{1}{2 \pi f_{\text {nocff }}} \sqrt{\frac{1}{R_{1}}\left(\frac{1}{R_{1}}+\frac{1}{R_{2}}\right)}
$$

This is the optimized feed forward capacitor, in conjunction with the resistor divider that will yield the most phase for an output filter that strays from the datasheet's recommended values of the output filter.

\subsection{TPS62120 Operating Parameters}

The TPS62120 will be modeled and tested under the following conditions in order to fully exhibit its capabilities.

$$
\begin{aligned}
& \mathrm{V}_{\text {in }}=12 \mathrm{~V} \\
& \mathrm{I}_{\mathrm{o}}=75 \mathrm{~mA} \text { (Full Load) } \\
& \mathrm{V}_{\text {out }}=1.8 \mathrm{~V}
\end{aligned}
$$

The 12 volt input utilizes the converters wide input range. Operating at full load will allow modeling for a transient that spans the bandwidth of the converter. The 1.8 volt output is typical for low voltage applications and battery technology [38].

Now that the optimum feed forward capacitor is derived, modeling will show whether this will help the stability in integrated DC-DC converter external components not recommended by its datasheet. 


\section{Chapter 6 : System Modeling}

System modeling and analysis was implemented using MathCAD after the frequency response of the DCS-Control topology were derived similar to the method described in Chapter 4.

\subsection{Ideal Modeling of the TPS62120 Stability Optimization}

Figure 6.1 shows the ideal bode plot model of the TPS62120 operating at the parameters described at the end of Chapter 5. The red line represents the total closed loop frequency response while the blue and orange represent the output filter and feedback network respectively. The bold line is the gain and the thin line is the phase of each individual bode plot.

The external components are within the range that the datasheet suggests:

$$
\begin{aligned}
& \mathrm{L}_{\mathrm{o}}=18 \mathrm{uH} \\
& \mathrm{C}_{\mathrm{o}}=4.7 \mathrm{uF} \\
& \mathrm{R}_{1}=300 \mathrm{kOhms} \\
& \mathrm{R}_{2}=240 \mathrm{kOhms} \\
& \mathrm{C}_{\mathrm{ff}}=22 \mathrm{pF}
\end{aligned}
$$




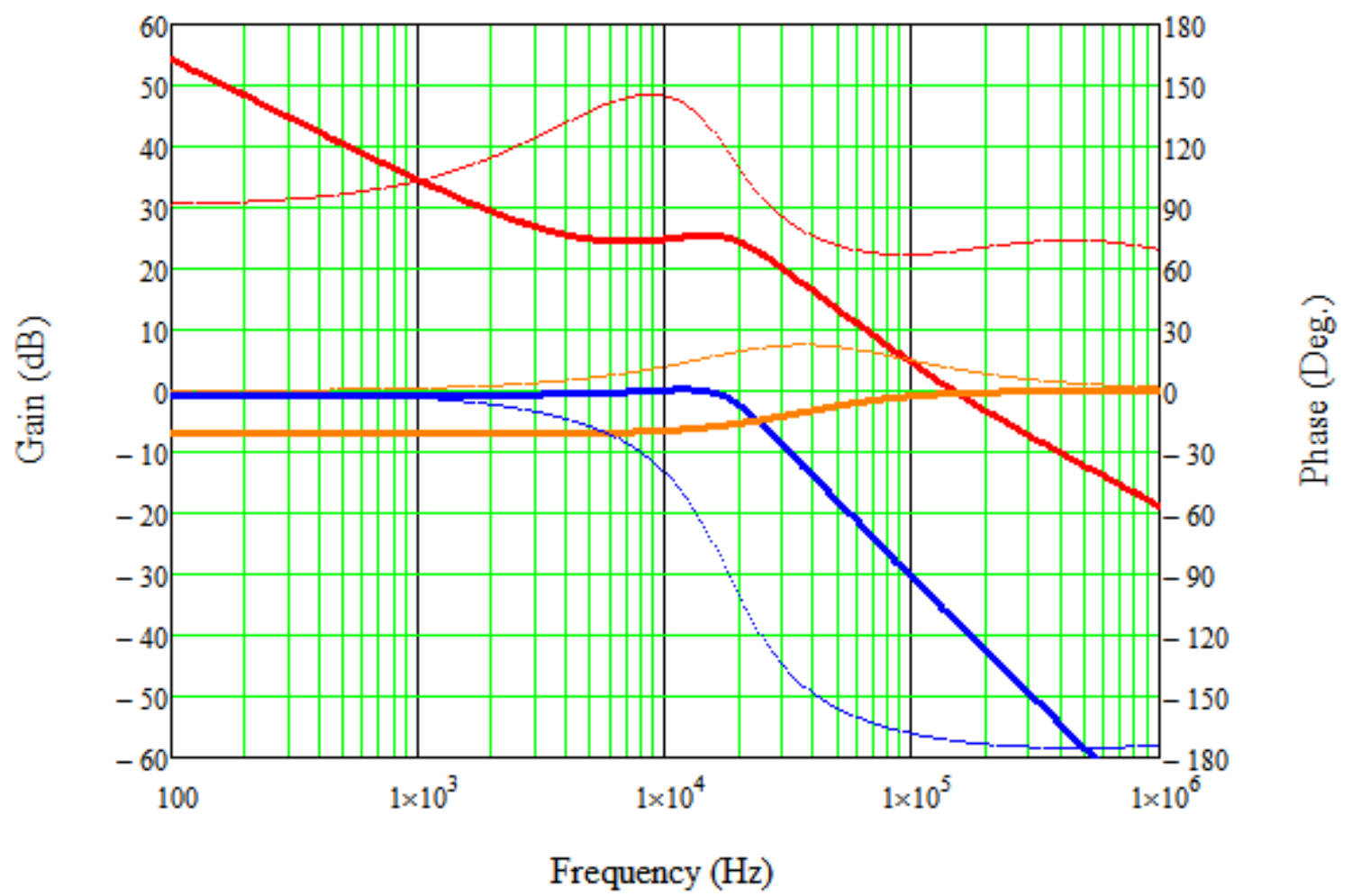

Figure 6.1 Ideal frequency response of the total system (red), output filter (blue), and feedback network (orange).

The bandwidth of the converter is the frequency at which the gain of the total closed loop system crosses over $0 \mathrm{~dB}$ and the phase at this point is the phase margin. For this operating point, the bandwidth and phase is:

$$
\begin{aligned}
& \mathrm{BW}=147.4 \mathrm{kHz} \\
& \mathrm{PM}=70.06 \mathrm{deg}
\end{aligned}
$$

This means that a transient at this operating point will regulate the output voltage quickly, because of the large bandwidth, with little voltage swing because the phase margin is greater than 45 degrees. 
Using the stability optimization technique we can see an improvement in the converter's transient response.

Figure 6.2 shows the bode plot without a feed forward capacitor.

$$
\begin{aligned}
& \mathrm{L}_{\mathrm{o}}=18 \mathrm{uH} \\
& \mathrm{C}_{\mathrm{o}}=4.7 \mathrm{uF} \\
& \mathrm{R}_{1}=300 \mathrm{kOhms} \\
& \mathrm{R}_{2}=240 \mathrm{kOhms} \\
& \mathrm{C}_{\mathrm{ff}}=0 \mathrm{pF}
\end{aligned}
$$

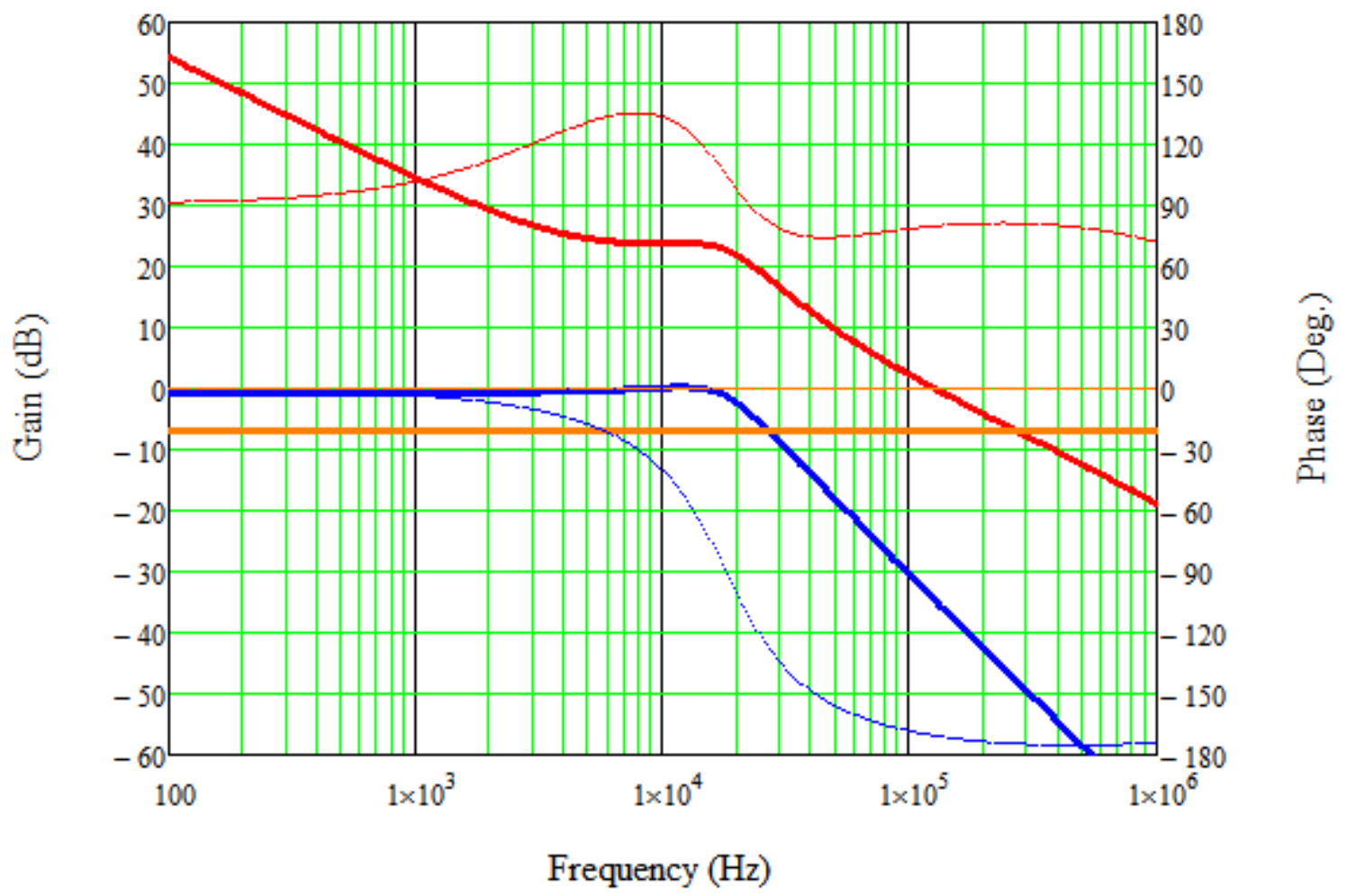

Figure 6.2: Frequency response of the total system (red), output filter (blue), and feedback network (orange) with no feed forward capacitor.

The bandwidth and phase margin can be determined to be

$$
\begin{aligned}
& \mathrm{BW}=126.4 \mathrm{kHz} \\
& \mathrm{PM}=79.83 \mathrm{deg}
\end{aligned}
$$


Because there is no feed forward capacitor, there is no phase boost as indicated by the flat phase line at 0 degrees for all frequencies in Figure 6.2. The bandwidth of the converter decreased while the phase margin increased. This improves the swing of the output voltage at the expense of a slower converter. Even so, this is a stable operating point.

Using Equation 5.7 the optimized feed forward capacitor is calculated to be 6.3pF. Figure 6.3 shows the bode plot from using the same output filter with the new feed forward capacitor.

$$
\begin{aligned}
& \mathrm{L}_{\mathrm{o}}=18 \mathrm{uH} \\
& \mathrm{C}_{\mathrm{o}}=4.7 \mathrm{uF} \\
& \mathrm{R}_{1}=300 \mathrm{kOhms} \\
& \mathrm{R}_{2}=240 \mathrm{kOhms} \\
& \mathrm{C}_{\mathrm{ff}}=6.3 \mathrm{pF}
\end{aligned}
$$

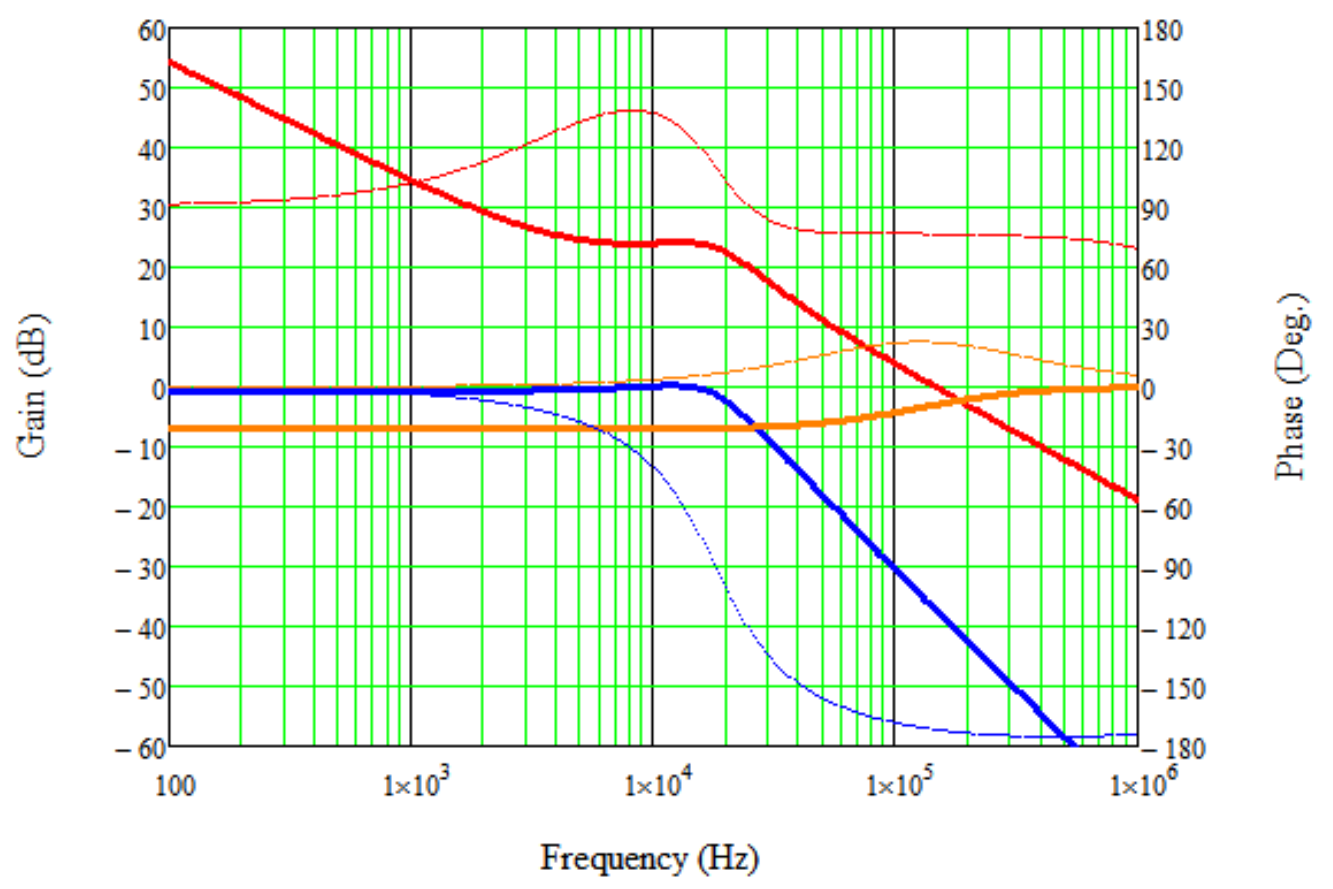

Figure 6.3: Frequency response of the total system (red), output filter (blue), and feedback network (orange) with optimized feed forward capacitor 
The optimized feed forward capacitor places the phase boost directly over the crossover frequency of the converter where it is needed most as opposed to Figure 6.1 where the phase boost occurs before crossing over. There is an improvement in the system's stability compared to the recommended feed forward capacitor value where both bandwidth and phase margin increased.

$$
\begin{aligned}
& \mathrm{BW}=146.9 \mathrm{kHz} \\
& \mathrm{PM}=76.57 \mathrm{deg} .
\end{aligned}
$$

At the recommended ranges, the stability will be stable. This optimization technique is geared toward values where the phase margin is not more than 45 degrees and extra phase is needed. Therefore, for an output filter outside the recommended range must be explored. For an operating point at the following, the bode plot is shown in Figure 6.4:

$$
\begin{aligned}
& \text { Lo }=68 \mathrm{uH} \\
& \text { Co }=10 \mathrm{uF} \\
& \mathrm{R} 1=300 \mathrm{kOhms} \\
& \mathrm{R} 2=240 \mathrm{kOhms} \\
& \mathrm{Cff}=0 \mathrm{pF}
\end{aligned}
$$




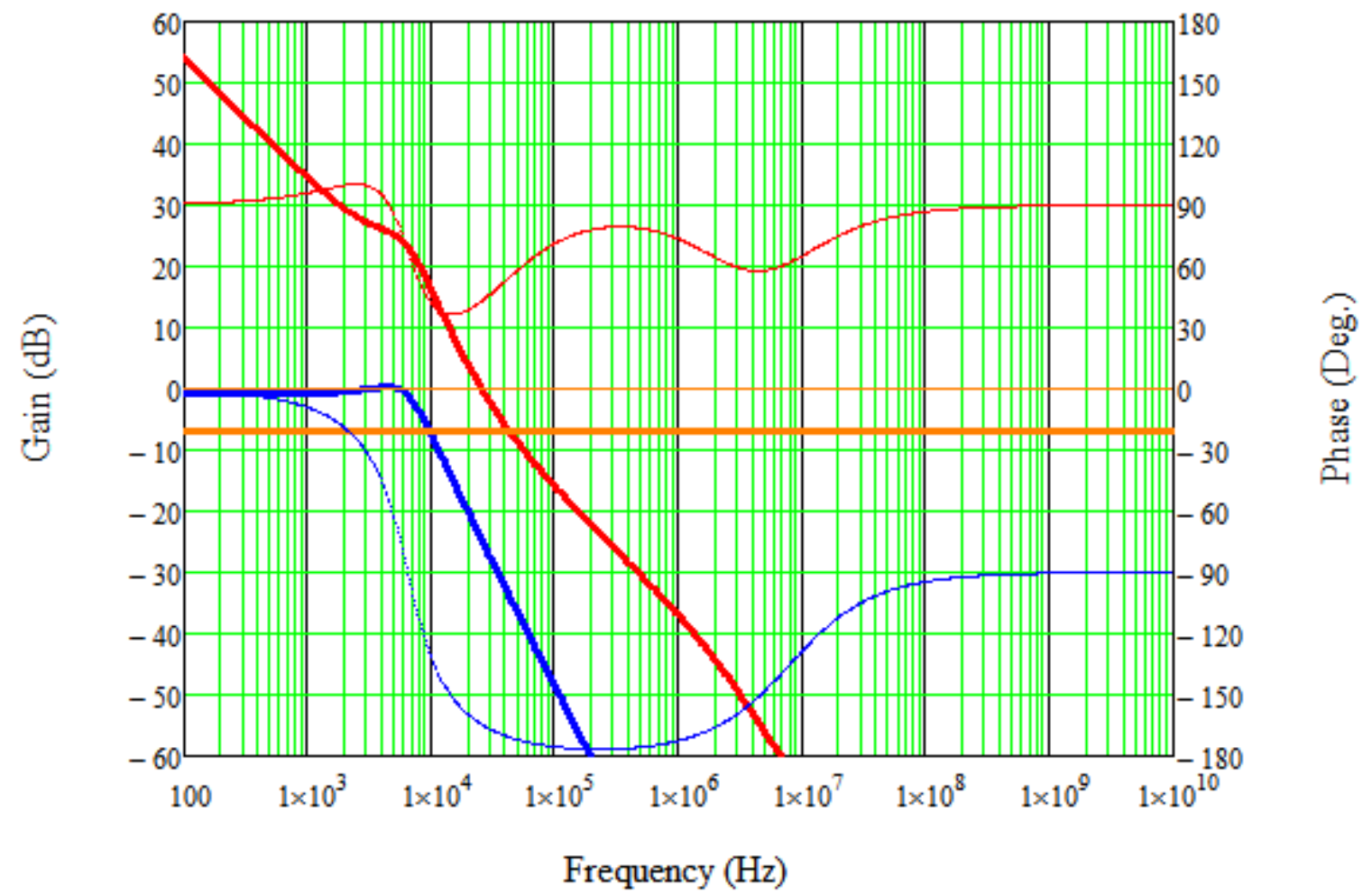

Figure 6.4: Moving the output filter out of the datasheets recommended range with no feed forward capacitor.

Figure 6.4 shows the bode plot at an output filter not recommended by the datasheet. The increase of the output inductor and capacitor decreased the corner frequency of the output filter and therefore decreased the bandwidth of the converter. The bandwidth and phase margin can be obtained as

$$
\begin{aligned}
& \mathrm{BW}=25.9 \mathrm{kHz} \\
& \mathrm{PM}=40.79 \mathrm{deg}
\end{aligned}
$$

The phase margin is unacceptable for converter design. Even with a slow converter, the phase margin must at least be greater than 45 degrees to ensure system stability. 
From this bandwidth, the optimized feed forward capacitor can be calculated to be 30.7pF. Figure 6.5 shows the bode plot at this capacitance.

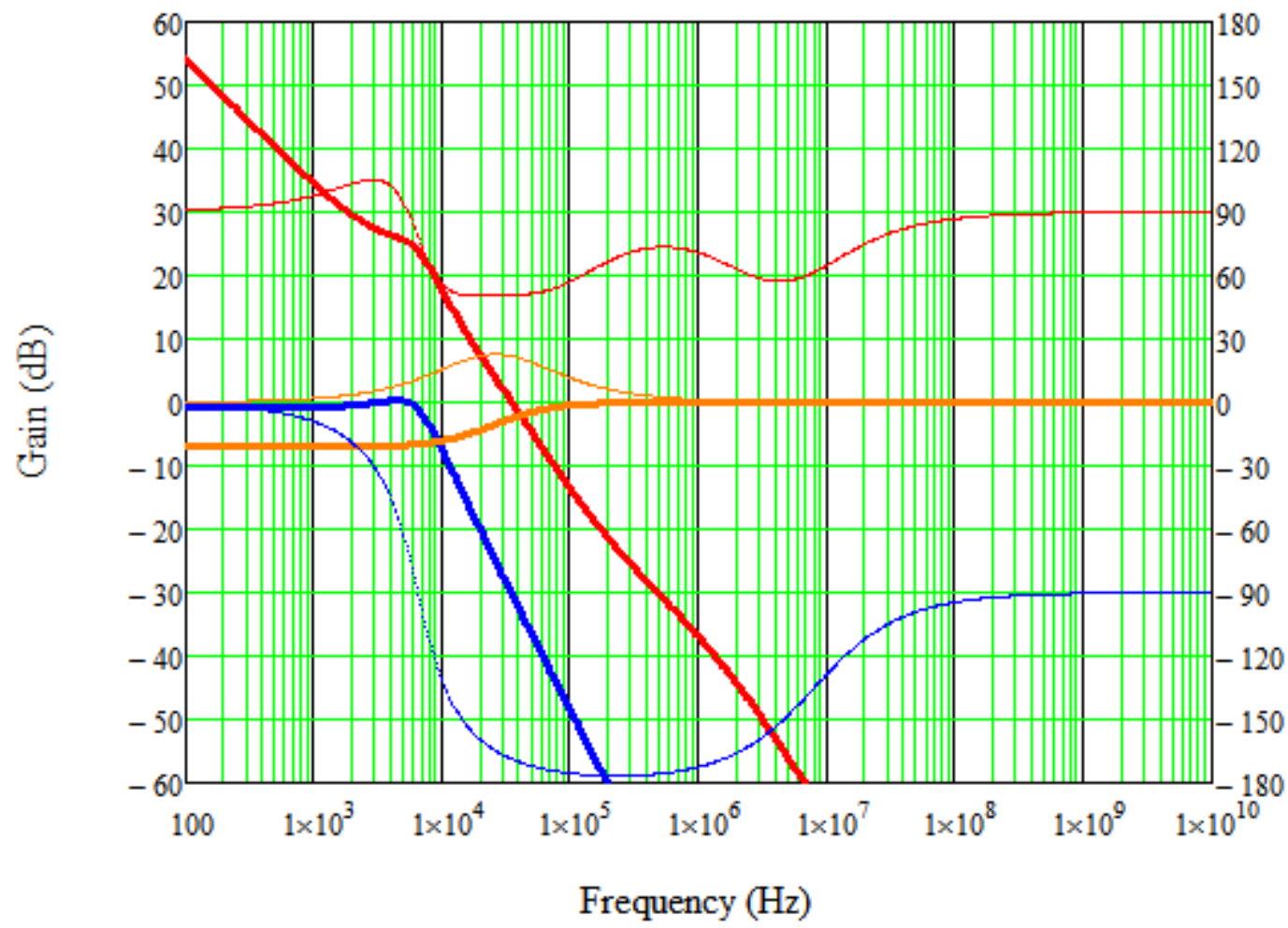

Figure 6.5: Improved performance for an output filter outside the recommended range.

The bandwidth and phase margin can be obtained as

$$
\begin{aligned}
& \mathrm{BW}=35.2 \mathrm{kHz} \\
& \mathrm{PM}=49.10 \mathrm{deg}
\end{aligned}
$$

The feed forward capacitor increased the bandwidth of the converter. In addition, the converter is stable with the increased phase margin. Figure 6.5 shows that the phase boost serves to prevent the phase from moving even lower near the crossover frequency. As a result, the phase flattens and keeps it steady while the gain goes to zero. 
This optimization process can be modeled for a wide range of output inductors and capacitors. Table 6-1 shows the bandwidth and phase margins for an inductor range of $0.22 \mathrm{uH}$ to $100 \mathrm{uH}$ and an output capacitor range of $0.22 \mathrm{uF}$ to $100 \mathrm{uF}$. In addition, Table 6-1 also shows the calculated feed forward capacitor needed to optimize converter stability. The box in the middle of each table is the datasheet's recommended range. Despite the various converter bandwidths, there is more interest in the phase margin that meets converter stability requirements. The highlighted areas in Table 6-1(b) shows that the requirements can be met outside the recommended range of output filters. These highlighted areas have phase margins greater than 45 degrees. 
Table 6-1: Ideal model of (a) bandwidth, (b) phase margin, (c) calculated feed forward capacitor for stability optimization at different ranges of output filter.

\begin{tabular}{|c|cccccccccc|}
\hline BW with Cff (Hz) & \multicolumn{10}{|c|}{100} \\
\hline Lo(uH)/Co(uF) & $\mathbf{0 . 2 2}$ & $\mathbf{0 . 4 7}$ & $\mathbf{1}$ & $\mathbf{2 . 2}$ & $\mathbf{4 . 7}$ & $\mathbf{1 0}$ & $\mathbf{2 2}$ & $\mathbf{3 3}$ & $\mathbf{4 7}$ & $\mathbf{1 0 0}$ \\
\hline $\mathbf{0 . 2 2}$ & 22860000 & 15610000 & 10660000 & 7122000 & 4766000 & 3077000 & 1611000 & 461300 & 88090 & 26450 \\
$\mathbf{0 . 4 7}$ & 15580000 & 10600000 & 7169000 & 4688000 & 3003000 & 1771000 & 771200 & 285900 & 87040 & 26450 \\
$\mathbf{1}$ & 10610000 & 7156000 & 4759000 & 2997000 & 1787000 & 946900 & 384900 & 184500 & 82700 & 26400 \\
$\mathbf{2 . 2}$ & 7043000 & 4668000 & 2994000 & 1752000 & 944100 & 464600 & 197700 & 117300 & 70720 & 26020 \\
$\mathbf{4 . 7}$ & 4667000 & 2985000 & 1791000 & 949300 & 477300 & 235300 & 111900 & 76170 & 53940 & 24540 \\
$\mathbf{1 0}$ & 2993000 & 1792000 & 978300 & 482200 & 241700 & 126200 & 67750 & 49960 & 38310 & 20960 \\
$\mathbf{1 8}$ & 2027000 & 1128000 & 579800 & 283000 & 146900 & 81790 & 47310 & 36210 & 28720 & 17210 \\
$\mathbf{3 3}$ & 1279000 & 663700 & 333800 & 167400 & 92130 & 54630 & 33330 & 26140 & 21190 & 13460 \\
$\mathbf{6 8}$ & 685200 & 343500 & 176900 & 94860 & 56150 & 35200 & 22380 & 17870 & 14730 & 9788 \\
$\mathbf{1 0 0}$ & 482200 & 243100 & 129000 & 72100 & 44070 & 28220 & 18220 & 14650 & 12160 & 8229 \\
\hline
\end{tabular}

(a)

\begin{tabular}{|c|ccccccccccc|}
\hline PM with Cff (Deg) & \multicolumn{10}{|c|}{$\mathbf{1 0}$} \\
\hline Lo/Co & $\mathbf{0 . 2 2}$ & $\mathbf{0 . 4 7}$ & $\mathbf{1}$ & $\mathbf{2 . 2}$ & $\mathbf{4 . 7}$ & $\mathbf{1 0}$ & $\mathbf{2 2}$ & $\mathbf{3 3}$ & $\mathbf{4 7}$ & $\mathbf{1 0 0}$ \\
\hline $\mathbf{0 . 2 2}$ & 15.16 & 22.03 & 31.91 & 46.69 & 66.60 & 93.15 & 130.81 & 159.04 & 144.65 & 121.08 \\
$\mathbf{0 . 4 7}$ & 15.12 & 21.94 & 31.75 & 46.42 & 66.11 & 92.15 & 128.03 & 148.04 & 140.62 & 119.89 \\
$\mathbf{1}$ & 17.23 & 24.92 & 35.84 & 51.72 & 71.62 & 94.73 & 122.51 & 134.70 & 132.51 & 117.37 \\
$\mathbf{2 . 2}$ & 22.00 & 31.56 & 44.66 & 61.94 & 79.58 & 95.60 & 112.41 & 118.14 & 118.34 & 111.74 \\
$\mathbf{4 . 7}$ & 29.56 & 41.69 & 56.71 & 72.41 & 83.71 & 91.53 & 98.20 & 100.25 & 101.07 & 101.19 \\
$\mathbf{1 0}$ & 40.43 & 54.77 & 68.70 & 78.25 & 81.92 & 82.19 & 81.63 & 81.89 & 82.63 & 85.27 \\
$\mathbf{1 8}$ & 50.99 & 65.04 & 74.81 & 78.34 & 76.57 & 72.30 & 68.73 & 68.13 & 68.40 & 70.77 \\
$\mathbf{3 3}$ & 62.40 & 72.96 & 76.91 & 74.62 & 68.34 & 61.39 & 56.30 & 54.96 & 54.48 & 55.22 \\
$\mathbf{6 8}$ & 73.31 & 77.08 & 74.31 & 66.40 & 57.15 & 49.10 & 42.95 & 40.68 & 39.14 & 37.00 \\
$\mathbf{1 0 0}$ & 77.03 & 77.05 & 71.10 & 61.18 & 51.35 & 43.10 & 36.39 & 33.59 & 31.45 & 27.68 \\
\hline
\end{tabular}

(b)

\begin{tabular}{|c|cccccccccc|}
\hline Cff $(\mathbf{F})$ & \multicolumn{10}{|c|}{$\mathbf{1 0}$} \\
\hline Lo/Co & $\mathbf{0 . 2 2}$ & $\mathbf{0 . 4 7}$ & $\mathbf{1}$ & $\mathbf{2 . 2}$ & $\mathbf{4 . 7}$ & $\mathbf{1 0}$ & $\mathbf{2 2}$ & $\mathbf{3 3}$ & $\mathbf{4 7}$ & $\mathbf{1 0 0}$ \\
\hline $\mathbf{0 . 2 2}$ & $3.48 \mathrm{E}-14$ & $5.10 \mathrm{E}-14$ & $7.47 \mathrm{E}-14$ & $1.12 \mathrm{E}-13$ & $1.67 \mathrm{E}-13$ & $2.60 \mathrm{E}-13$ & $5.07 \mathrm{E}-13$ & $5.50 \mathrm{E}-12$ & $2.50 \mathrm{E}-11$ & $6.61 \mathrm{E}-11$ \\
$\mathbf{0 . 4 7}$ & $5.11 \mathrm{E}-14$ & $7.52 \mathrm{E}-14$ & $1.11 \mathrm{E}-13$ & $1.70 \mathrm{E}-13$ & $2.66 \mathrm{E}-13$ & $4.54 \mathrm{E}-13$ & $1.09 \mathrm{E}-12$ & $6.50 \mathrm{E}-12$ & $2.50 \mathrm{E}-11$ & $6.60 \mathrm{E}-11$ \\
$\mathbf{1}$ & $7.51 \mathrm{E}-14$ & $1.11 \mathrm{E}-13$ & $1.68 \mathrm{E}-13$ & $2.67 \mathrm{E}-13$ & $4.50 \mathrm{E}-13$ & $8.60 \mathrm{E}-13$ & $2.29 \mathrm{E}-12$ & $8.42 \mathrm{E}-12$ & $2.51 \mathrm{E}-11$ & $6.60 \mathrm{E}-11$ \\
$\mathbf{2 . 2}$ & $1.13 \mathrm{E}-13$ & $1.71 \mathrm{E}-13$ & $2.67 \mathrm{E}-13$ & $4.58 \mathrm{E}-13$ & $8.61 \mathrm{E}-13$ & $1.80 \mathrm{E}-12$ & $4.86 \mathrm{E}-12$ & $1.17 \mathrm{E}-11$ & $2.56 \mathrm{E}-11$ & $6.60 \mathrm{E}-11$ \\
$\mathbf{4 . 7}$ & $1.71 \mathrm{E}-13$ & $2.68 \mathrm{E}-13$ & $4.48 \mathrm{E}-13$ & $8.56 \mathrm{E}-13$ & $1.75 \mathrm{E}-12$ & $3.75 \mathrm{E}-12$ & $9.34 \mathrm{E}-12$ & $1.67 \mathrm{E}-11$ & $2.79 \mathrm{E}-11$ & $6.64 \mathrm{E}-11$ \\
$\mathbf{1 0}$ & $2.67 \mathrm{E}-13$ & $4.48 \mathrm{E}-13$ & $8.30 \mathrm{E}-13$ & $1.73 \mathrm{E}-12$ & $3.62 \mathrm{E}-12$ & $7.56 \mathrm{E}-12$ & $1.62 \mathrm{E}-11$ & $2.40 \mathrm{E}-11$ & $3.37 \mathrm{E}-11$ & $6.88 \mathrm{E}-11$ \\
$\mathbf{1 8}$ & $3.96 \mathrm{E}-13$ & $7.18 \mathrm{E}-13$ & $1.42 \mathrm{E}-12$ & $3.04 \mathrm{E}-12$ & $6.30 \mathrm{E}-12$ & $1.24 \mathrm{E}-11$ & $2.35 \mathrm{E}-11$ & $3.19 \mathrm{E}-11$ & $4.16 \mathrm{E}-11$ & $7.45 \mathrm{E}-11$ \\
$\mathbf{3 3}$ & $6.31 \mathrm{E}-13$ & $1.24 \mathrm{E}-12$ & $2.55 \mathrm{E}-12$ & $5.42 \mathrm{E}-12$ & $1.07 \mathrm{E}-11$ & $1.94 \mathrm{E}-11$ & $3.32 \mathrm{E}-11$ & $4.29 \mathrm{E}-11$ & $5.34 \mathrm{E}-11$ & $8.63 \mathrm{E}-11$ \\
$\mathbf{6 8}$ & $1.20 \mathrm{E}-12$ & $2.47 \mathrm{E}-12$ & $5.09 \mathrm{E}-12$ & $1.04 \mathrm{E}-11$ & $1.87 \mathrm{E}-11$ & $3.07 \mathrm{E}-11$ & $4.86 \mathrm{E}-11$ & $6.07 \mathrm{E}-11$ & $7.35 \mathrm{E}-11$ & $1.10 \mathrm{E}-10$ \\
$\mathbf{1 0 0}$ & $1.73 \mathrm{E}-12$ & $3.59 \mathrm{E}-12$ & $7.28 \mathrm{E}-12$ & $1.42 \mathrm{E}-11$ & $2.43 \mathrm{E}-11$ & $3.84 \mathrm{E}-11$ & $5.91 \mathrm{E}-11$ & $7.29 \mathrm{E}-11$ & $8.74 \mathrm{E}-11$ & $1.27 \mathrm{E}-10$ \\
\hline
\end{tabular}

(c) 
This optimization technique is capable of stabilizing converters outside of the recommended output filter range. Although, Table 6-1 shows that at extreme output inductor and capacitor values, the converter is unstable. At very low values such as $\mathrm{L}_{\mathrm{o}}=0.22 \mathrm{uH}$ and $\mathrm{C}_{0}=0.22 \mathrm{uF}$. The bandwidth of the converter is very large such that it is far away from the DCS-Control phase as shown in Figure 6.6. At these high frequencies, all that is left is the double pole roll-off and a phase margin dictated by the output filter. Not even the phase boost coming from the feedback network can compensate.

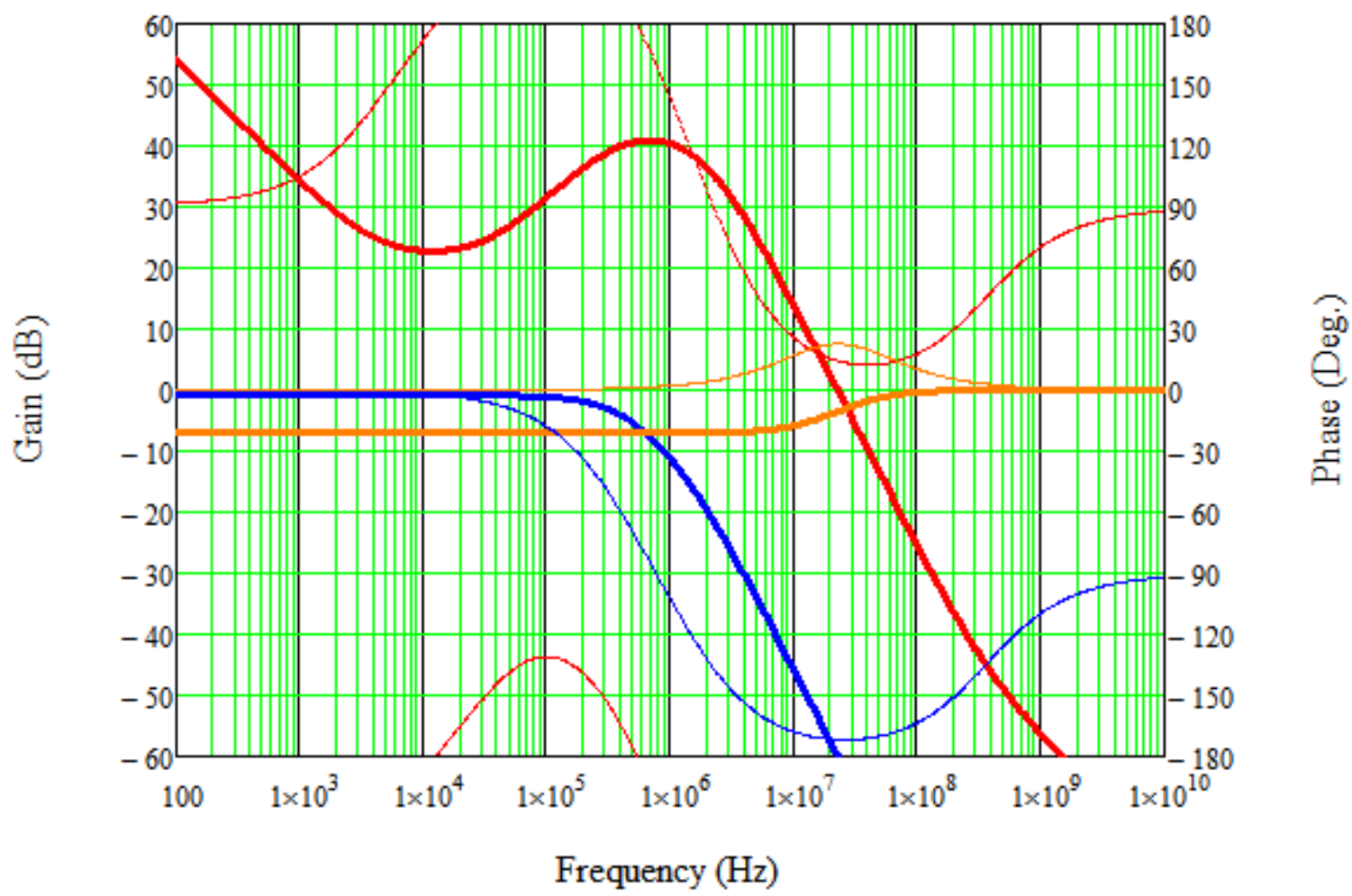

Figure 6.6: Frequency response at extremely low output filter.

On the other extreme, at very high values such as $\mathrm{L}_{0}=100 \mathrm{uH}$ and $\mathrm{C}_{0}=100 \mathrm{uF}$. The bandwidth of the converter is very low such that it creates a dominant pole in the entire 
control loop as shown in Figure 6.7. Like with low output filter values, the dominant pole is dictated by the output filter. The double pole roll-off is what starts the phase low at low frequencies. Not even the phase boost coming from the feedback network can compensate.

These extreme examples describe the extent at which this technique can optimize the stability of the converter for the ideal case. Introducing additional parasitic inductance, capacitance, and resistance will present further limitations to converter stability.

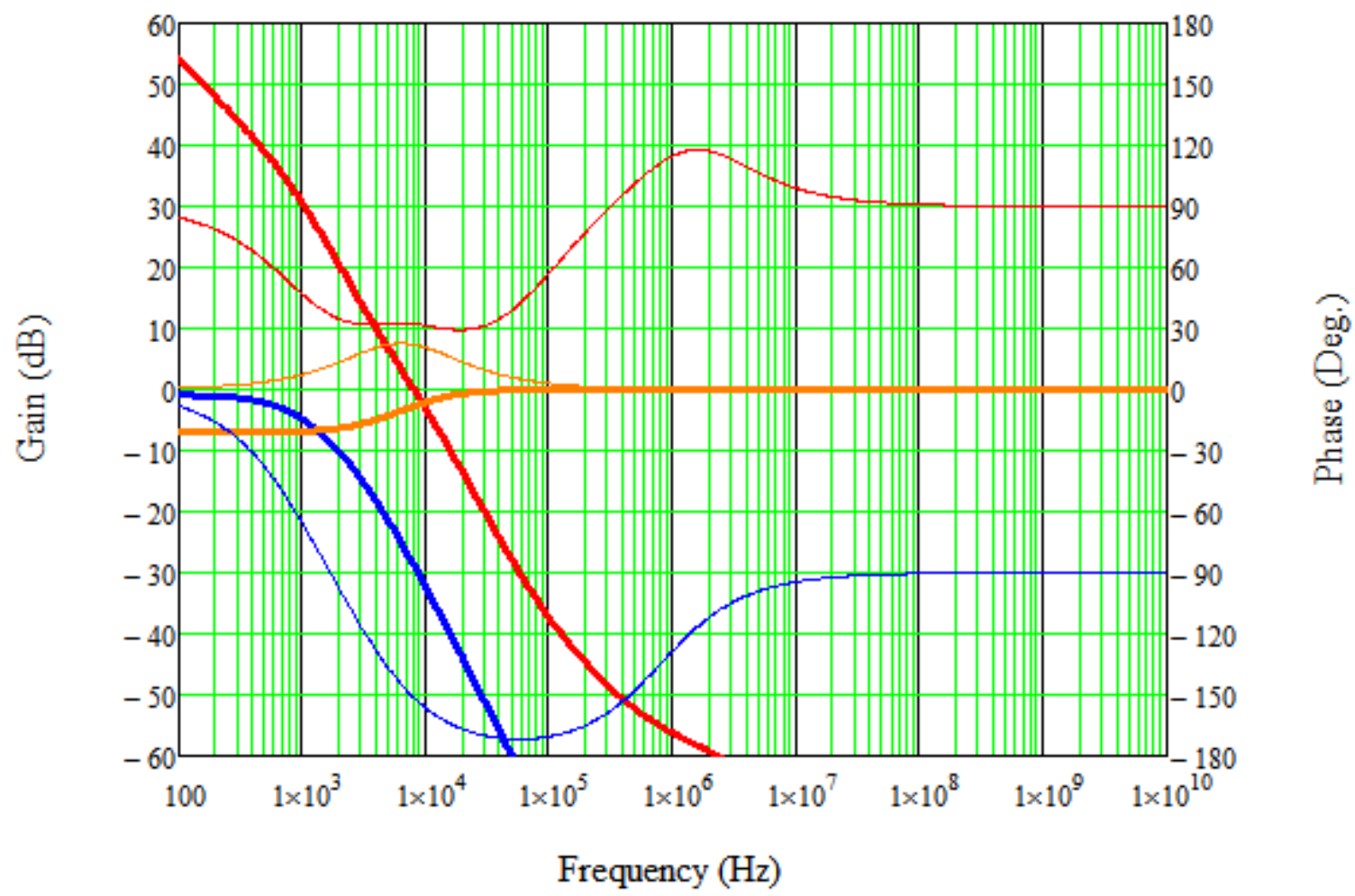

Figure 6.7: Frequency response at extremely high output filter. 


\subsection{Optimization Limitations and PCB Parasitics}

Motivation for investigating PCB parasitics in the control loop of the converter stems from the simple example shown in Figure 6.8 of the feedback network with stray capacitance to ground possibly from a PCB pad to ground plane.

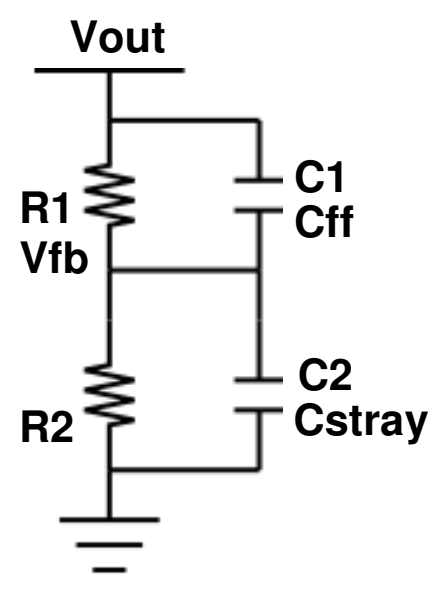

Figure 6.8: Feedback network with stray capacitance.

The transfer function for this circuit can be calculated as

$$
H_{\text {stray }}=\frac{1+s C_{f f} R_{1}}{1+\frac{R_{1}}{R_{2}}+s R_{1}\left(C_{f f}+C_{\text {stray }}\right)}
$$

where the pole and zero are the following:

$$
\begin{gathered}
f_{z_{\text {stray }}}=\frac{1}{2 \pi R_{1} C_{f f}} \\
f_{p_{\text {stray }}}=\frac{1}{2 \pi\left(C_{f f}+C_{\text {stray }}\right) \frac{R_{1} R_{2}}{R_{1}+R_{2}}}
\end{gathered}
$$


Depending on the value of $\mathrm{C}_{2}$ or stray capacitance, it may place the pole at the frequency where there is a zero thereby preventing a phase boost at the desired frequency. In addition, with a large enough stray capacitance or small enough feed forward capacitor, the feedback network may yield a dominant pole and decrease the phase margin of the converter. These scenarios are very likely using the optimization technique. Small values in the output filter will create high bandwidth frequencies and subsequent small values of feed forward capacitance on par with PCB stray capacitance rendering the phase boost useless and causing possible instability in the converter.

Because the PCB is plagued with parasitics, all possible inductance, capacitance, and resistance in the output filter and feedback network must be investigated.

\subsection{Non-Ideal Modeling of the TPS62120 Stability Optimization}

Figure 6.9 shows the circuit model of the output filter and feedback network along with possible $\mathrm{PCB}$ parasitics that may affect the stability of the converter. 


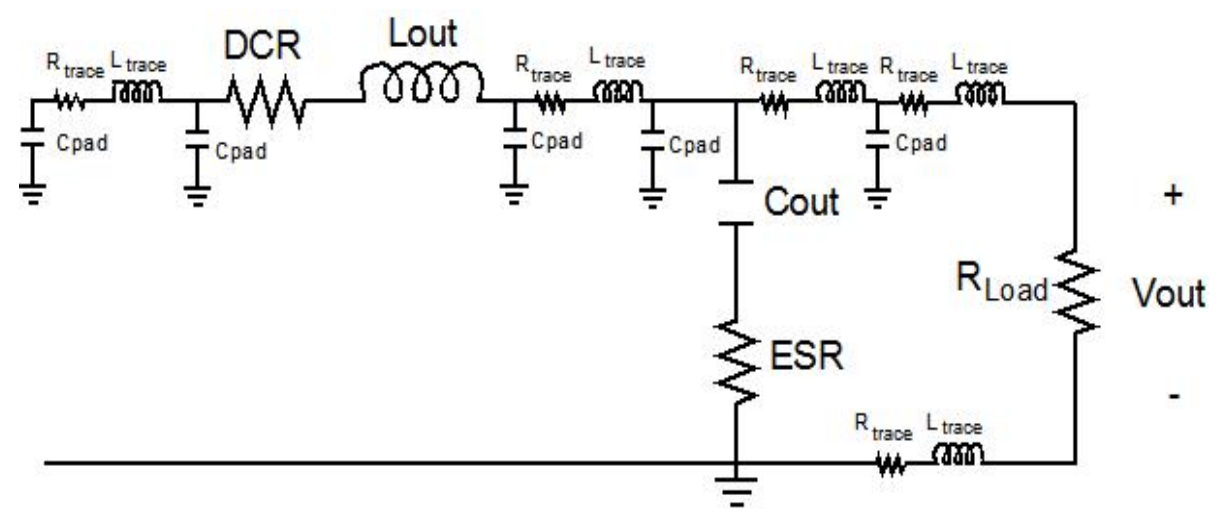

(a)

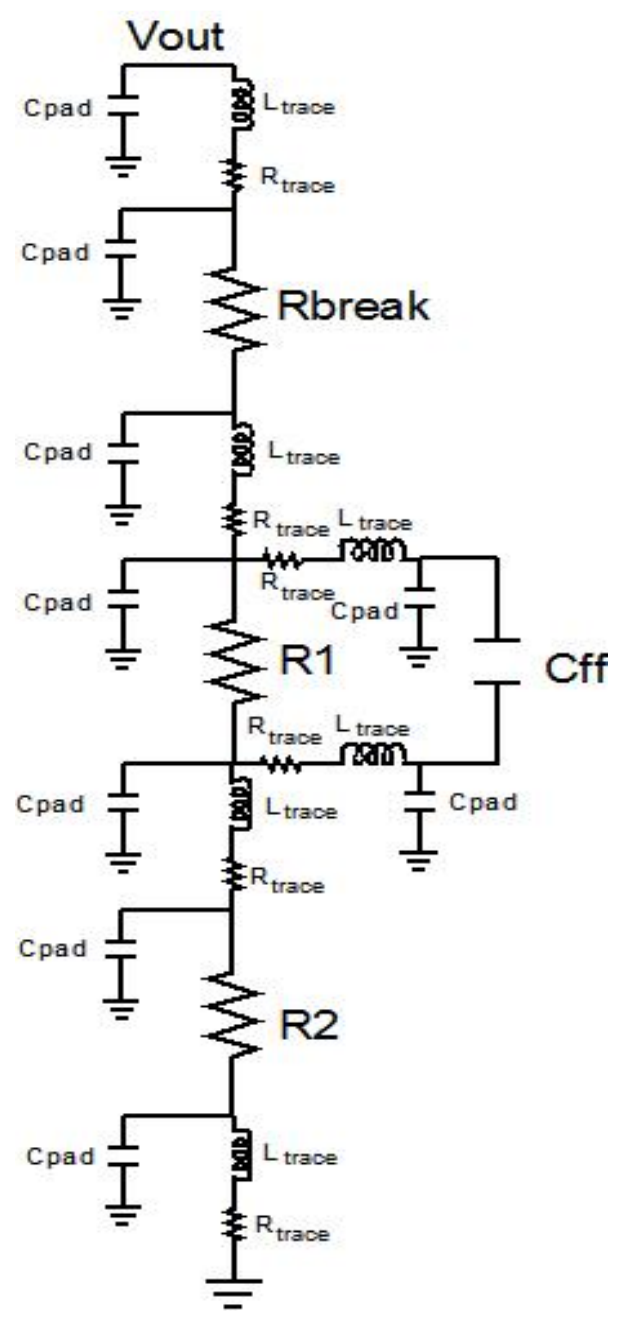

(b)

Figure 6.9: Non-ideal circuit model of the (a) output filter and (b) feedback network. 
PCB parasitic trace inductance and resistance is calculated from the electrical properties of the copper and its geometry as described in Chapter 3. PCB parasitic pad capacitance is calculated from the electrical properties of the dielectric FR-4 material and its geometry also described in Chapter 3. Table 6-2 shows the electrical properties of the PCB the average geometries of the traces and pads, and the calculated parasitic values for a PCB board layout that will be discussed in the next chapter.

Table 6-2: PCB parasitic calculations.

\begin{tabular}{|c|c|c|c|}
\hline Parasitic & \multicolumn{2}{|c|}{ Mechanical/Electrical Parameters } & Parasitic Value \\
\hline $\mathbf{R}_{\text {trace }}$ & Height (mm) & 0.04318 & $5.34 \mathrm{~m} \Omega$ \\
& Length (mm) & 10.6 & \\
& Width (mm) & 4.5 & \\
& Copper Resistivity (Ohm-cm) & $1.7 \times 10^{-6}$ & \\
\hline L $_{\text {trace }}$ & Height (mm) & 0.04318 & $5.4 \mathrm{nH}$ \\
& Length (mm) & 10.6 & \\
& Width (mm) & 4.5 & \\
& k (FR-4) & $4.2-5.0$ & $0.4 \mathrm{pF}$ \\
\hline $\mathbf{C}_{\text {pad }}$ & Area (mm^2) & 14.4 & \\
& Distance (mm) & 1.57 & \\
& & & \\
& &
\end{tabular}

Figure 6.10 shows the bode plot of the transfer function for the output filter with the PCB parasitics from Table 6-2 (orange) compared to a lossless output filter (red) and an output filter with ESR-resistance of the capacitor and DCR-resistance of the inductor (blue). 


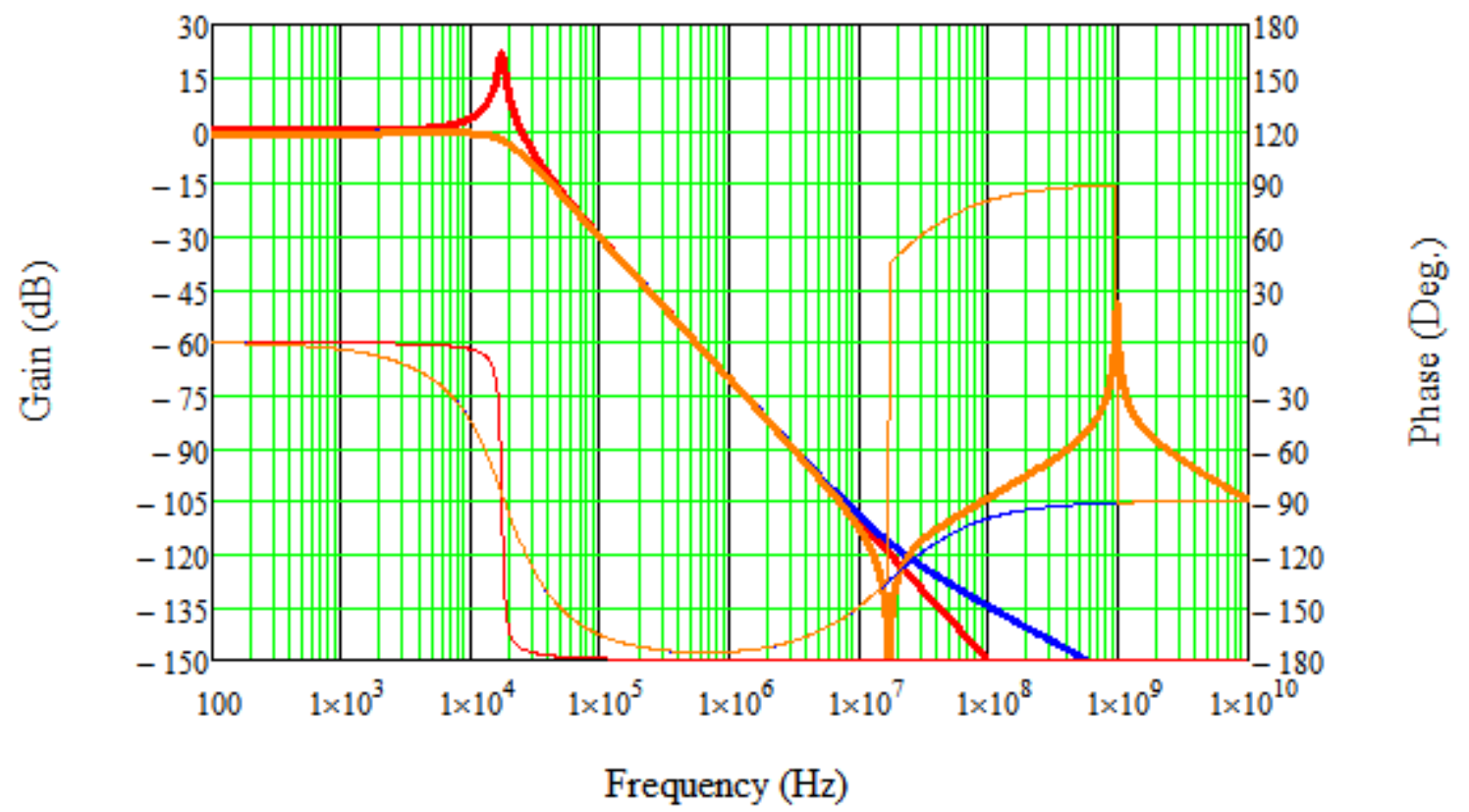

Figure 6.10: Bode plot comparing PCB parasitic output filter with an ideal and lossy output filter.

The model of the output filter with PCB parasitics shows no significant change in gain and phase compared to the output filter with ESR and DCR except at high frequencies. From a design standpoint, PCB parasitics in the output filter do not have to be taken into account because the crossover frequency will not exceed 1 megahertz unless the switching frequency of the converter is tens of megahertz which have yet to be realized in power applications because of high switching losses, lower efficiencies, EMI, and noise. 


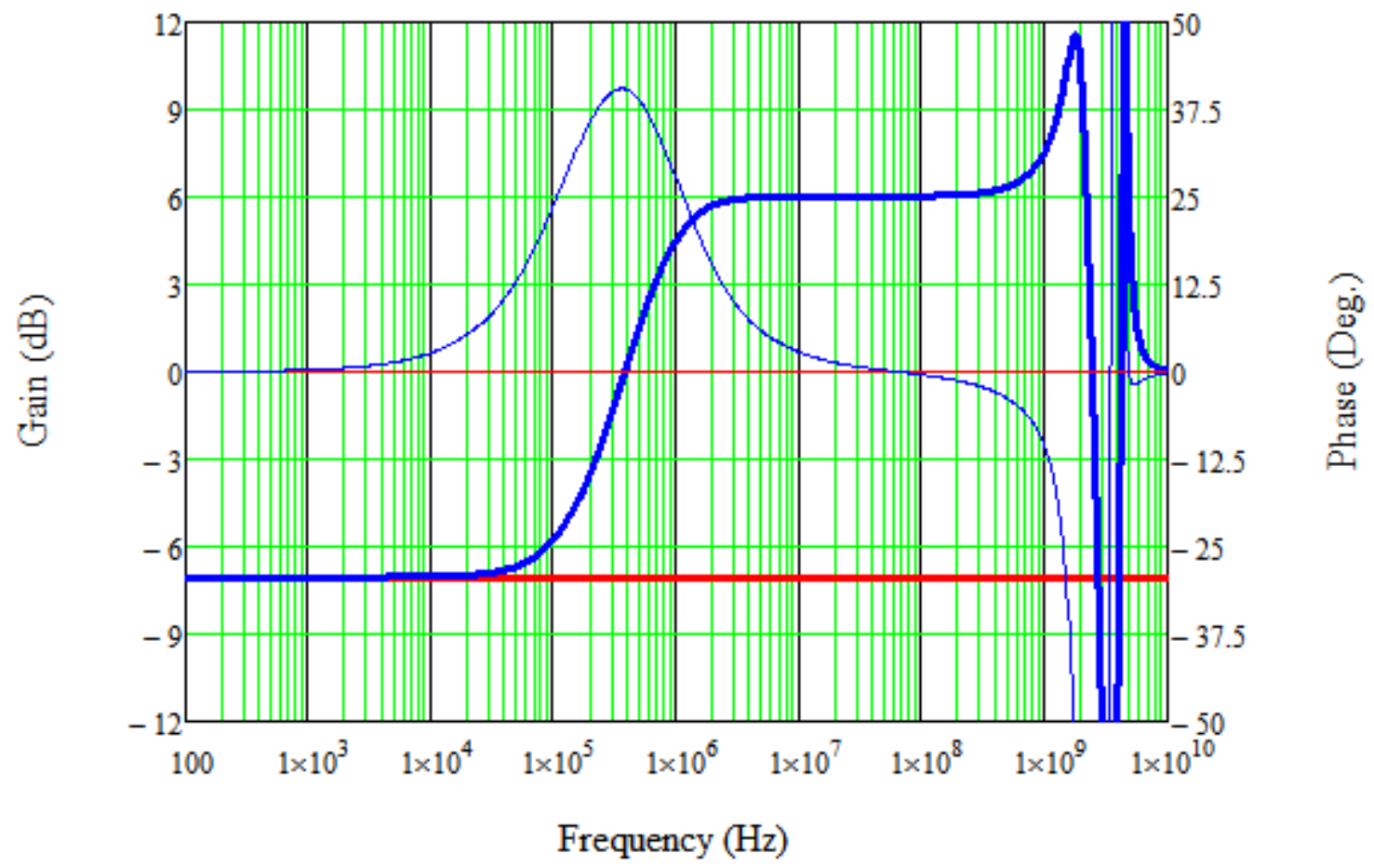

Figure 6.11: Bode plot comparing the feedback network with parasitics compared with an ideal feedback network both with no feed forward capacitor.

Figure 6.11 shows the bode plot of the transfer function for the feedback network with the PCB parasitics from Table 6-2 (blue) without a feed forward capacitor compared to the ideal feedback network also without a feed forward capacitor (red). Because there is no feed forward capacitor, it is expected not to have a phase boost as shown in the flat lines in the ideal case. However, in the nonideal case, PCB parasitics create a dominant zero thus increasing the phase boost. This is unexpected given the simple example in Figure 6.8. This suggests the phase margin may increase for converter bandwidths around the parasitic phase boost frequency. Also, the phase boost may increase the phase more than the ideal. However, this phase boost is based on the PCB parasitics and is fixed at a 
specific frequency unlike the feed forward capacitor that can vary the phase boost across different frequencies.

Table 6-3 shows the bandwidth and phase margins implementing the optimization technique with the parasitic models for an inductor range of $0.22 \mathrm{uH}$ to $100 \mathrm{uH}$ and an output capacitor range of $0.22 \mathrm{uF}$ to $100 \mathrm{uF}$. In addition, Table 6-1 also shows the calculated feed forward capacitor needed to optimize converter stability. The box in the middle of each table is the datasheet's recommended range. As suggested, there is a wider range of output filter components that allow for a more stable converter because of the phase boost from the PCB parasitics and the additional feed forward capacitor. Areas where the bandwidth of the converter is away from the parasitic phase boost such as the low inductor and low capacitor range should not be affected. However, it is interesting that the phase margin has decreased instead of staying the same for these low output filter components. This can be explained by analyzing the feedback network's contributions to the closed loop system of the converter. 
Table 6-3: Non-ideal model of (a) bandwidth, (b) phase margin, (c) calculated feed forward capacitor for stability optimization at different ranges of output filter.

\begin{tabular}{|c|rrrrrrrrr|r|}
\hline BW with Cff (Hz) & \multicolumn{10}{|c|}{10} \\
\hline Lo(uH)/Co(uF) & $\mathbf{0 . 2 2}$ & $\mathbf{0 . 4 7}$ & $\mathbf{1}$ & $\mathbf{2 . 2}$ & $\mathbf{4 . 7}$ & $\mathbf{1 0}$ & $\mathbf{2 2}$ & $\mathbf{3 3}$ & $\mathbf{4 7}$ & $\mathbf{1 0 0}$ \\
\hline $\mathbf{0 . 2 2}$ & 22250000 & 15170000 & 10310000 & 6812000 & 4452000 & 2713000 & 1144000 & 235700 & 65250 & 20700 \\
$\mathbf{0 . 4 7}$ & 15370000 & 10440000 & 7051000 & 4589000 & 2912000 & 1687000 & 697500 & 206400 & 65030 & 20700 \\
$\mathbf{1}$ & 10530000 & 7103000 & 4723000 & 2976000 & 1787000 & 969300 & 393400 & 160000 & 63870 & 20700 \\
$\mathbf{2 . 2}$ & 7015000 & 4654000 & 2994000 & 1775000 & 990900 & 508200 & 209000 & 111200 & 59240 & 20600 \\
$\mathbf{4 . 7}$ & 4659000 & 2992000 & 1820000 & 1002000 & 528000 & 262600 & 117500 & 74880 & 49290 & 20090 \\
$\mathbf{1 0}$ & 3001000 & 1822000 & 1032000 & 534900 & 272100 & 138300 & 70100 & 49860 & 36870 & 18390 \\
$\mathbf{1 8}$ & 2052000 & 1178000 & 636600 & 319100 & 163300 & 87580 & 48510 & 36310 & 28200 & 15930 \\
$\mathbf{3 3}$ & 1325000 & 722000 & 375800 & 187300 & 99890 & 57230 & 33940 & 26270 & 21030 & 12910 \\
$\mathbf{6 8}$ & 743700 & 386600 & 198500 & 103200 & 59130 & 36230 & 22660 & 17960 & 14710 & 9606 \\
$\mathbf{1 0 0}$ & 535700 & 274500 & 142900 & 77100 & 45860 & 28850 & 18400 & 14730 & 12160 & 8133 \\
\hline
\end{tabular}

(a)

\begin{tabular}{|c|c|c|c|c|c|c|c|c|c|c|}
\hline PM with Cff (Deg.) & & & & & & & & & & \\
\hline Lo/Co & 0.22 & 0.47 & 1 & 2 & 5 & 10 & 22 & 33 & 47 & 100 \\
\hline 0.22 & 13.95 & 20.29 & 29.46 & 43.41 & 62.75 & 90.03 & 132.39 & 156.37 & 141.05 & 117.45 \\
\hline 0.47 & 14.13 & 20.51 & 29.71 & 43.60 & 62.56 & 88.43 & 126.96 & 149.06 & 138.69 & 116.72 \\
\hline 1 & 16.23 & 23.45 & 33.70 & 48.61 & 67.40 & 90.31 & 122.75 & 138.48 & 133.71 & 115.15 \\
\hline 2.2 & 20.78 & 29.72 & 41.86 & 57.71 & 74.50 & 92.75 & 116.11 & 124.38 & 123.55 & 111.59 \\
\hline 4.7 & 27.87 & 39.04 & 52.59 & 67.12 & 80.11 & 92.33 & 104.69 & 108.09 & 108.54 & 104.41 \\
\hline 10 & 37.87 & 50.69 & 63.34 & 74.34 & 81.90 & 86.38 & 89.21 & 90.12 & 90.79 & 91.61 \\
\hline 18 & 47.32 & 59.79 & 70.08 & 77.11 & 79.23 & 77.95 & 76.08 & 75.88 & 76.29 & 78.12 \\
\hline 33 & 57.38 & 67.78 & 74.59 & 76.24 & 72.83 & 67.30 & 62.83 & 61.75 & 61.52 & 62.52 \\
\hline 68 & 67.95 & 74.41 & 75.35 & 70.32 & 62.19 & 54.27 & 48.21 & 46.11 & 44.81 & 43.28 \\
\hline 100 & 72.61 & 76.16 & 73.60 & 65.63 & 56.14 & 47.71 & 40.97 & 38.31 & 36.37 & 33.23 \\
\hline
\end{tabular}

(b)

\begin{tabular}{|c|c|c|c|c|c|c|c|c|c|c|}
\hline Cff (F) & & & & & & & & & & \\
\hline Lo/Co & 0.22 & 0.47 & 1 & 2.2 & 4.7 & 10 & 22 & 33 & 47 & 100 \\
\hline 0.22 & $3.58 \mathrm{E}-14$ & $5.25 \mathrm{E}-14$ & $7.72 \mathrm{E}-14$ & $1.17 \mathrm{E}-13$ & $1.79 \mathrm{E}-13$ & $2.94 \mathrm{E}-13$ & $7.22 \mathrm{E}-13$ & 1.19E-11 & 3.27E-11 & $8.13 \mathrm{E}-11$ \\
\hline 0.47 & $5.18 \mathrm{E}-14$ & $7.62 \mathrm{E}-14$ & $1.13 \mathrm{E}-13$ & $1.74 \mathrm{E}-13$ & $2.74 \mathrm{E}-13$ & $4.76 \mathrm{E}-13$ & $1.21 \mathrm{E}-12$ & $1.20 \mathrm{E}-11$ & $3.27 \mathrm{E}-11$ & $8.12 \mathrm{E}-11$ \\
\hline 1 & $7.56 \mathrm{E}-14$ & $1.12 \mathrm{E}-13$ & $1.69 \mathrm{E}-13$ & $2.68 \mathrm{E}-13$ & $4.49 \mathrm{E}-13$ & 8.37E-13 & 2.22E-12 & $1.25 \mathrm{E}-11$ & 3.27E-11 & $8.12 \mathrm{E}-11$ \\
\hline 2.2 & $1.13 E-13$ & $1.71 \mathrm{E}-13$ & $2.66 \mathrm{E}-13$ & $4.51 \mathrm{E}-13$ & $8.17 \mathrm{E}-13$ & $1.63 \mathrm{E}-12$ & $4.50 \mathrm{E}-12$ & $1.44 \mathrm{E}-11$ & $3.28 \mathrm{E}-11$ & $8.11 \mathrm{E}-11$ \\
\hline 4.7 & $1.71 \mathrm{E}-13$ & $2.67 \mathrm{E}-13$ & $4.40 \mathrm{E}-13$ & 8.07E-13 & $1.56 \mathrm{E}-12$ & 3.27E-12 & 8.73E-12 & $1.84 \mathrm{E}-11$ & $3.39 \mathrm{E}-11$ & $8.12 \mathrm{E}-11$ \\
\hline 10 & $2.66 \mathrm{E}-13$ & $4.40 \mathrm{E}-13$ & $7.83 \mathrm{E}-13$ & $1.54 \mathrm{E}-12$ & $3.13 \mathrm{E}-12$ & $6.64 \mathrm{E}-12$ & $1.56 \mathrm{E}-11$ & $2.51 \mathrm{E}-11$ & $3.80 \mathrm{E}-11$ & 8.23E-11 \\
\hline 18 & $3.90 \mathrm{E}-13$ & $6.84 \mathrm{E}-13$ & $1.28 \mathrm{E}-12$ & $2.64 \mathrm{E}-12$ & $5.46 \mathrm{E}-12$ & 1.12E-11 & $2.29 \mathrm{E}-11$ & 3.27E-11 & 4.46E-11 & 8.57E-11 \\
\hline 33 & $6.07 \mathrm{E}-13$ & 1.13E-12 & $2.22 \mathrm{E}-12$ & $4.69 \mathrm{E}-12$ & $9.52 \mathrm{E}-12$ & $1.81 \mathrm{E}-11$ & $3.27 \mathrm{E}-11$ & 4.34E-11 & $5.55 \mathrm{E}-11$ & $9.44 \mathrm{E}-11$ \\
\hline 68 & $1.09 \mathrm{E}-12$ & 2.16E-12 & $4.40 \mathrm{E}-12$ & $9.15 \mathrm{E}-12$ & $1.73 \mathrm{E}-11$ & 2.96E-11 & 4.83E-11 & $6.11 \mathrm{E}-11$ & $7.48 \mathrm{E}-11$ & $1.15 \mathrm{E}-10$ \\
\hline 100 & 1.53E-12 & $3.10 \mathrm{E}-12$ & 6.33E-12 & $1.28 \mathrm{E}-11$ & 2.29E-11 & $3.74 \mathrm{E}-11$ & $5.88 \mathrm{E}-11$ & 7.33E-11 & 8.83E-11 & $1.31 \mathrm{E}-10$ \\
\hline
\end{tabular}

(c) 
Figure 6.12 shows the bode plot of the converter (red) operating at a low bandwidth and uses the optimized feed forward capacitance. The external components are represented as the output filter in blue and the feedback network in orange. The gains are the solid lines while the phases are the thin lines.

$$
\begin{aligned}
& \mathrm{L}_{\mathrm{o}}=46 \mathrm{uH} \\
& \mathrm{C}_{\mathrm{o}}=68 \mathrm{uF} \\
& \mathrm{R}_{1}=300 \mathrm{kOhms} \\
& \mathrm{R}_{2}=240 \mathrm{kOhms} \\
& \mathrm{C}_{\mathrm{ff}}=74.79 \mathrm{pF}
\end{aligned}
$$

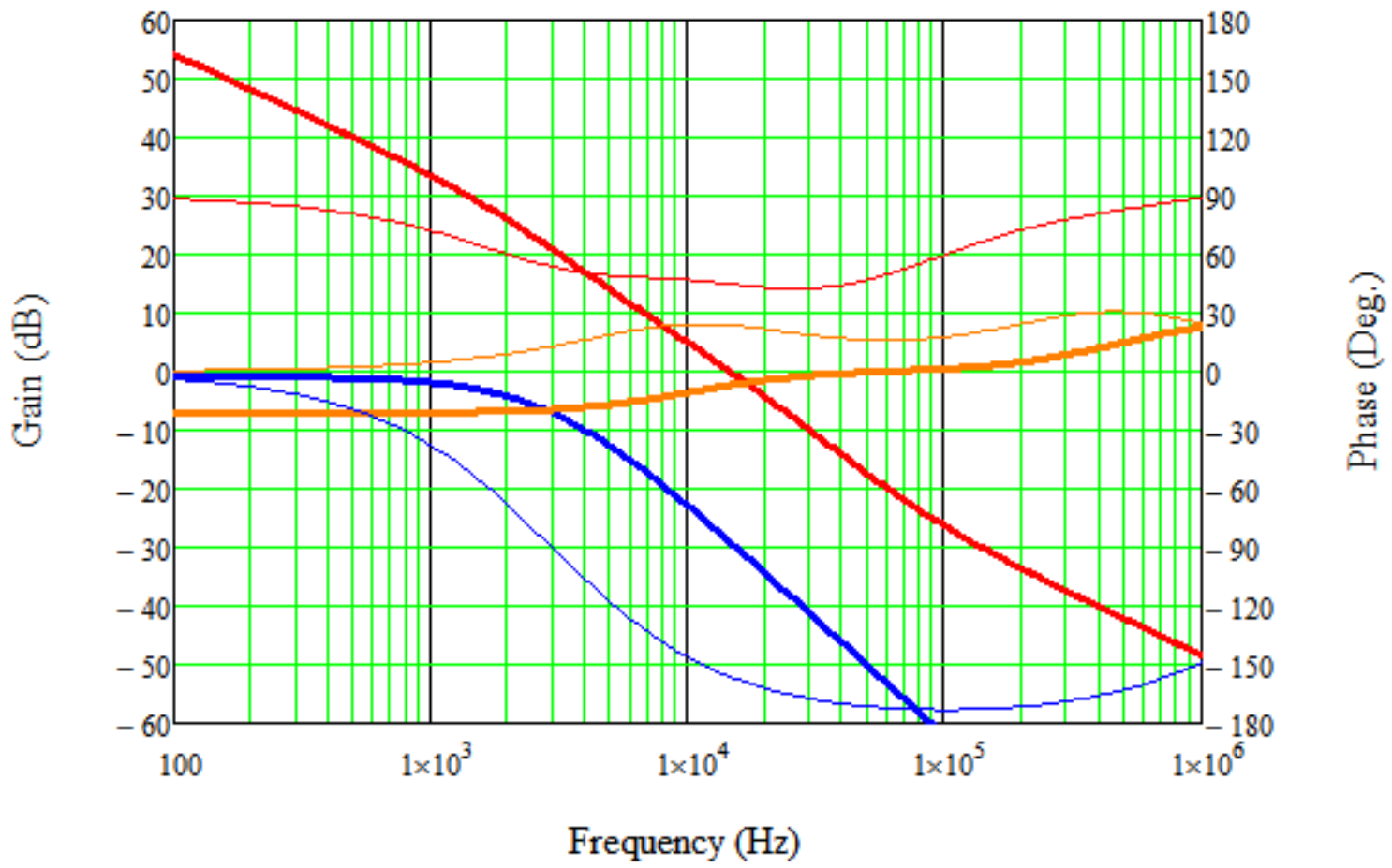

Figure 6.12: Bode plot of total closed loop (red), output filter (blue), and feedback network (orange) with PCB parasitics operating at low bandwidths

At large values of the output filter's inductor and capacitor, the closed loop system benefits by having phase boosts coming from both the feed forward capacitor and the PCB parasitics. This increases the phase margin enough for stability. 


$$
\begin{aligned}
& \mathrm{BW}=14.7 \mathrm{kHz} \\
& \mathrm{PM}=44.80 \mathrm{deg}
\end{aligned}
$$

Compared to Table 6-1, the above results show the ideal model has less stability at this operating point.

$$
\begin{aligned}
& \mathrm{BW}=14.7 \mathrm{kHz} \\
& \mathrm{PM}=39.14 \mathrm{deg}
\end{aligned}
$$

Figure 6.13 shows the bode plot with a low inductor and capacitor and operating at high bandwidths.

$$
\begin{aligned}
& \mathrm{L}_{\mathrm{o}}=0.22 \mathrm{uH} \\
& \mathrm{C}_{\mathrm{o}}=2.2 \mathrm{uF} \\
& \mathrm{R}_{1}=300 \mathrm{kOhms} \\
& \mathrm{R}_{2}=240 \mathrm{kOhms} \\
& \mathrm{C}_{\mathrm{ff}}=0.12 \mathrm{pF}
\end{aligned}
$$

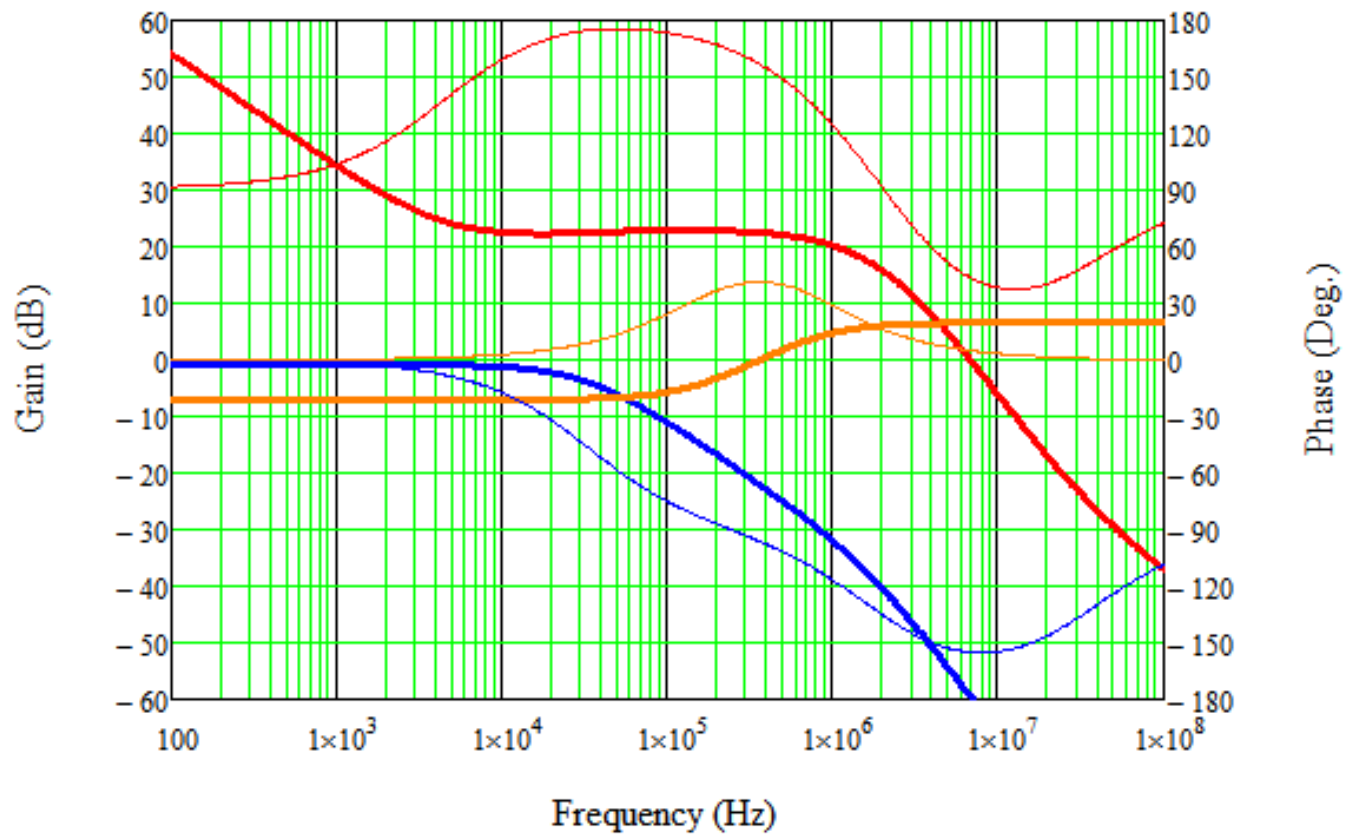

Figure 6.13: Bode plot of total closed loop (red), output filter (blue), and feedback network (orange) with PCB parasitics operating at high bandwidths 
At low output filter inductors and capacitors, Table 6-3 shows a decrease in phase margin suggesting the feed forward capacitor did not aid in increasing the phase of the converter. Figure 6.13 shows that this presumption is correct. The parasitic phase boost can be seen; however, at high frequencies, the phase boost from the feed forward capacitor is non-existent. As a result, the phase margin decreased and does not meet stability requirements.

$$
\begin{aligned}
& \mathrm{BW}=6.8 \mathrm{MHz} \\
& \mathrm{PM}=43.50 \mathrm{deg}
\end{aligned}
$$

Table 6-1 shows the ideal model with more stability at this operating point.

$$
\begin{aligned}
& \mathrm{BW}=7.1 \mathrm{MHz} \\
& \mathrm{PM}=46.7 \mathrm{deg}
\end{aligned}
$$

Figure 6.14 further investigates the effects of the feed forward capacitor in the parasitic model of the feedback network (blue). This is compared to the ideal feedback network model (red). At low frequencies the parasitic model includes the phase boost. As the feed forward capacitor decreases, the zero frequency increases moving the phase boost towards the parasitic phase boost thus increasing its peak phase. This continues until the zero frequency of the feed forward capacitor reaches the zero frequency of the PCB parasitics after which the feed forward capacitor gain and phase is ineffective. 


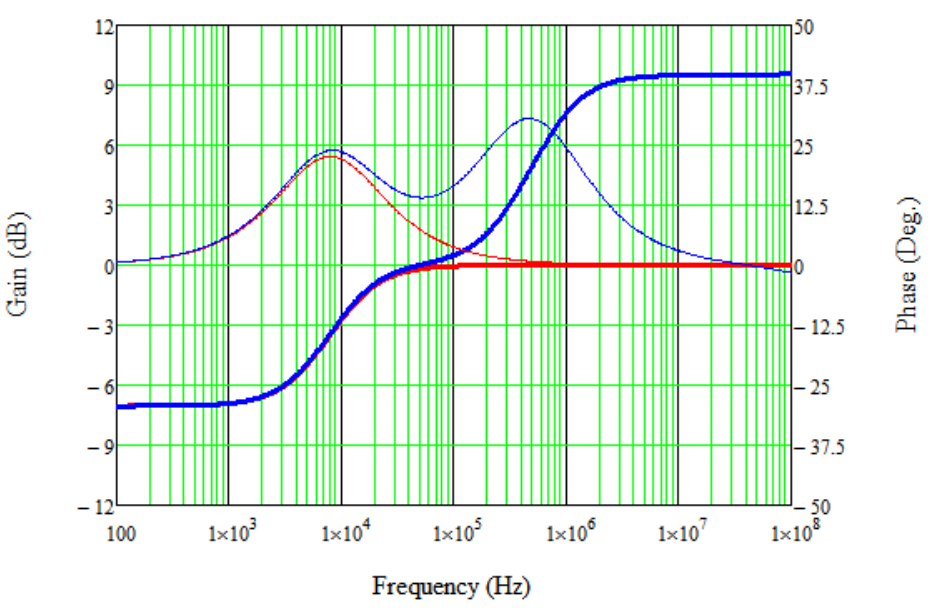

(a) $\mathrm{Cff}=100 \mathrm{pF}$

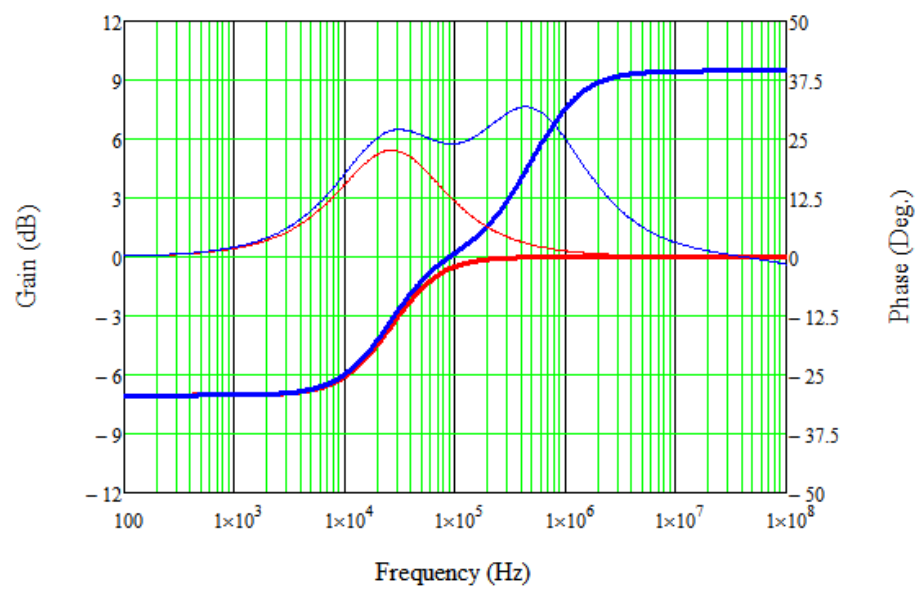

(b) $\mathrm{Cff}=20 \mathrm{pF}$

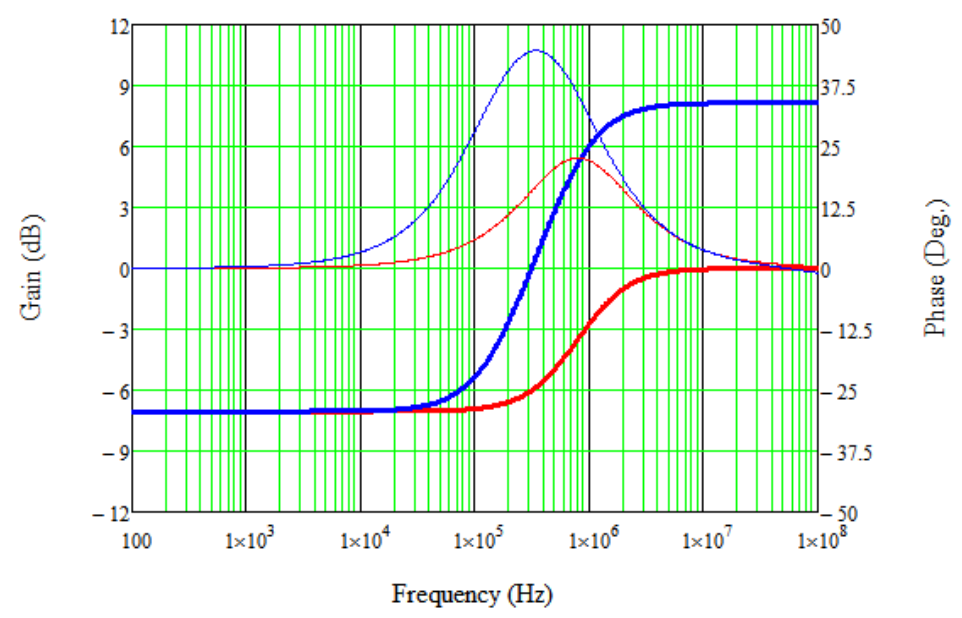

(c) $\mathrm{Cff}=1 \mathrm{pF}$

Figure 6.14: Observing the effects of the feed forward capacitor in the parasitic model. 
The ineffectiveness of the feed forward capacitor at high frequencies in the PCB parasitic model of the converter can be attributed to its small value that is comparable to the feedback network's parasitics as suggested in the simple stray capacitance model. However, instead of creating a parasitic pole that cancels the zero of the feed forward capacitor, the feed forward capacitor may be so small that its value is insignificant feedback network's transfer function.

System modeling for both ideal and non-ideal external components reveals improvement in stability at low bandwidth frequencies and decreased phase margins at high bandwidth frequencies. In order to verify the validity of these theoretical models, experimental data must be obtained. 


\section{Chapter 7 : PCB Design and Testing}

Verifying the effects of the PCB parasitics on converter stability and optimization involves measuring the frequency response of the closed loop system. This chapter discusses the PCB design of the converter and the laboratory setup to test the closed loop system. The TPS62120 is used as the system under test at the operating conditions described in Chapter 5.

\subsection{PCB design}

Figure 7.1 shows the circuit of the TPS62120 buck converter that will be used for measuring the control loop of the system. The circuit is similar to the typical circuit application shown in Figure 5.1. The extra output filter capacitors are added to allow for a large range of different sizes as the capacitance varies. The $50 \mathrm{ohm}$ resistor $\mathrm{R}_{\text {break }}$ is used to break the feedback loop of the system so that an AC signal can be injected in the control loop to analyze its stability.

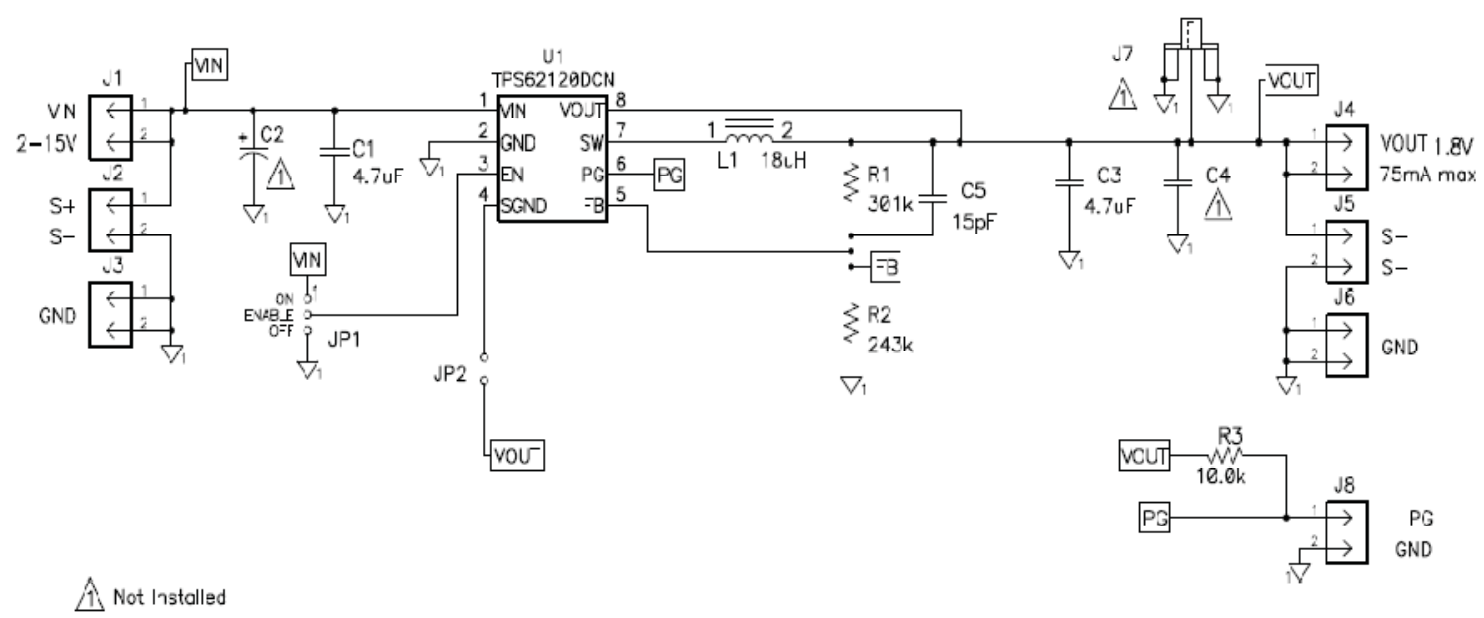

Figure 7.1: Typical application circuit schematic of the TPS62120 [39]. 
Figure 7.2 shows the PCB layout of the circuit shown in Figure 7.1. The PCB layout consists of the two layers and the entire board contains three of the same circuits. The top two circuits in Figure 7.2c are the same circuits shown in Figure 7.2a and Figure 7.2b. These can be considered a typical design layout that a designer would create. On the other hand, the layout on the bottom contains long trace lengths and large capacitive pads. This layout is a poorly made design that is infected with a larger amount of PCB parasitics. Unfortunately, the effects of this layout will not be used to measure the converter's stability. Instead, the typical design layout that a designer would create will be under test. Figure 7.3 shows the fully assembled circuit. 


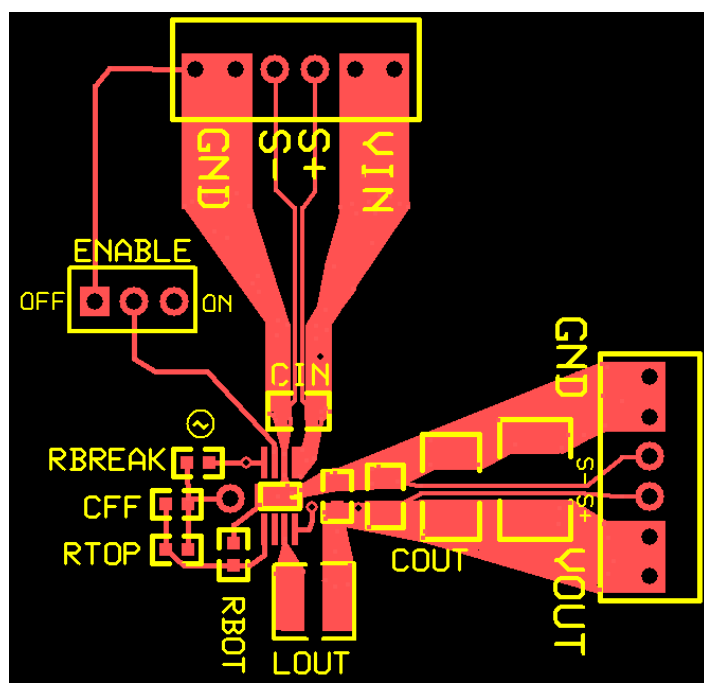

(a)

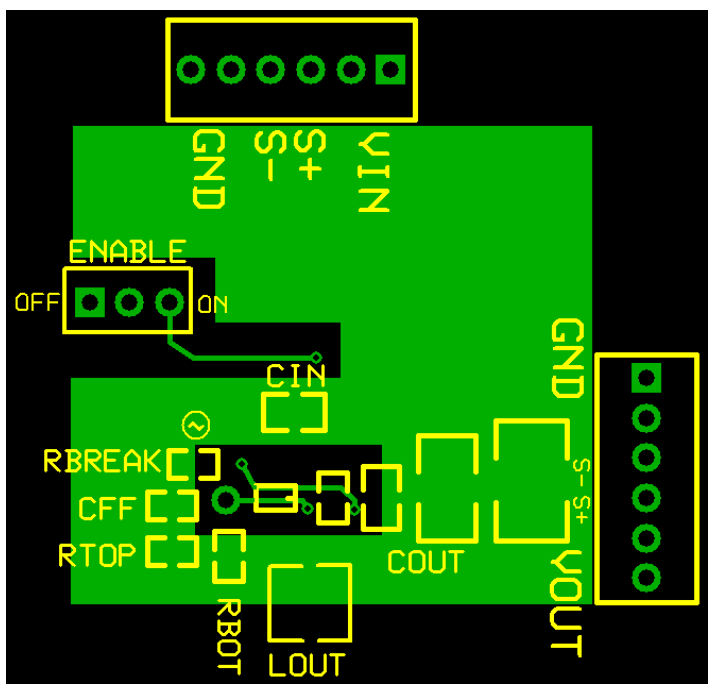

(b)

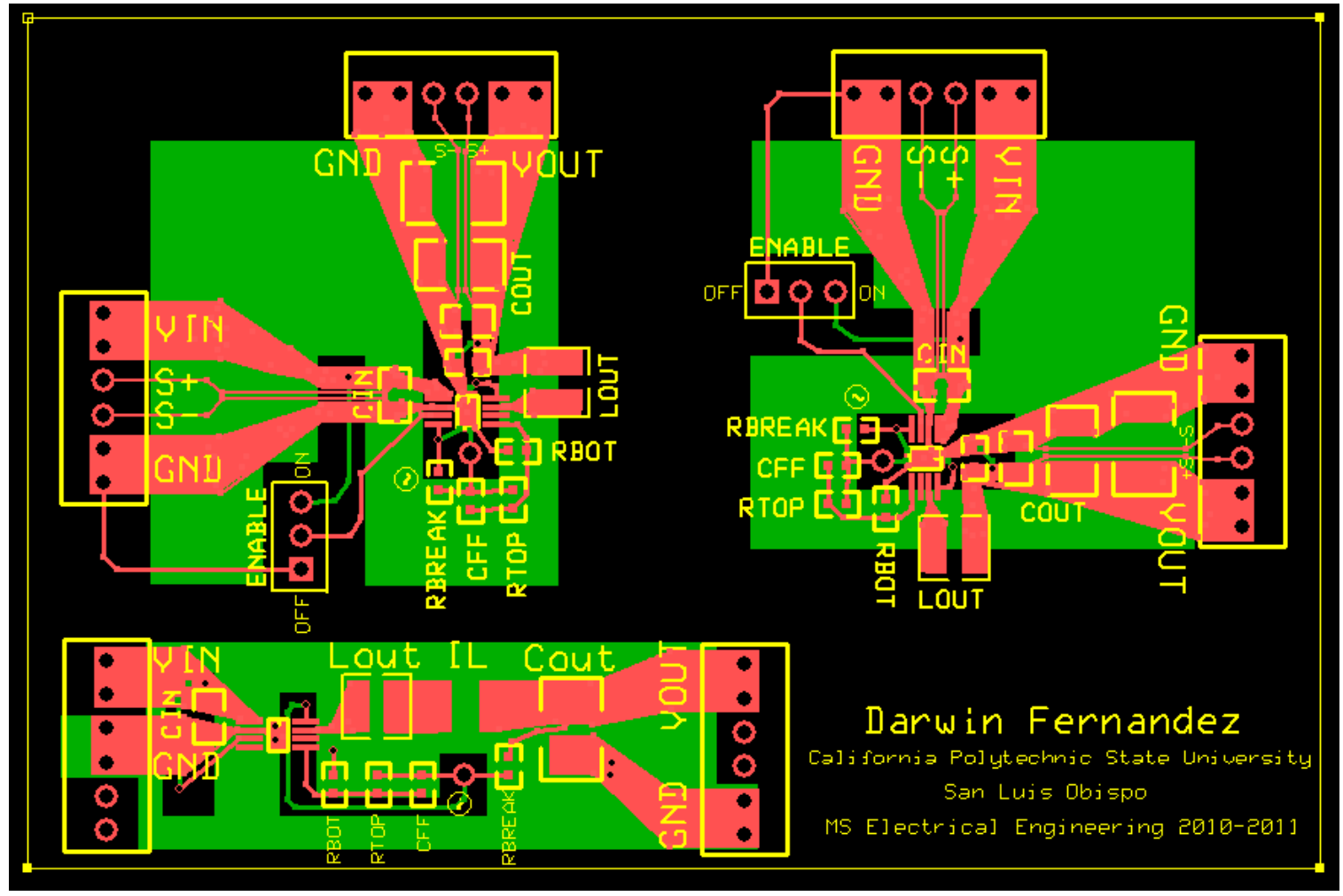

(c)

Figure 7.2: PCB layout of the TPS62120 with its (a) top layer (b) bottom layer and (c) entire board. 


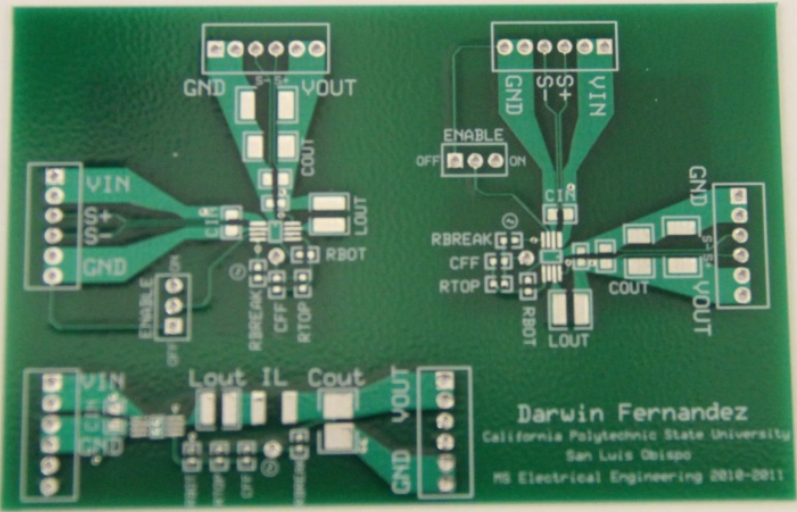

(a)

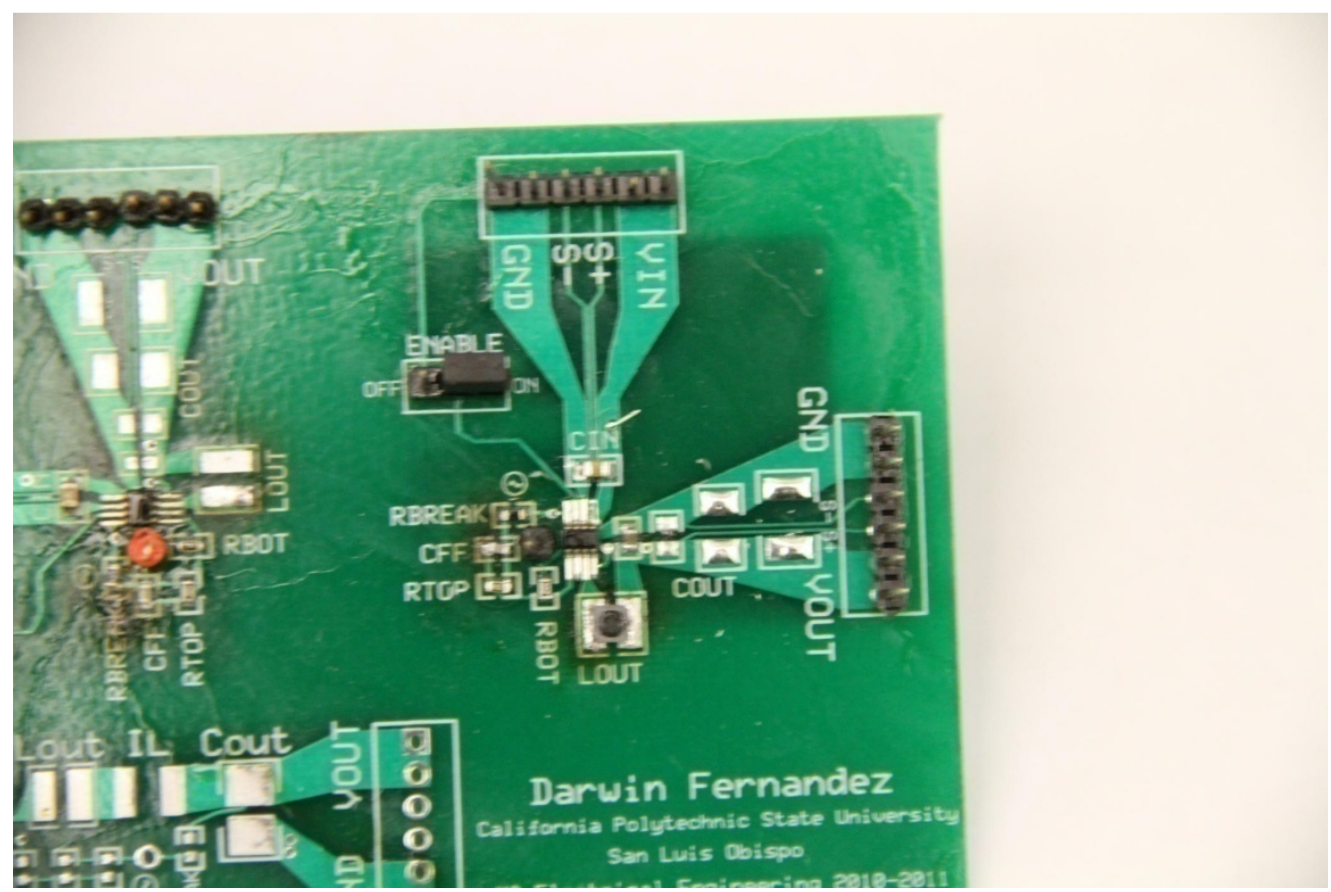

(b)

Figure 7.3: (a) Final PCB assembly and (b) populated board. 


\subsection{Test Setup}

Experimental measurements involve measuring the frequency response of the closed loop system to determine the bandwidth and phase margin of the converter. Figure 7.4 shows the block diagram test setup to accomplish this and Figure 7.5 shows the actual experimental setup in lab.

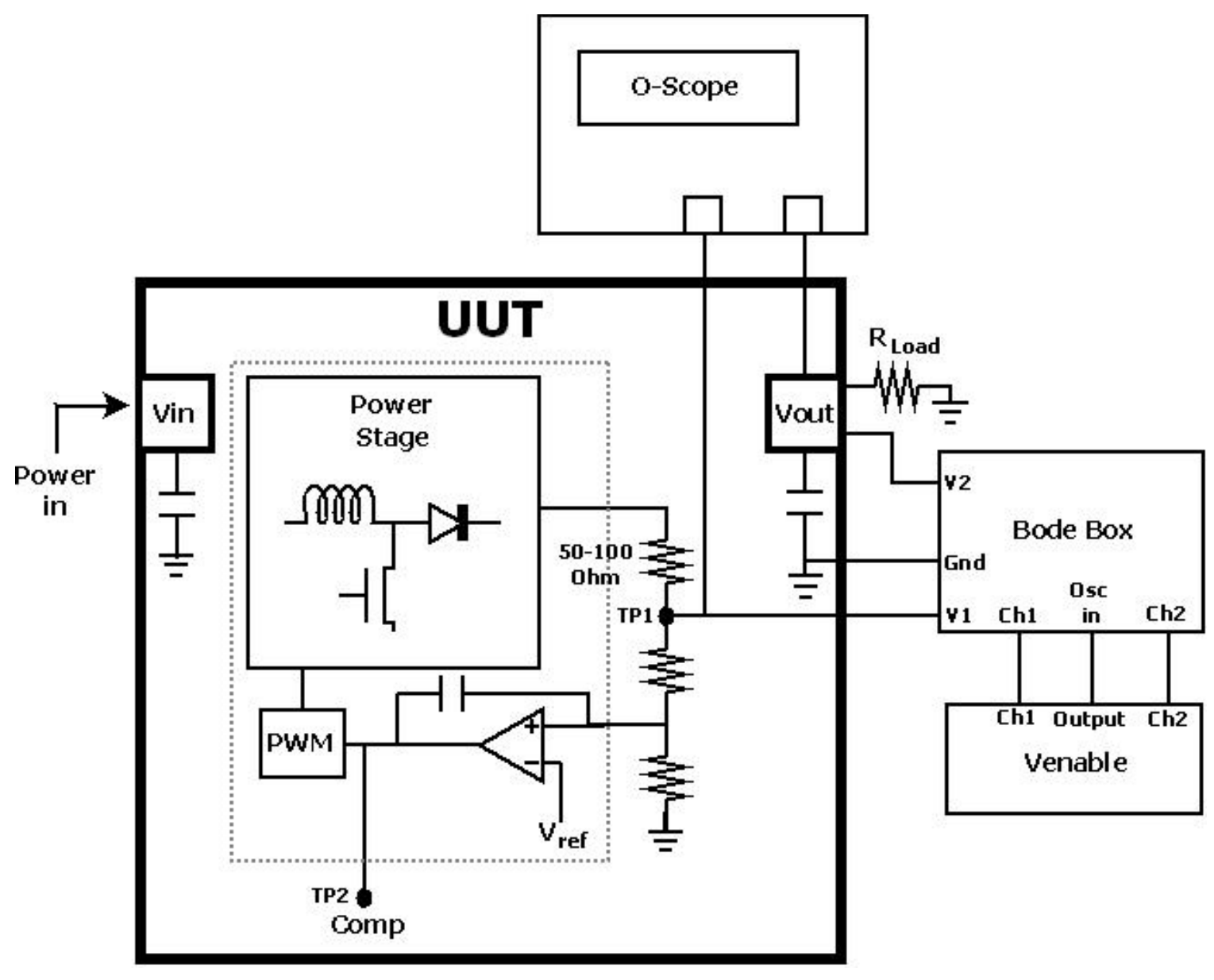

Figure 7.4: Experimental lab set up of the TPS62120. 


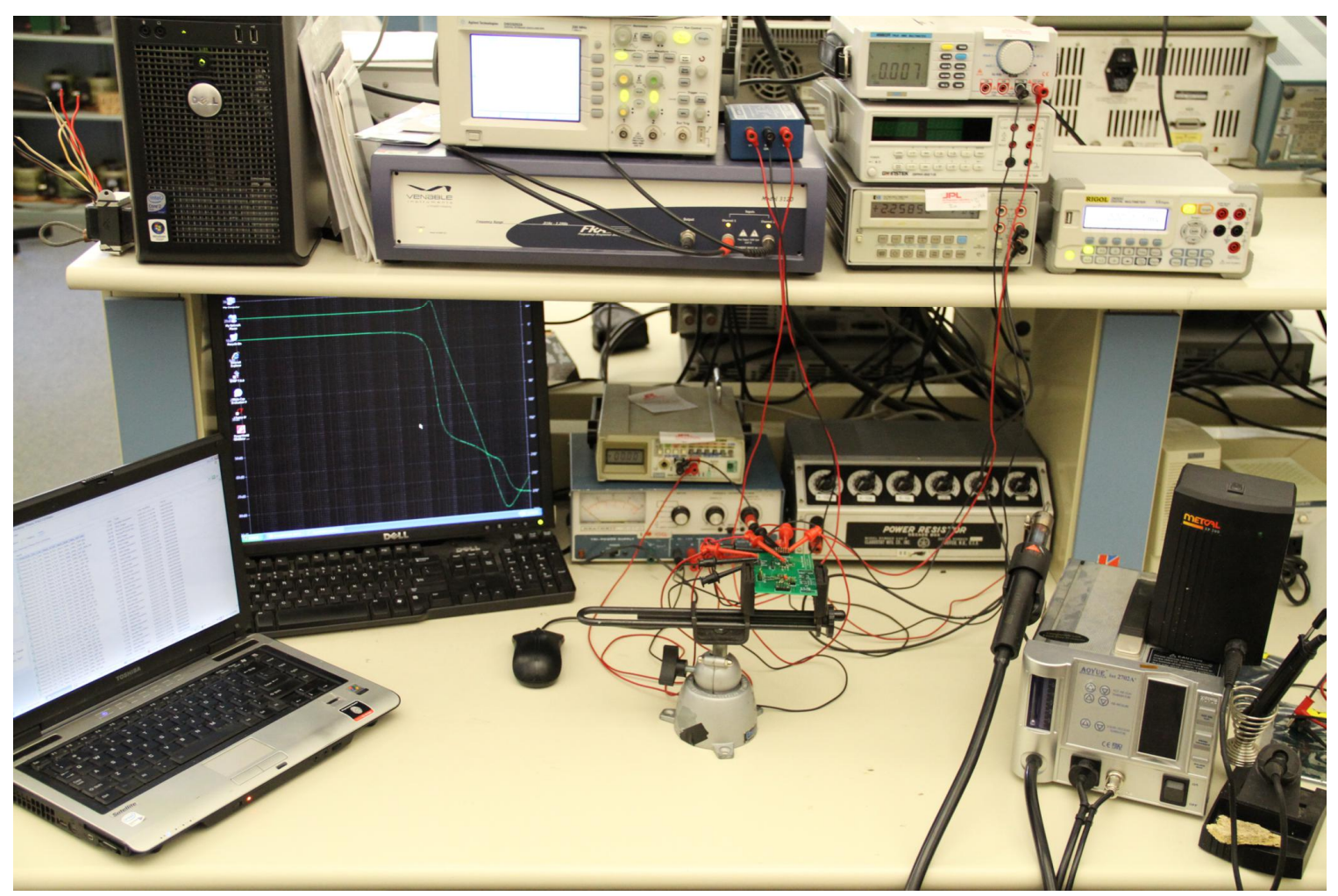

Figure 7.5: Laboratory set up.

The 12 volt power supply supplies power to the converter with an output voltage of 1.8 volts operating under full load conditions at $75 \mathrm{~mA}$ using a resistive load box to minimize noise during AC excitation. The oscilloscope is used to see the AC signal and its integrity at various parts of the circuit at different frequencies. Multimeters are used to monitor the input and output voltages and currents. To vary output the inductors and capacitor and change the feed forward capacitor, a heat gun and soldering iron is used close by for quick adjustments.

AC excitation is done using the Venable Instrument's frequency analyzer and the frequency response is calculated using Venable Instrument's bode box. Figure 7.6 shows how the AC signal is injected into the control loop. A resistor is inserted into the 
feedback loop and is AC coupled to an oscillator through a capacitor and transformer. This converts the resistor into a floating sinusoidal error voltage in series with the feedback loop and modulates the operating point of the entire circuit.

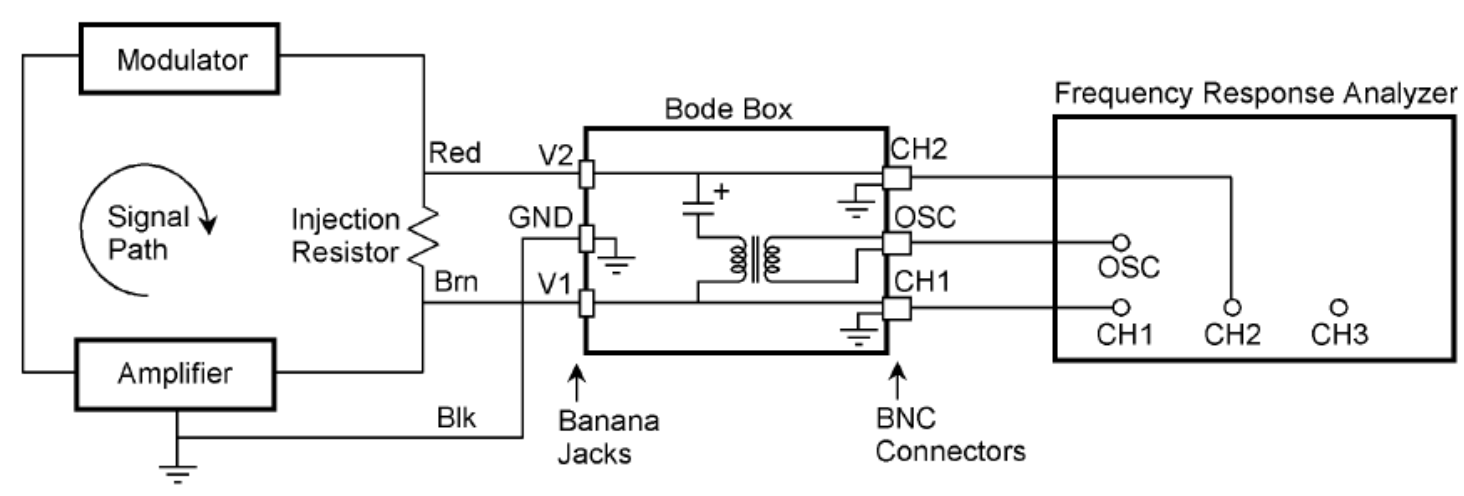

Figure 7.6: Frequency response analyzer technique for injecting AC signal

The frequency response analyzer sweeps the frequency of the oscillator. Direct connections to Channel 1 and Channel 2 allow for signal acquisition to measure changes in amplitude and phase differences to plot the gain and phase of the converter.

\subsection{Data Acquisition}

Figure 7.7 shows a typical gain and phase plot acquired from the frequency response analyzer. This operating point is at the datasheet's recommended external components.

$$
\begin{aligned}
& \mathrm{L}_{\mathrm{o}}=18 \mathrm{uH} \\
& \mathrm{C}_{\mathrm{o}}=4.7 \mathrm{uF} \\
& \mathrm{R}_{1}=300 \mathrm{kOhms} \\
& \mathrm{R}_{2}=240 \mathrm{kOhms} \\
& \mathrm{C}_{\mathrm{ff}}=22 \mathrm{pF}
\end{aligned}
$$


The bandwidth and phase margin are measured to be:

$\mathrm{BW}=73.6 \mathrm{kHz}$
$\mathrm{PM}=71.78 \mathrm{deg}$

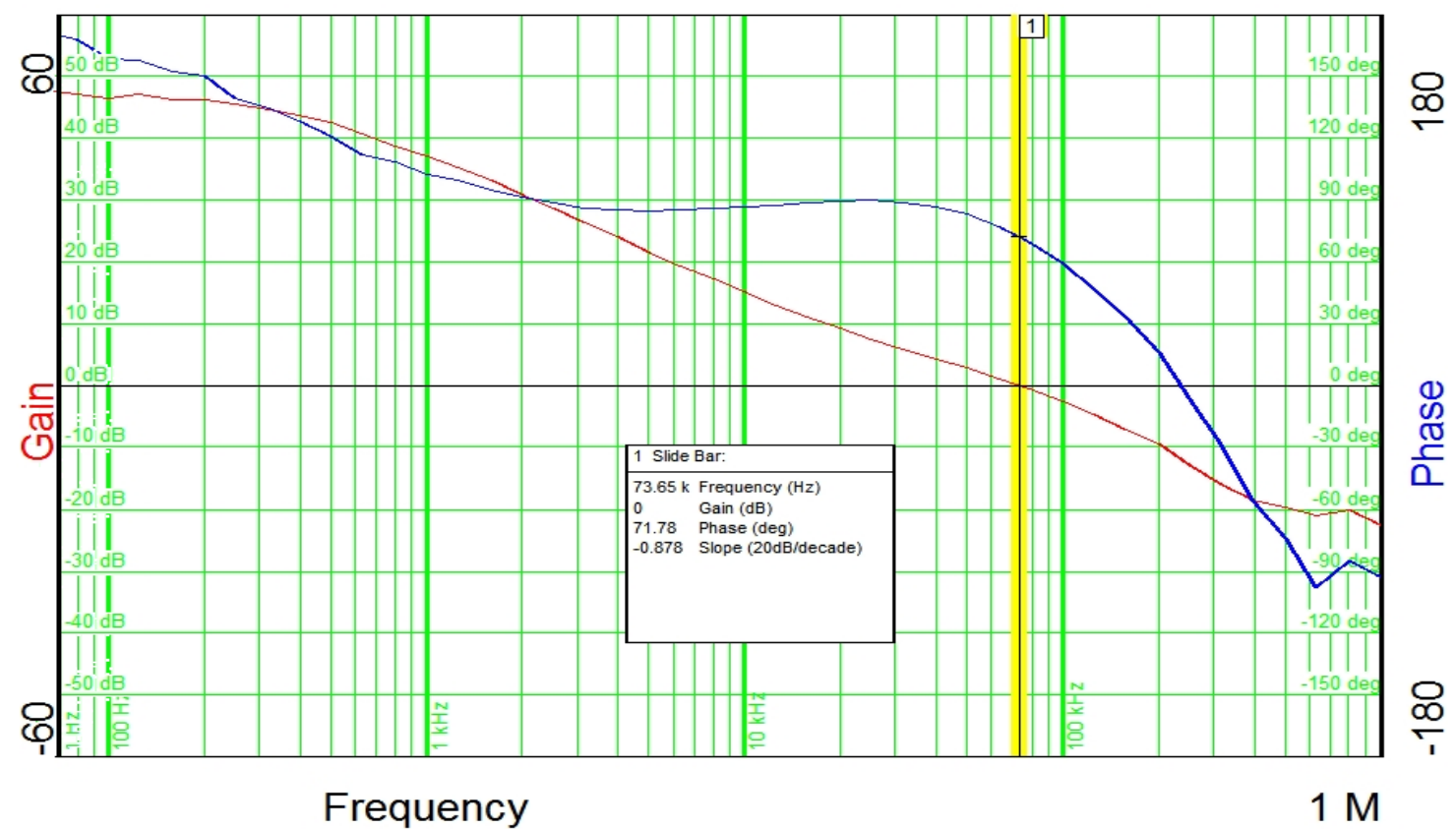

Figure 7.7: Frequency response measurement at datasheet's recommended external component values.

Figure 7.8 compares the measured bode plot to our (a) ideal model and (b) non ideal model. 


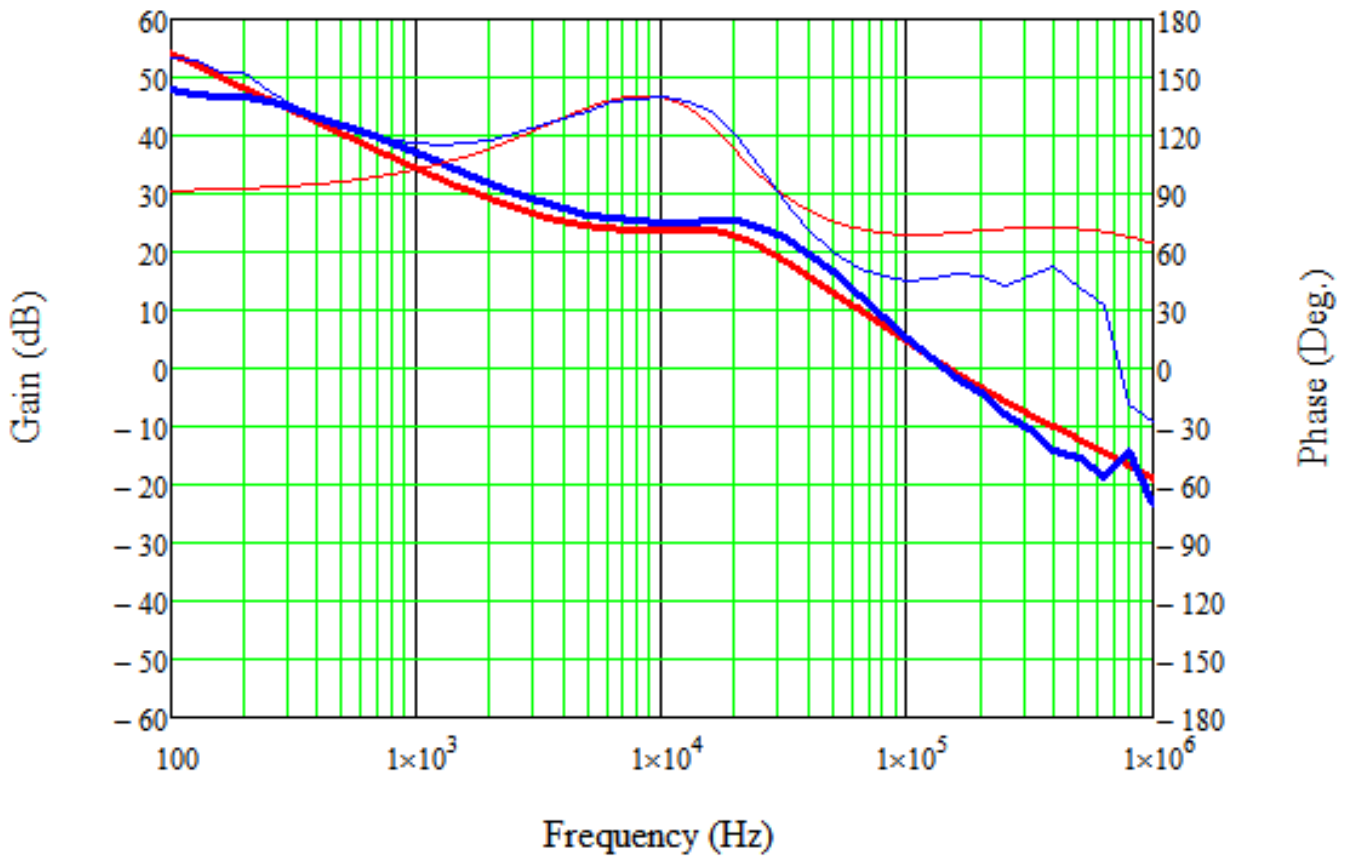

(a)

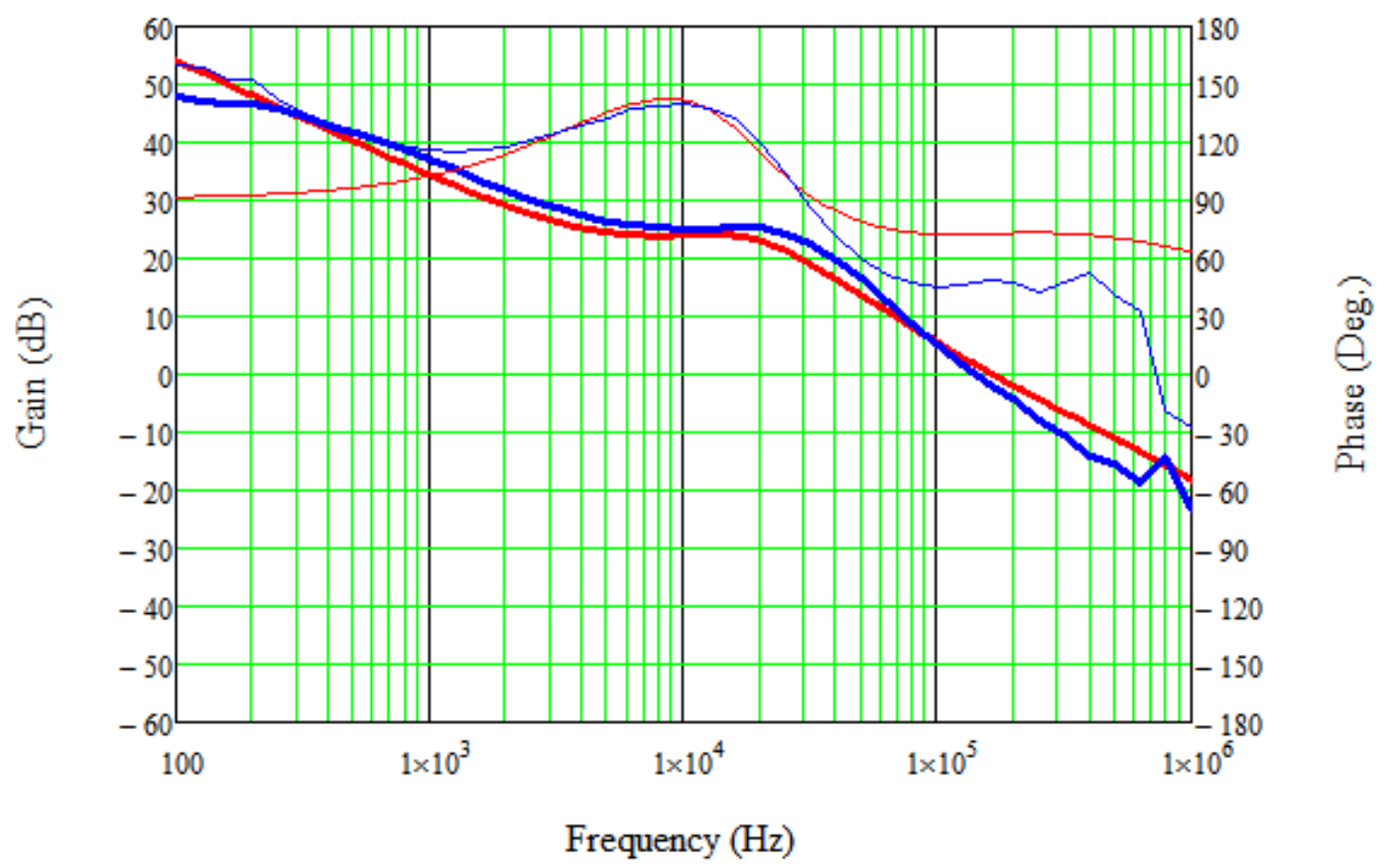

(b)

Figure 7.8: Experimental data compared to (a) ideal and (b) non-ideal model at datasheets recommended external component values. 
At recommended range, the shape of the ideal and non-ideal models follow the experimental data. The values of the gain are close to the data while the phase is slightly higher. An operating point out of the recommended range is what we're more interested in for this thesis. Therefore, at an operating point of

$$
\begin{aligned}
& \mathrm{L}_{\mathrm{o}}=68 \mathrm{uH} \\
& \mathrm{C}_{\mathrm{o}}=47 \mathrm{uF} \\
& \mathrm{R}_{1}=300 \mathrm{kOhms} \\
& \mathrm{R}_{2}=240 \mathrm{kOhms} \\
& \mathrm{C}_{\mathrm{ff}}=0 \mathrm{pF}
\end{aligned}
$$

the experimental bode plot with the (a) ideal and (b) non-ideal model is shown in Figure 8.9. The models are much like the previous operating point compared to the data. the gain follows the data close except this time the phase is slightly lower. The sudden drop in phase for the experimental data may be attributed to the converter itself where the injected signal frequency may be exceeding the bandwidth of the error amplifier in the compensation of the TPS62120. 


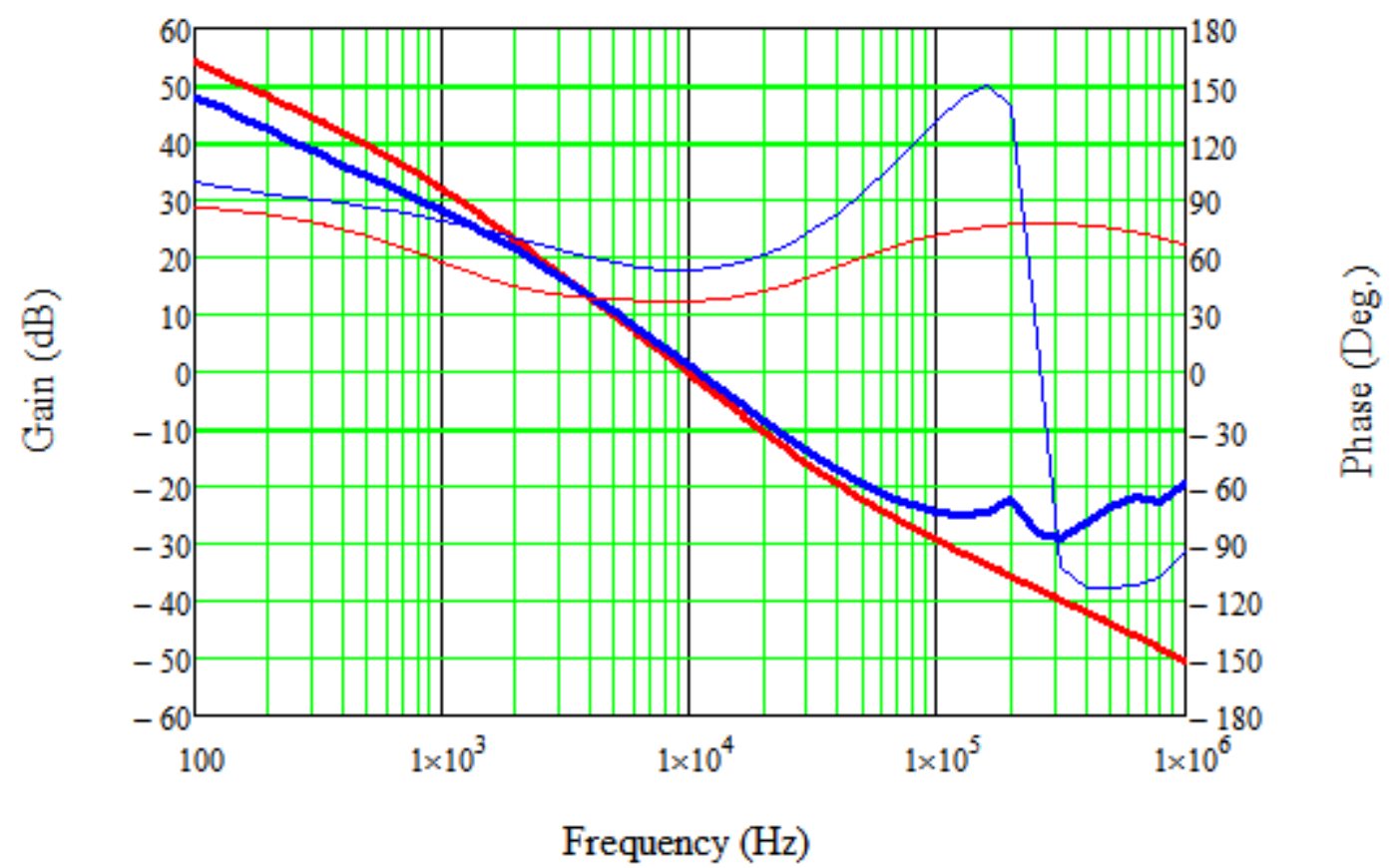

(a)

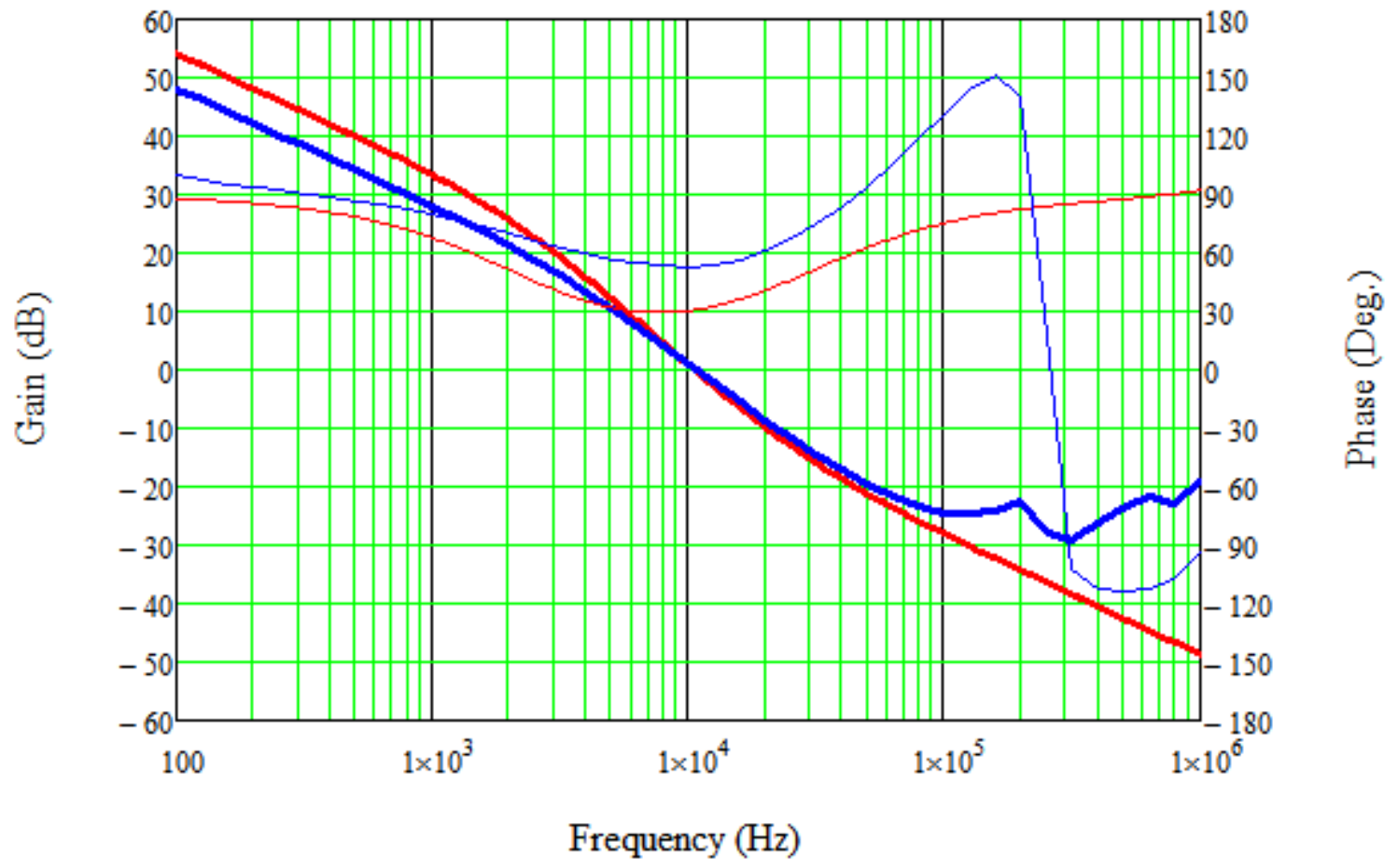

(b)

Figure 7.9: Experimental data compared to (a) ideal and (b) non-ideal model at external component values out of the datasheets recommended range. 
Like system modeling, the output inductor and capacitor in our experimental set up will be varied and the stability of the converter will be optimized using the optimized feed forward capacitor. Table 7-1 shows the bandwidth and phase margins for an inductor range of $0.22 \mathrm{uH}$ to $100 \mathrm{uH}$ and an output capacitor range of $0.22 \mathrm{uF}$ to $100 \mathrm{uF}$. In addition, Table 7-1 also shows the calculated feed forward capacitor needed to optimize converter stability. The box in the middle of each table is the datasheet's recommended range. Despite the various converter bandwidths, there is more interest in the phase margin that meets converter stability requirements. The highlighted areas in Table 7-1(b) shows that the stability requirements are met and have phase margins greater than $45^{\circ}$. The pink regions represent an operating point where the converter is not regulating at the designed output voltage. Therefore, these data points are omitted from analysis.

In terms of stability, the data show that it is possible to have an output filter outside the recommended range of the datasheet and have adequate phase margin for a stable converter. The diagonal across the table is similar to the ideal and non-ideal models. However, there are areas that do not meet stability requirements such as the pink areas where the converter does not regulate. Three issues that may account for this is the bandwidth criteria discussed in Chapter 4 , the converter operating at discontinuous conduction mode (DCM), and large output voltage ripple. The Nyquist criteria that must be satisfied is the converter's bandwidth must be at most $50 \%$ of the switching frequency. Typically designers add an extra cushion of 10-30\% to assure that the converter will not encounter aliasing effects and possible instability. At such low values of inductance and capacitance at this pink area, the bandwidths of the model are as high as the megahertz range while the switching frequency of the converter is only $800 \mathrm{KHz}$. This effect may be 
also accounting for the areas of white that have less or do not have phase margins above 45 degrees while the models do. In addition, such low values of inductance may be causing the converter to operate in DCM. Low inductance means a large inductor current ripple. The ripple may be so large that the current can discharge to zero for a given load. At this point, the output voltage does not follow CCM calculations and the transfer function of the converter changes which means the frequency response system modeling may not be accurate at low inductor values. The critical inductance of the converter can be calculated

$$
\begin{aligned}
& L_{\text {min }}=\frac{(1-D) R_{\text {load }}}{2 f} \\
& L_{\text {min }}=\frac{\left(1-\frac{1.8}{12}\right) \frac{1.8}{0.075}}{2(800000)}=10 \mu \mathrm{H}
\end{aligned}
$$

This means that values below $10 \mathrm{uH}$ will yield a converter operating under DCM. Lastly, low output capacitance can create a large output voltage ripple. The capacitor acts as a way for the current ripple to not flow through the output of the converter. The larger the capacitance, the more ripple it can filter out. The minimum capacitance for a $5 \%$ output voltage ripple is

$$
\begin{aligned}
C_{\text {min }} & =\frac{1-D}{8 \times L \times f^{2} 5 \%} \\
C_{\text {min }} & =\frac{1-\frac{1.8}{12}}{8 \times 10 \mu \times 800000^{2} 5 \%}=0.33 \mu F
\end{aligned}
$$

This means that below $0.33 \mathrm{uF}$ will yield a larger output voltage ripple that may change the overall DC output voltage. 
Table 7-1: Experimental data of (a) bandwidth, (b) phase margin, (c) calculated feed forward capacitor for stability optimization at different ranges of output filter.

\begin{tabular}{|c|c|c|c|c|c|c|c|c|c|c|}
\hline BW with Cff & & & & & & & & & & \\
\hline Lo/Co & 0.22 & 0.47 & 1 & 2.2 & 4.7 & 10 & 22 & 33 & 47 & 100 \\
\hline 0.22 & & & & & 107000 & 115700 & 58650 & 63260 & 39410 & 28980 \\
\hline 0.47 & & & & & 114500 & 98020 & 65040 & 68920 & 32940 & 29400 \\
\hline 1 & & & & & 103300 & 120000 & 65080 & 67270 & 32640 & 22930 \\
\hline 2.2 & & & 187300 & 164700 & 126000 & 119600 & 68150 & 91670 & 29780 & 23510 \\
\hline 4.7 & 347800 & 279700 & 206200 & 195800 & 206500 & 157300 & 70060 & 103300 & 41500 & 25270 \\
\hline 10 & 306400 & 297500 & 291100 & 263300 & 213900 & 138900 & 63030 & 65660 & 31640 & 24310 \\
\hline 18 & 621000 & 498500 & 305500 & 188200 & 111700 & 87680 & 49090 & 53380 & 27690 & 18140 \\
\hline 33 & 552900 & 357800 & 209500 & 136500 & 88990 & 58970 & 33320 & 34780 & 23000 & 18420 \\
\hline 68 & 359800 & 216100 & 136800 & 92540 & 64480 & 43070 & 27810 & 27960 & 16670 & 12810 \\
\hline 100 & 283500 & 173100 & 105400 & 79080 & 52390 & 36560 & 21860 & 22650 & 13990 & 11990 \\
\hline
\end{tabular}

(a)

\begin{tabular}{|c|c|c|c|c|c|c|c|c|c|c|}
\hline PM with Cff & & & & & & & & & & \\
\hline Lo/Co & 0.22 & 0.47 & 1 & 2.2 & 4.7 & 10 & 22 & 33 & 47 & 100 \\
\hline 0.22 & & & & & 99.10 & 98.87 & 89.33 & 84.86 & 88.79 & 101.90 \\
\hline 0.47 & & & & & 95.26 & 95.17 & 102.00 & 101.50 & 109.40 & 112.40 \\
\hline 1 & & & & & 85.40 & 99.79 & 103.20 & 107.10 & 116.30 & 117.90 \\
\hline 2.2 & & & 78.15 & 90.02 & 87.72 & 84.04 & 99.06 & 73.87 & 119.60 & 115.60 \\
\hline 4.7 & 30.78 & 73.75 & 65.14 & 55.60 & 44.55 & 60.15 & 77.06 & 79.46 & 120.40 & 125.60 \\
\hline 10 & 74.44 & 63.85 & 59.19 & 61.61 & 55.93 & 45.87 & 69.07 & 68.57 & 95.57 & 104.00 \\
\hline 18 & 2.05 & 34.94 & 53.08 & 56.63 & 54.55 & 51.28 & 57.83 & 55.33 & 73.60 & 85.74 \\
\hline 33 & 17.80 & 50.67 & 57.30 & 55.26 & 48.66 & 47.59 & 50.82 & 51.30 & 63.59 & 68.33 \\
\hline 68 & 50.51 & 57.14 & 54.46 & 48.14 & 42.90 & 42.20 & 38.65 & 39.58 & 53.12 & 58.88 \\
\hline 100 & 50.96 & 53.34 & 48.53 & 44.02 & 41.78 & 41.16 & 40.75 & 41.66 & 50.32 & 53.20 \\
\hline
\end{tabular}

(b)

\begin{tabular}{|c|c|c|c|c|c|c|c|c|c|c|}
\hline Cff Calc & & & & & & & & & & \\
\hline Lo/Co & 0.22 & 0.47 & 1 & 2.2 & 4.7 & 10 & 22 & 33 & 47 & 100 \\
\hline 0.22 & & & & & $6.76 \mathrm{E}-12$ & 1.27E-11 & $5.21 \mathrm{E}-11$ & $5.12 \mathrm{E}-11$ & $3.45 \mathrm{E}-11$ & $3.24 \mathrm{E}-11$ \\
\hline 0.47 & & & & & $9.83 \mathrm{E}-12$ & 1.03E-11 & $1.66 \mathrm{E}-11$ & $1.59 \mathrm{E}-11$ & $1.91 \mathrm{E}-11$ & 3.27E-11 \\
\hline 1 & & & & & $7.5 \mathrm{E}-12$ & $8.72 \mathrm{E}-12$ & $1.74 \mathrm{E}-11$ & $1.59 \mathrm{E}-11$ & $2.92 \mathrm{E}-11$ & 3.53E-11 \\
\hline 2.2 & & & 4.32E-12 & $4.86 \mathrm{E}-12$ & $5.04 \mathrm{E}-12$ & $1.22 \mathrm{E}-11$ & 4.96E-11 & $5.06 \mathrm{E}-11$ & $2.73 \mathrm{E}-11$ & 3.82E-11 \\
\hline 4.7 & 2.15E-12 & $2.94 \mathrm{E}-12$ & $3.43 \mathrm{E}-12$ & $3.47 \mathrm{E}-12$ & 4.2E-12 & $1.41 \mathrm{E}-11$ & $4.71 \mathrm{E}-11$ & $4 \mathrm{E}-11$ & $1.79 \mathrm{E}-11$ & $2.7 \mathrm{E}-11$ \\
\hline 10 & $1.38 \mathrm{E}-12$ & 2.65E-12 & $2.73 \mathrm{E}-12$ & $3.36 \mathrm{E}-12$ & 3.89E-12 & 7.73E-12 & $1.44 \mathrm{E}-11$ & $1.27 \mathrm{E}-11$ & 2.26E-11 & $2.86 \mathrm{E}-11$ \\
\hline 18 & $1.54 \mathrm{E}-12$ & $1.71 \mathrm{E}-12$ & 2.72E-12 & $4 \mathrm{E}-12$ & $6.99 \mathrm{E}-12$ & $1.23 \mathrm{E}-11$ & $2.36 \mathrm{E}-11$ & $2.24 \mathrm{E}-11$ & $3.74 \mathrm{E}-11$ & 4.53E-11 \\
\hline 33 & $1.54 \mathrm{E}-12$ & $2.43 \mathrm{E}-12$ & 3.89E-12 & $6.4 \mathrm{E}-12$ & $1.11 \mathrm{E}-11$ & $1.86 \mathrm{E}-11$ & $3.5 \mathrm{E}-11$ & $3.24 \mathrm{E}-11$ & $5.21 \mathrm{E}-11$ & $6.86 \mathrm{E}-11$ \\
\hline 68 & $2.56 \mathrm{E}-12$ & $3.76 \mathrm{E}-12$ & $6.55 \mathrm{E}-12$ & $1.07 \mathrm{E}-11$ & $1.98 \mathrm{E}-11$ & $2.68 \mathrm{E}-11$ & $8.5 \mathrm{E}-11$ & $9.07 \mathrm{E}-11$ & $7.4 \mathrm{E}-11$ & $9.19 \mathrm{E}-11$ \\
\hline 100 & $3.31 \mathrm{E}-12$ & $5.24 \mathrm{E}-12$ & $8.52 \mathrm{E}-12$ & $1.36 \mathrm{E}-11$ & $2.39 \mathrm{E}-11$ & $4.46 \mathrm{E}-11$ & $1.01 \mathrm{E}-10$ & $9.19 \mathrm{E}-11$ & $9.71 \mathrm{E}-11$ & $1.23 \mathrm{E}-10$ \\
\hline
\end{tabular}

(c) 
For the operating points that were stable, the phase margin increased, particularly in low bandwidths, compared to the ideal and non-ideal model which is why high output inductors and high capacitors showed stability. This means a modified non-ideal model that increases PCB parasitics will move the parasitic phase boost to lower frequencies, as shown in Figure 7.10, and may show a more accurate model.

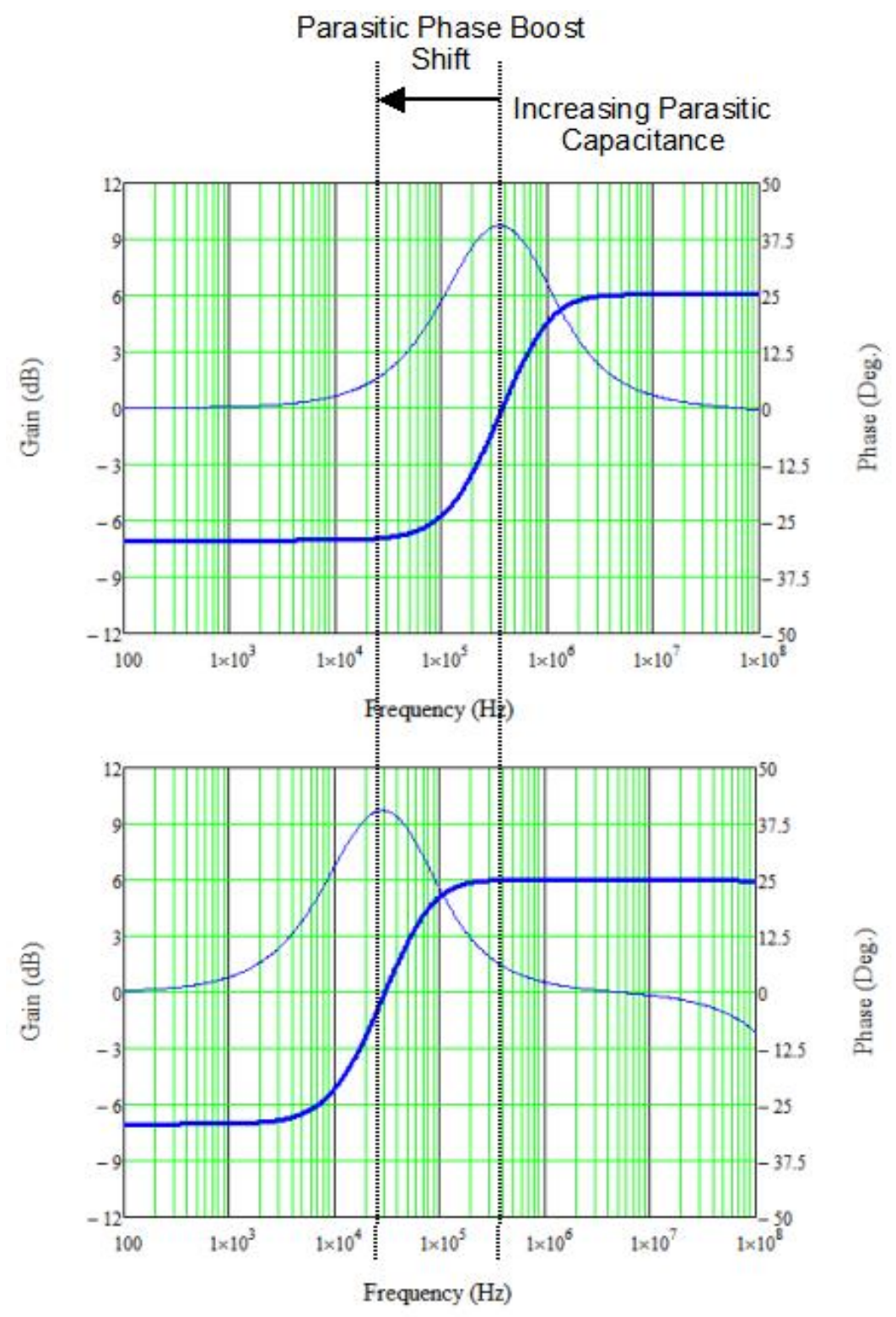

Figure 7.10: Effects of parasitic capacitance on the parasitic phase boost. 


\subsection{Modified Non-Ideal System Modeling}

The increase in phase margin in the experimental data at lower bandwidth frequencies suggests that there may be PCB parasitics that are not accounted for in the calculations in Chapter 6. Typically, it is common to assume a PCB parasitic capacitance of up to $5 \mathrm{pF}$ [40]. Figure 7.11 shows the modified non-ideal model with the experimental data comparing Figure 7.8 and Figure 7.9. Increasing the non-ideal model of the capacitance to $5 \mathrm{pF}$ improves the accuracy of the frequency response. Unlike Figure 7.8 and Figure 7.9, the phase margin is closer to the experimental data. 


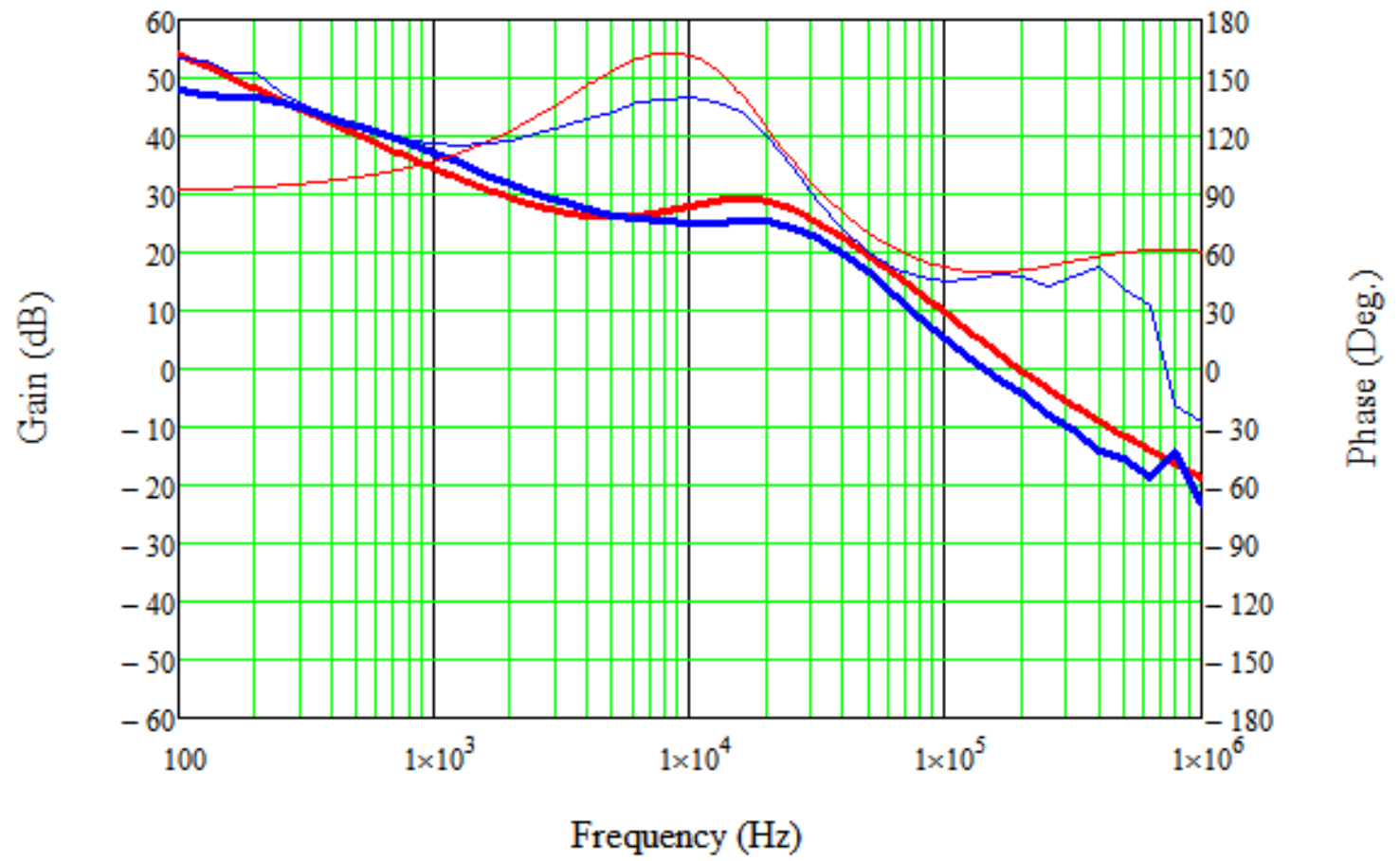

(a)

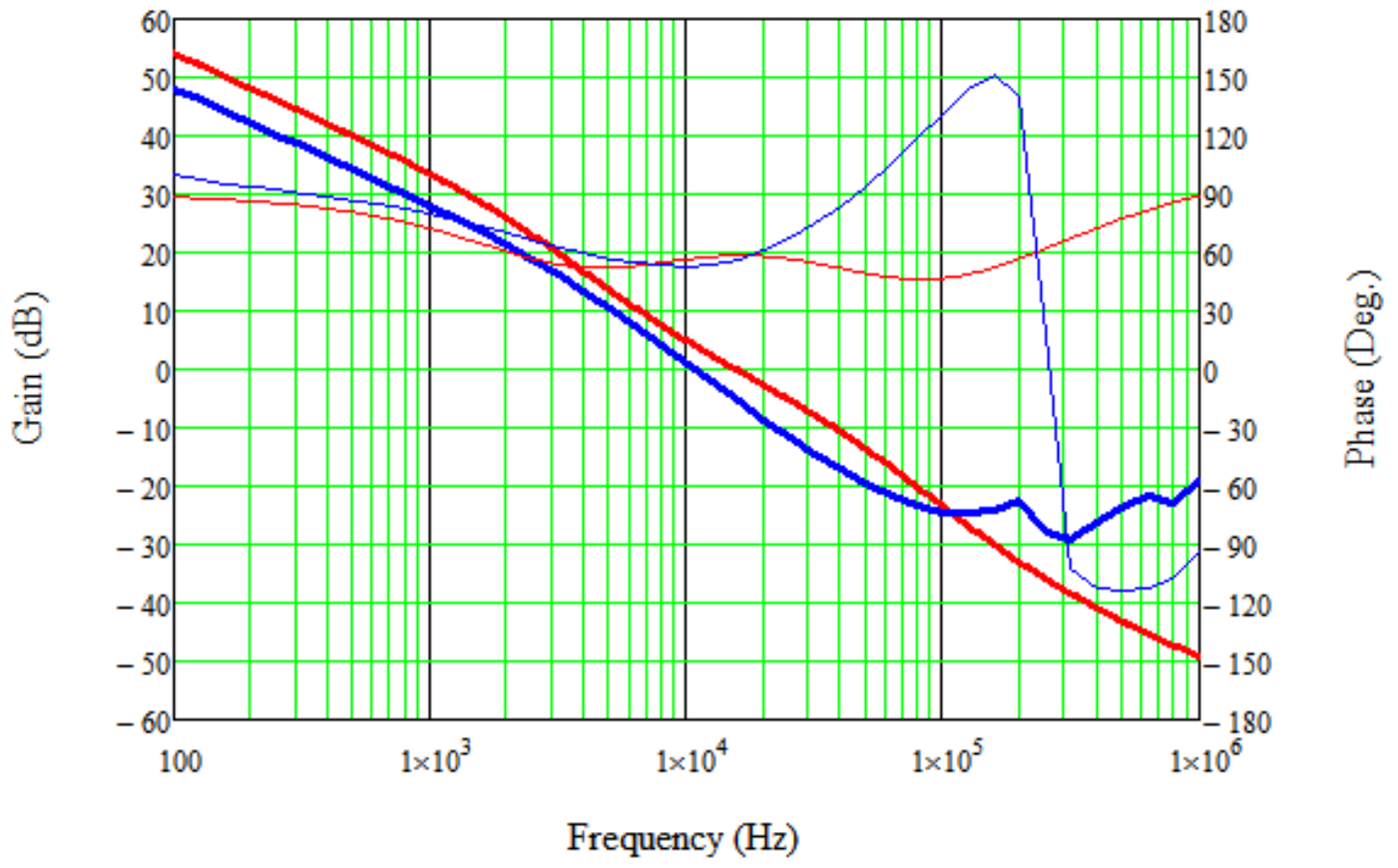

(b)

Figure 7.11: Modified non-ideal model on increasing parasitic capacitance compared to experimental data and nominal and low bandwidths. 
The modified non-ideal model suggests that there is parasitic capacitance that is not accounted for. These other sources may include package lead capacitance, trace-trace capacitance, pad-trace capacitance, and soldering capacitance. Including these parasitics into the model along with their relating parasitic inductances and resistances will yield a higher order model and possibly a more accurate model. 


\section{Chapter 8 : Conclusion}

Load transients are prevalent in every electronic device including semiconductor memory, card readers, microprocessors, disc drives, piezoelectric devices, and digitally based systems. They are capable of producing voltage stress and introducing noise thus compromising the protection of the system and degrading device functionality which can be a serious issue for medical, military, telecom, and computing applications.

In order to avoid damage to the device, a system feedback control loop must be implemented to regulate any output voltage deviations to the converter. How effectively the converter stabilizes the output voltage depends on the type of control topology and its compensation. Compensation design can quickly become time consuming and complex depending on the application. Integrated DC-DC converters minimize design and complexity by incorporating compensation design in the chip. Using an integrated converter constrains design flexibility and therefore limits the available external components of the integrated converter to values suggested by the datasheet.

This thesis extends the limitations set by the datasheet with a stability optimization technique by use of feed forward capacitor and pole-zero placement that allows for design flexibility and maintains stability converter requirements.

Ideal system modeling shows that this optimization technique increases design flexibility and stability by allowing a broader range of external components with larger phase margins. However, PCB parasitics may compromise the stability of the converter 
by adding poles and zeros that negate the phase boost effects of the feed forward capacitor.

The non-ideal system model that includes PCB trace resistant, trace inductance, and pad capacitance into the system modeling of the control loop show a dominant zero in the feedback network which relate to a parasitic phase boost. This parasitic phase boost along with the feed forward capacitor phase boost produces larger phase margins, higher stability, and more flexibility in integrated converter design. However, the non-ideal model shows that the phase boost from the feed forward capacitor is only effective at high output filter inductances and capacitances or lower bandwidths and is ineffective at low output filter inductances and capacitances or high bandwidths due to relatively small magnitude of the feed forward capacitance compared to the PCB parasitics.

The experimental data on the TPS62120 buck converter is DCS-control shows that the optimization technique allows design flexibility and a broader range of external components with phase margins that meet converter stability requirements. The non-ideal model is correct in that the data show higher phase margins than the ideal model. However, the amount of which the phase margin increases was not accurately shown by both ideal and non-ideal models. The data showed higher phase margins at low bandwidths which suggest a parasitic phase boost at lower frequencies. This can be modeled by increasing the PCB parasitic capacitance of the non-ideal model. 
The modified non-ideal model shows more accuracy compared to the experimental data. This indicates that there is PCB parasitics that is unaccounted for. Modeling the non-ideal model to high orders may yield even more accuracy and insight into PCB effects on the stability of DC-DC converters and optimization of integrated compensation. 


\section{Bibliography}

[1] J.F. Iannuzzi, "Measuring Power Supply Control Loop Stability," Core Technology Group, Application Note 2. [Online] Available: http://www.coretechgroup.com/pdf_files/AN2_Measuring\%20Power\%20Supply\%20Control\%20Loop\%20Stability.pdf Accessed: February 25, 2011

[2] N. Tang, "Presentation on Voltage Mode Control for Buck Converters," Texas Instruments. Accessed: July 26, 2010

[3] M. Day, “Understanding LDO Dropout,” Texas Instruments, SLVA207, May 2005. [Online] Available: http://www.focus.ti.com/lit/an/slva207/slva207.pdf. Accessed: July 26, 2010.

[4] Taufik, 2009. Introduction to Power Electronics, 7th Rev. OTaufik.

[5] M.S. Rahman. (2007, Jul.) "Buck Converter Design Issues," [Online]. Available: http://www.liu.diva-portal.org/smash/get/diva2:24104/FULLTEXT01. Accessed: Jan. 29, 2011.

[6] D. Meeks, "Loop Stability Analysis of Voltage Mode Buck Regulator with Different Output Capacitor Types - Continuous and Discontinuous Modes," Texas Instruments, SLVA301, Apr. 2008. [Online] Available: http://focus.ti.com/general/docs/litabsmultiplefilelist.tsp?literatureNumber=slva301. Accessed: January 2, 2011.

[7] Q. He, Y. Zhao, "The Design of Controller of Buck Converter," 2010 International Conference on Computer Applications and System Modeling at Southwest University, 2010.

[8] A. Ghosh, "State-Space Average Modeling of DC-DC Converters with parasitic in Discontinuous Conduction Mode (DCM)," National Institute of Technology, Rourkela, Jun. 2010. [Online] Available: http://ethesis.nitrkl.ac.in/1640/1/Project_Report\%28Mayank_Kandpal_and_Antip_G hosh\%29.pdf. Accessed: January 2, 2011.

[9] Energy Saving Trust. "Renewable Energy", Nov. 2005. Available: www.brightenergy.biz/renewable\%20energy.pdf 
[10] P. Bernardo, Z. Peixoto, L.Neto, "A High Efficient Micro-controlled Buck Converter with Maximum Power Point Track for Photovoltaic Systems," International Conference on Renewable Energies and Power Quality, Apr. 2009.

[11] J. Thornton. (2011, April.) "Design and Analysis of a Wind Energy Harvesting Circuit Using Piezoelectric Polymers" [Online]. Available: http://digitalcommons.calpoly.edu/theses/491/

[12] Taufik, R. Prasetyo, A. Hernadi, D. Garnito, "Multiphase Interleaving Buck Converter With Input-Output Bypass Capacitor," International Conference on Information Technology, 2011.

[13] "Designing Fast Response Synchronous Buck Regulators the TPS5210," Texas Instruments, SLVA044, Mar. 1999. [Online] Available:

http://focus.ti.com/lit/an/slva044/slva044.pdf. Accessed: January 22, 2011.

[14] "Printed Circuit Board (PCB) Power Delivery Network (PDN) Design Methodology," Altera, AN 574, May 2009. [Online] Available: www.altera.com/literature/an/an574.pdf. Accessed: February 2, 2011.

[15] B. Pauplis, "Power Supply Design Considerations for High di/dt Loads," Vicor, Jun. 2002. [Online] Available: wwwhttp://www.vicorchina.com/documents/webcasts/webcast_didt.pdf. Accessed: February 8, 2011.

[16] J. Williams, "Load transient Response Testing for Voltage Regulators," Linear Technology, Oct. 2006. [Online] Available: http://cds.linear.com/docs/Application\%20Note/an104f.pdf. Accessed: February 17, 2011.

[17] M. Day, "Optimizing Low_Power DC/DC Designs - External versus Internal Compensation," Texas Instruments. 2004. [Online] Available: http://focus.ti.com/lit/ml/slyp090/slyp090.pdf. Accessed: August 1, 2010.

[18] B. Carter, "The PCB is a Component of Op Amp Design," Texas Instruments. Aug. 2000. [Online] Available: focus.ti.com/general/docs/lit/getliterature.tsp?.slyt166.pdf. Accessed: April 4, 2011. 
[19] R. Kollman, "Constructing Your Power Supply - Layout Considerations," Texas Instruments. SLUP224. 2005. [Online] Available:

focus.ti.com/lit/ml/slup224/slup224.pdf. Accessed: April 4, 2011.

[20] Texas Instruments, TPS62120 “15V, 75mA High Efficiency Buck Converter”, Data sheet. [online] Available: http://focus.ti.com/docs/prod/folders/print/tps62120.html. Accessed January 1, 2011

[21] D. Ng, "DC/DC uModule Regulator Printed Circuit Board Design Guidelines," Linear Technology. Application Note 117. Apr. 2008. [Online] Available: www.linear.com/docs/26308. Accessed: April 4, 2011.

[22] "RF Design Guidelines: PCB Layout and Circuit Optimization," Semtech. AN 1200.04. 2006. [Online] Available:

http://www.semtech.com/images/datasheet/rf_design_guidelines_semtech.pdf. Accessed: April 4, 2011.

[23] G. Rincon-Mora, H. Porghani-zadeh, "Using a Circuit-Driven Approach to Teach Printed-Circuit Board (PCB) Layout Techniques for Switching Power Supply Circuits," Georgia Institute of Technology. [Online] Available: http://users.ece.gatech.edu/rincon-mora/research/pcb.pdf. Accessed: April 4, 2011.

[24] M. Pajovic, J. Yu, D. Milojkovic, "Analysis of Via Capacitance in Artbitrary Multilayer PCBs," IEEE Transactions on Electromagnetic Compatibility, 00189375, Dec. 12, 2006.

[25] J. Ardizzoni, "A Practical Guide to High-Speed Printed-Circuit-Board Layout," Analog Devices, 39-09, Sept. 2005. [Online] Available: http://www.analog.com/library/analogdialogue/archives/39-09/layout.html. Accessed: Feb 4, 2011.

[26] B. Wadell, "Modeling Circuit Parasitics: Part 1," IEEE Instrumentation and Measurement Magazine, Mar. 1998. Pg. 31-33. [Online] Available: ieeexplore.ieee.org/iel4/5289/14328/00658191.pdf?arnumber=658191. Accessed: Feb 4, 2011. 
[27] B. Wadell, "Modeling Circuit Parasitics: Part 2," IEEE Instrumentation and Measurement Magazine, Jun. 1998. Pg. 6-9. [Online] Available: ieeexplore.ieee.org/ie14/5289/15321/00706022.pdf?arnumber=706022. Accessed: Feb 4, 2011.

[28] C. Ionescu, “Analysis of PCB Parasitic Influences in Uninterruptible PowerSupplies," International Spring Seminar on Electronics Technology, May 2001. [Online] Available: ieeexplore.ieee.org/iel5/7413/20131/00931017.pdf?arnumber=931017. Accessed: Feb 4, 2011.

[29] P.Musznicki, J.L. Schanen, B. Allard, P. Chrzan, “Accurate Modeling of Layout Parasitic to Forecast EMI Emitted from a DC-DC Converter,", [Online] Available: ieeexplore.ieee.org/iel5/9371/29757/01355756.pdf. Accessed: May 1, 2011.

[30] A. Rivera-Ramos, M. Jimenez, "Analytical Models for Estimating Parasitic Components in Power Electronics PCBs," University of Puerto Rico at Mayaguez. [Online] Available: ieeexplore.ieee.org/iel5/10622/33557/01594331.pdf. Accessed: Feb 6, 2011.

[31] R. Schmid, "Measuring Board Parasitics in High Speed Analog Design," Texas Instruments, Aug. 2003. [Online] Available: http://focus.ti.com.cn/cn/lit/an/sboa094/sboa094.pdf. Accessed: Feb 22, 2011.

[32] J.L. Schanen, L. Jourdan, J. Roudet, "Layout Optimization to reduce EMI of a Switch Mode Power Supply," Laboratoire d'Electrotechnique de Grenoble, 2002. [Online] Available: http://ieeexplore.ieee.org/xpls/abs_all.jsp?arnumber=1023111\&tag=1. Accessed: Feb. 22, 2011

[33] M. Zhang, M. Jovanovic, F. Lee, "Design Considerations for Low-Voltage on Board DC/DC Modules for Next Generations of Data Processing Circuits," IEEE Catalogue, No. 95 ${ }^{\mathrm{TH}} 8025$. 1995. [Online] Available: ieeexplore.ieee.org/iel2/3200/9101/00404890.pdf. Accessed: Feb. 22, 2011

[34] R. Mammano, "Switching Power Supply Topology Voltage Mode vs. Current Mode," Unitrode, DN-62. Oct. 1994. [Online] Available: http://focus.tij.co.jp/jp/lit/an/slua119/slua119.pdf. Accessed: Feb. 22, 2011 
[35] O. Nachbaur, "Evaluation and Performance Optimization of Fully Integrated DC/DC Converters," Texas Instruments. [Online] Available:

http://focus.ti.com/download/trng/docs/seminar/Topic\%207\%20-

\%20Evaluation\%20and\%20Performance\%20Optimization\%20of\%20Fully\%20Integ rated\%20DC-DC\%20Converter.pdf. Accessed: Feb. 22, 2011

[36] D. Mattingly, "Designing Stable Compensation Networks for Single Phase Voltage Mode Buck Regulators," Intersil. [Online] Available: www.intersil.com/data/tb/tb417.pdf. Accessed: Jan. 13, 2011

[37] B. Butterfield, "Optimizing Transient Response of Internally Compensated DC-DC Converters with Feedforward Capacitor," Texas Instruments. [Online] Available: http://focus.tij.co.jp/jp/lit/an/slva289/slva289.pdf. Accessed: Jan. 13, 2011

[38] T. Tyson, "1.8 Volt Technology - Benefits," Microchip. AN550. 1993. [Online] Available: ww1.microchip.com/downloads/en/AppNotes/00550.pdf. Accessed: Jan. 13, 2011.

[39] “User’s Guide TPS62120,” Texas Instruments. SLVU411. Sept. 2010. [Online] Available: http://focus.ti.com.cn/cn/lit/ug/slvu411/slvu411.pdf. Accessed: Jan. 13, 2011.

[40] G. Litovsky,"Beginning Microcontrollers with the MSP430 Tutorial," Texas Instruments. Sept. 2010. [Online] Available: www.glitovsky.com/Tutorialv0_3.pdf. Accessed: Jan. 15, 2011. 